Aridification of the Indian subcontinent during the Holocene:

Implications for landscape evolution, sedimentation, carbon cycle, and human civilizations

By

Camilo Ponton

B.S., M.S., Geology, Florida International University, 2003, 2006

Submitted in partial fulfillment of the requirements for the degree of

Doctor of Philosophy

at the

MASSACHUSETTS INSTITUTE OF TECHNOLOGY

and the

WOODS HOLE OCEANOGRAPHIC INSTITUTION

JUNE 2012

(C)2012 Camilo Ponton. All rights reserved.

The author hereby grants to MIT and WHOI permission to reproduce and to distribute publicly paper and electronic copies of this thesis document in whole or in part in any medium now

known or heareafter created.

Signature of Author

Joint Program in Oceanography/Applied Ocean Science and Engineering Massachusetts Institute of Technology and Woods Hole Oceanographic Institution

May 21, 2012

Certified by

Dr. Timothy I. Eglinton

Thesis Co-Supervisor

Certified by

Dr. Liviu Giosan

Thesis Co-Supervisor

Accepted by

Dr. Robert L. Evans

Chair, Joint Committee for Geology and Geophysics Massachusetts Institute of Technology/Woods Hole Oceanographic Institution 
Aridification of the Indian Subcontinent during the Holocene:

Implications for landscape evolution, sedimentation, carbon cycle, and human civilizations

by

Camilo Ponton

Submitted to the MIT/WHOI Joint Program in Oceanography on May 21, 2012, in partial fulfillment of the requirements for the degree of Doctor of Philosophy in the field of Marine Geology and Geophysics

\begin{abstract}
The Indian monsoon affects the livelihood of over one billion people. Despite the importance of climate to society, knowledge of long-term monsoon variability is limited. This thesis provides Holocene records of monsoon variability, using sediment cores from river-dominated margins of the Bay of Bengal (off the Godavari River) and the Arabian Sea (off the Indus River). Carbon isotopes of terrestrial plant leaf waxes $\left(\delta^{13} C_{w a x}\right)$ preserved in sediment provide integrated and regionally extensive records of flora for both sites. For the Godavari River basin the $\delta^{13} \mathrm{C}_{\text {wax }}$ record shows a gradual increase in aridity-adapted vegetation from $\sim 4,000$ until 1,700 years ago followed by the persistence of aridity-adapted plants to the present. The oxygen isotopic composition of planktonic foraminifera from this site indicates drought-prone conditions began as early as $\sim 3,000$ years BP. The aridity record also allowed examination of relationships between hydroclimate and terrestrial carbon discharge to the ocean. Comparison of radiocarbon measurements of sedimentary plant waxes with planktonic foraminifera reveal increasing age offsets starting 4,000 yrs BP, suggesting that increased aridity slows carbon cycling and/or transport rates. At the second site, a seismic survey of the Indus River subaqueous delta describes the morphology and Holocene sedimentation of the Pakistani shelf and identified suitable coring locations for paleoclimate reconstructions. The $\delta^{13} \mathrm{C}_{\mathrm{wax}}$ record shows a stable arid climate over the dry regions of the Indus plain and a terrestrial biome dominated by $\mathrm{C}_{4}$ vegetation for the last 6,000 years. As the climate became more arid $\sim 4,000$ years, sedentary agriculture took hold in central and south India while the urban Harappan civilization collapsed in the already arid Indus basin. This thesis integrates marine and continental records to create regionally extensive paleoenvironmental reconstructions that have implications for landscape evolution, sedimentation, the terrestrial organic carbon cycle, and prehistoric human civilizations in the Indian subcontinent.
\end{abstract}


A mi Tito y mi Sense,

por haberme despertado el interés por la Ciencia. 
Creo muy poco en lo que veo. Y de lo que me cuentan... nada.

-Juan Sáyago 


\section{Acknowledgements}

I am indebted to my Advisors for their unconditional support and generosity with their ideas and their time. Thank you for keeping me afloat when the seas were rough and I had started to drown. I learned that persistence is key and Science is humbling. Through this journey Liviu's tenacity and strong guidance, and Tim's enthusiasm and optimistic outlook delivered me safely to shore.

I will like to thank my committee members and Chair for their invaluable contributions to improve this thesis, but most importantly for their continuous support, concern and encouragement through out these years. Delia, for always being my advocate and offering your experience to suggest alternative solutions. Valier, I have learned immensely from you in the lab and our discussions have always been fruitful. I always leave your office with more questions that I came with, but this is terribly insightful. Ed, for always having an open door and for your innate ability to point out the possible caveats before I have invested too much time and efforts on bad ideas. The Paleoceanography community patiently awaits your return. Dan, your fairness and insight have kept me balanced along the way.

The technical support I received in Woods Hole was certainly top-notch not only consisting of cutting edge technology but also and most importantly of an abundance of human quality. Honorable mentions go to Daniel Montluçon, Carl Johnson, Al Gagnon, and the NOSAMS team. Thank you!

To everyone at the Academic Programs Office for knitting such a strong safety net for all students to rely on. Thank you very much Julia, Marsha and Tricia for your friendly attitude, constant support and advocacy for students. Thank you to Jim Yoder, Meg Tivey and Jim Price who have held the helm during my time in the JP under the policy of no student left behind.

To the many people I interacted in the friendly environment at WHOI and enriched my life both professionally and personally, thank you. Among them Lloyd Keigwin, Henry Dick, Karen Bice, Olivier Marchal, Bill Curry, Jeff Donnelly, Andrew Ashton, Rob Sohn, Chris Reddy, Maryanne Ferreira, Suellen Garner, Kelly Servant, Lori Floyd.

To the few but very good friends that I had the privilege to meet during these years in Woods Hole, I want them to know that they made me feel much closer to home. Especially to Fern for her outlandish sense of humor almost always accompanied by my favorite spice: sarcasm. To my compadre Ricardo, muchas gracias por la buena vida que nos dimos en las altas latitudes! To Casey and Emily for showing me the way on many things and always having encouraging words. To Andrea, Dave, Mike, Andrew and Peggy for sharing some good laughs! I want to express especial gratitude to my dear friend Min who forced me to increase my tolerance for spicy food and taught me that the simplest way of life is the best one. Finally, to our dear neighbors Nathan and Katie: may the yummy food and spirits keep flowing freely between our homes for times to come.

To all of you, fair winds and following seas. 
Para con mi familia no tengo más que infinitos agradecimientos por todo. A mis padres por tantos sacrificios y por haber siempre puesto mi educación como su prioridad más importante. A mi Papá por su interés en mi ciencia, a mi Mamá por su incondicional apoyo y buenos consejos, a mi hermanita por dejar todo botado y despurrundungarse siempre a ayudarme porque a mi se me hizo tarde con la tarea para el día siguiente. A Sense por oírme las explicaciones de lo que estoy haciendo y a mi Madrinita por consentirme tanto y traerme arequipe siempre. De todos ustedes siempre percibo ese sentido de incondicionalidad a prueba de todo que sólo la familia puede brindar. A mi familia de Ohio muchas gracias por haberme acogido como a uno de los suyos desde el principio.

Por último pero, en muchos sentidos más importante, muchas gracias a Karin por haberme querido tanto durante estos años y por haberme aguantando siempre con una sonrisa en la boca cuando me pongo chinchoso, que no ha sido poco. Compartir mi vida contigo y ser felíz han sido aspectos primordiales en este proceso en el que me ha cambiado la vida. Ahora espero que podamos seguir disfrutando de más aventuras juntos.

This thesis was funded by the National Science Foundation, Woods Hole Oceanographic Institution (Arctic Research Initiative, Ocean and Climate Change Institute, Coastal Oceans Institute, Stanley Watson Chair for Excellence in Oceanography and the Academic Programs Office), and by the ETH Zurich. 


\section{TABLE OF CONTENTS}

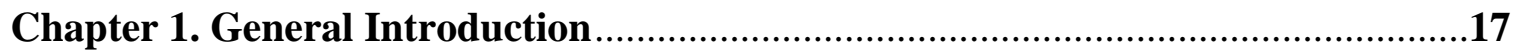

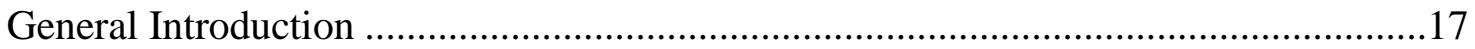

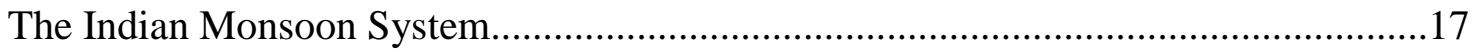

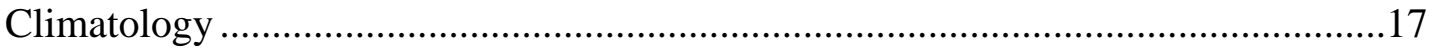

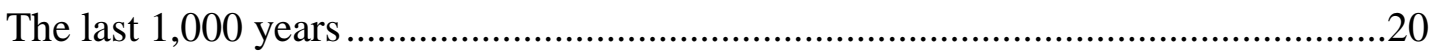

The last 10,000 years and beyond .........................................................................21

River-dominated continental margins in monsoonal settings ........................................23

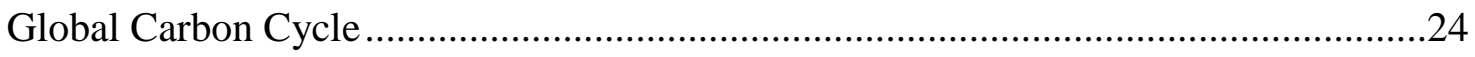

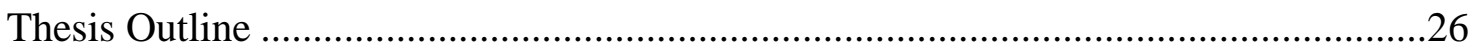

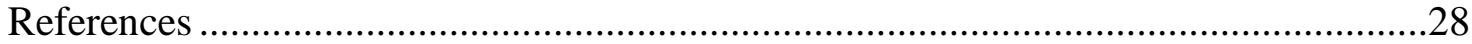

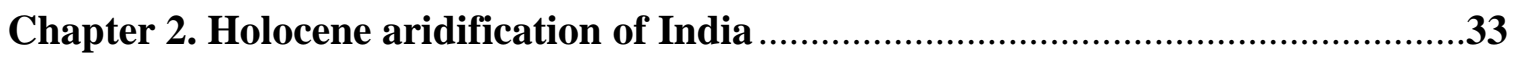

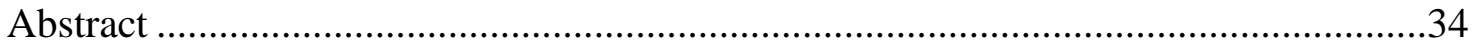

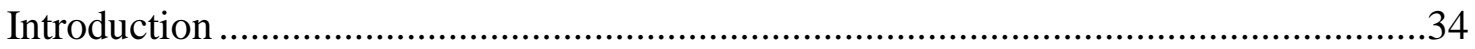

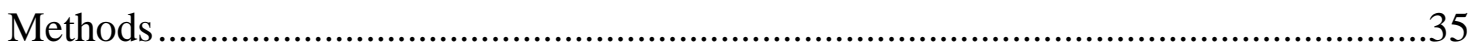

Monsoon Variability in the Core Monsoon Zone …………............................................36

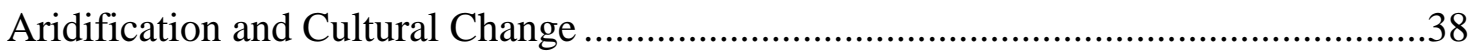

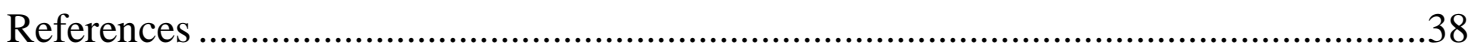

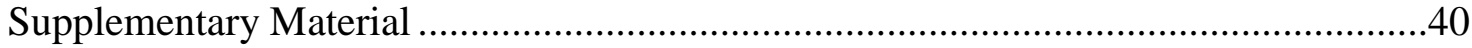

\section{Chapter 3. Climate Controls Residence Time of Organic Carbon in Monsoonal}

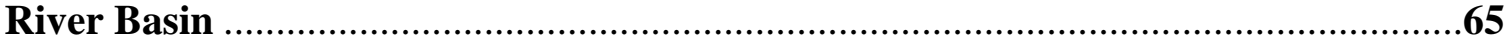

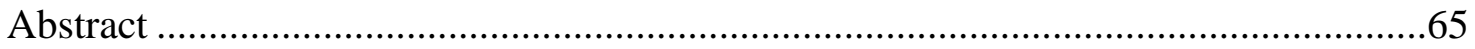

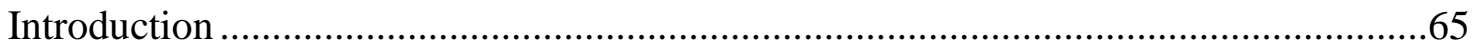

Terrestrial organic carbon: from source to sink …………………………………...65

Residence times of terrestrial organic carbon .........................................................67

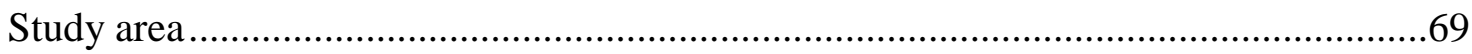




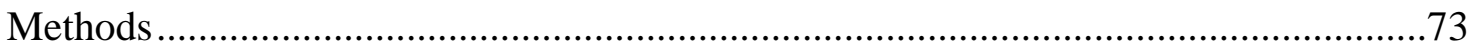

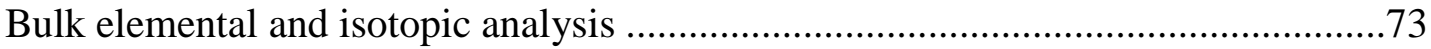

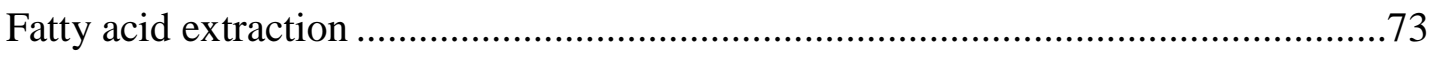

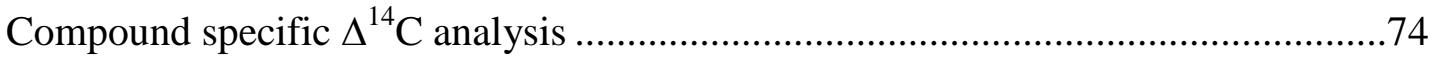

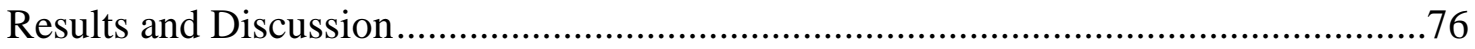

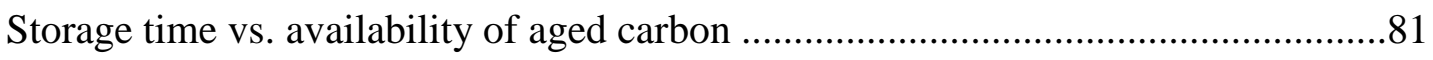

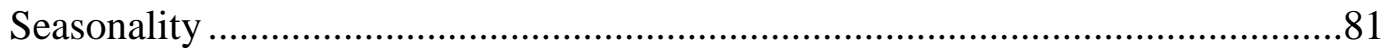

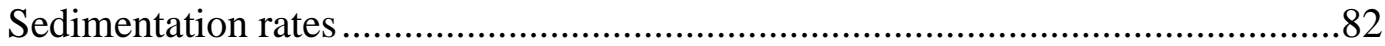

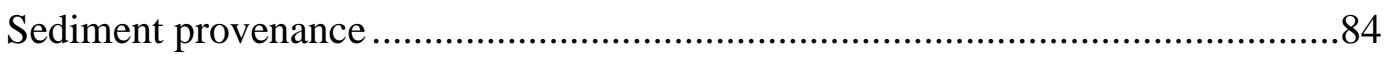

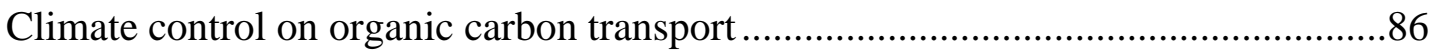

Implications for increased carbon storage time...........................................................87

Implications of mixing fresh biospheric carbon with aged carbon .............................8

Additional implications for paleoclimate proxies …………......................................92

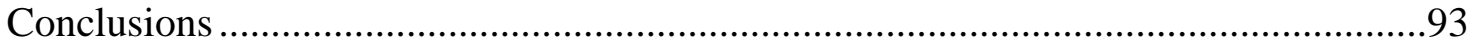

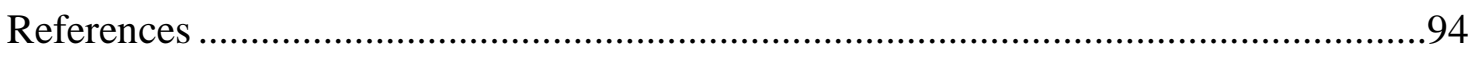

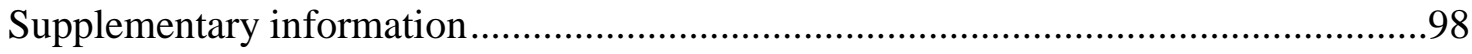

\section{Chapter 4. The Indus Shelf: Holocene Sedimentation and Paleoclimate}

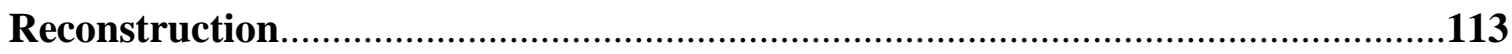

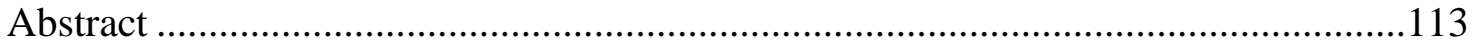

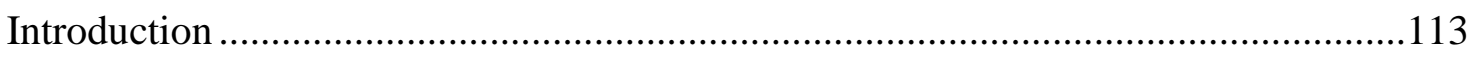

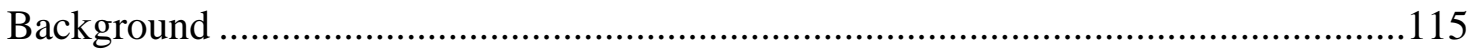

Shelf morphology ……………………………………….............................115

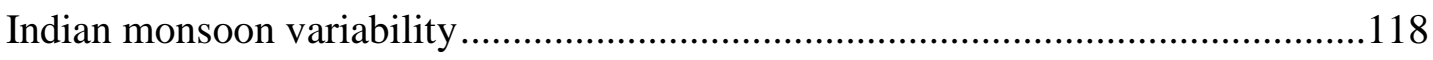

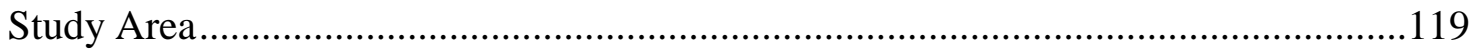

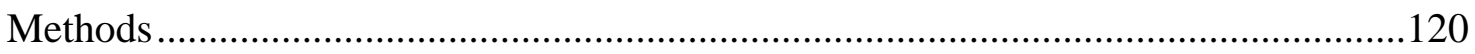

Results and Discussion.....................................................................................122

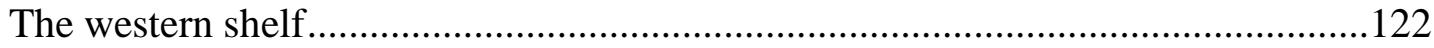

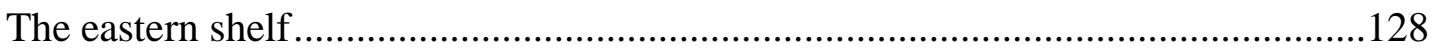




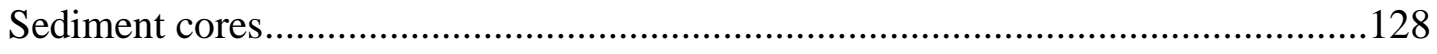

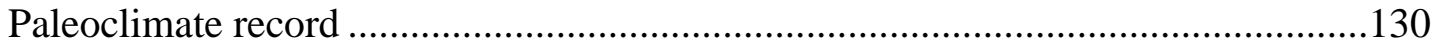

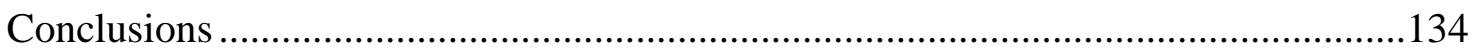

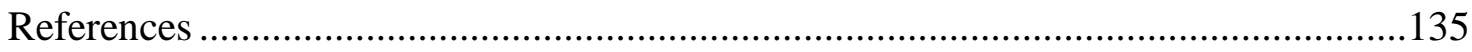

Chapter 5. Conclusions and Directions for Future Research .................................141 


\section{LIST OF FIGURES}

\section{Chapter 1}

Figure 1. Physiographic map of the Indian peninsula and adjacent ocean regions ...19

\section{Chapter 2}

Figure 1. (a) Physiographic map of the Indian peninsula and adjacent ocean regions

(b) Average $\delta^{13} \mathrm{C}$ of bulk terrestrial biomass in modern-day India

Figure 2. (a) Indian monsoon $\delta^{18} \mathrm{O}$ record from Qunf Cave, Oman (b) Indian monsoon upwelling record (c) $\delta^{13} \mathrm{C}$ plant wax from core $16 \mathrm{~A}(\mathrm{~d})$ Calibrated radiocarbon ages from core $16 \mathrm{~A}$

Figure 3. (a) $\delta^{13} \mathrm{C}$ plant wax record from core $16 \mathrm{~A}$ as the weighted average of $n$ alkanoic acids $\mathrm{C}_{26}-\mathrm{C}_{32}$ (b) calibrated radiocarbon ages in core $16 \mathrm{~A}$ (c) $\delta^{18} \mathrm{O}$ measured on $G$. ruber from core 16A (d) Number of settlements based on archeological data.37

Figure S1. Age-depth relationship for core NGHP-16A .....................................56

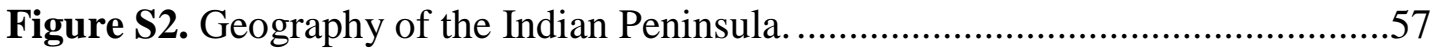

Figure S3. Hydro-climatology of the Indian peninsula and Bay of Bengal ..............58

Figure S4. Proxies for population dynamics in peninsular India between 5,000 and

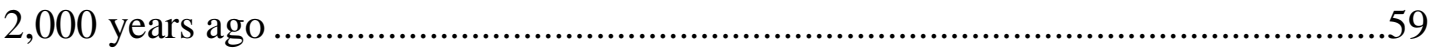

Figure S5. $\delta^{13} \mathrm{C}$ values of $n$-alkanoic acids from core NGHP-16A. ......................60

\section{Chapter 3}

Figure 1. Conceptual model for the transport of riverine terrestrial OC into the oceans

Figure 2. Godavari River drainage basin in its geological and physiographical context.

Figure 3. Sedimentation rates from core NGHP-16A.

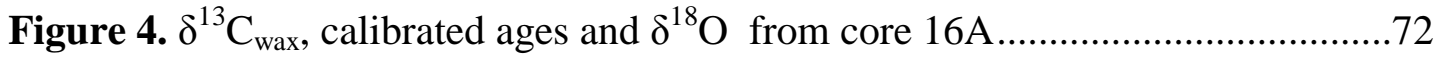

Figure 5. Comparative ages of planktonic forminifera, TOC, and long chain fatty acids .77

Figure 6. Age offsets between different dated fractions..... .79

Figure 7. Age offset between long chain fatty acids and forminifera .80

Figure 8. Sedimentation rates and age offsets between fatty acids and forminifera .83 
Figure 9. $\varepsilon \mathrm{Nd}$ (provenance proxy) and $\delta^{13} \mathrm{C}$ of fatty acids (aridification proxy).......85

Figure 10. Two different chronologies for $\delta^{13} \mathrm{C}$ of $\mathrm{C}_{26-32}$ fatty acids .88

\section{Chapter 4}

Figure 1. (a) Cross section along direction of propagation of the Lewis-Fox Hill shelf margin (b) Anatomy of a clinoform (c) Schematic illustrating controls in clinoform geometry

Figure 2. Map of the Indus shelf with bathymetry of the subaqueous delta and ship track of the seismic survey

Figure 3. Composite of chirp lines along the western shelf clinoform extending westward from the canyon.

Figure 4. Two dip-oriented chirp lines across the western shelf clinoform

Figure 5. Two dip-oriented chirp lines across the eastern shelf clinofrom.

Figure 6. Sediment cores from the Indus shelf

Figure 7. Age-depth relationships for core 10

Figure 8. $\delta^{13} \mathrm{C}_{\mathrm{wax}}$ from the Indus River drainage basin compared to other regional records 


\section{LIST OF TABLES}

\section{Chapter 2}

Table S1. Radiocarbon ages for mixed planktonic foraminifera and corresponding

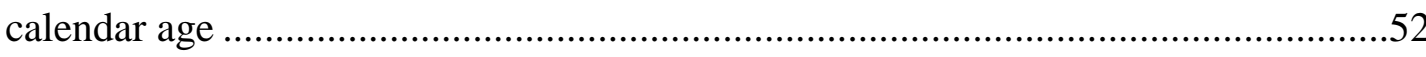

Table S2. Tally of archaeological sites by period and region ................................53

Table S3. Tally of sites and radiocarbon dates for Neolithic/Chalcolithic Indian peninsula

Table S4. Tally of Iron Age ("megalithic") sites in South India in relation to rainfall zone.

\section{Chapter 3}

Table 1. ${ }^{14} \mathrm{C}$ ages of long-chain fatty acids, total organic carbon and mixed planktonic foraminifera

Table 2. Percent of aged and fresh carbon required to yield 1000 and 5000 yr age offsets.

Table 3. Age offsets for mixing with dead carbon .92

Table S1. Total organic carbon and fatty acid estimated fluxes .98

Table S2. Fatty acid $\delta^{13} \mathrm{C}$ data. 99

Table S3. $\mathrm{Nd}$ isotopic data 100

Table S4. $\delta^{18} \mathrm{O} G$. ruber data 101 


\section{CHAPTER 1}

\section{General Introduction}

The Asian monsoon, composed of the East Asian and Indian systems, affects the most densely populated region of the planet. The Indian monsoon is one of the most energetic and dynamic climate processes that occurs today on Earth. It is characterized by a seasonal reversal in wind direction over the Arabian Sea during the summer that brings major amounts of precipitation to the otherwise arid Indian subcontinent. This creates a very pronounced seasonality: from June to September India receives over $80 \%$ of its annual precipitation (Gadgil, 2003). Variability in monsoon onset, duration and/or magnitude has been responsible for floods, droughts and agricultural failure leading to human tragedies on massive scales, including historical famines and unrest. This symbiotic relationship between climate and society continues to provide impetus for development of a more predictive understanding of the monsoon after over three centuries of dedicated research, especially as abrupt hydroclimatic shifts are expected for monsoon regions in a warming world (Ashfaq et al., 2009). Long-term high-resolution records that extend beyond instrumental measurements and historical data, and which allow for synoptic reconstructions, are needed to explore the spatial complexity of the monsoon and its effects on the interplay between landscape evolution, climate, and human civilization.

\section{The Indian Monsoon System}

\subsection{Climatology}

For centuries, the Indian monsoon has been seen as a giant land-sea breeze (Halley, 1686) caused by seasonal differential heating between the Indian Ocean and the Asian landmass due to incoming solar radiation (Webster et al., 1998). In the northern hemisphere summer, as the continent warms rapidly, atmospheric pressure drops and an intense lowpressure system develops over the Indian landmass. Meanwhile, the ocean remains much 
cooler and a low-pressure cell installs over the south Indian Ocean. This pressure gradient initiates a strong moist-wind flow across the equator from the ocean onshore, bringing heavy precipitation inland (Schott and McCreary, 2001). In the winter, as the Asian continent cools, the winds blow from the continent to the ocean and bring dry, cool air down from the Himalaya, significantly reducing precipitation over South Asia.

An emerging view considers the monsoon as a global phenomenon resulting from the seasonal overturning of the atmosphere over tropical and sub-tropical latitudes (Sikka and Gadgil, 1980; Chao, 2000; Boos and Kuang, 2010; Sinha et al., 2011a) in response to the seasonal variation of the latitude of maximum insolation (Trenberth et al., 2000; Gadgil, 2003). Under this view, the Indian monsoon is the expression of the northward summer migration of the Intertropical Convergence Zone (ITCZ) over the heated continental South Asia instead of remaining above the warm waters of the equatorial Indian Ocean. The maximum excursion of the ITCZ depends on the temperature of continental South Asia, which is primarily controlled by insolation (Webster et al., 1998).

Although these two proposed views differ, the net result is the seasonal reversal in the direction of the wind over the monsoon region and a unimodal rainfall distribution throughout the year. Southwesterly winds of the Arabian Sea branch of the monsoon deliver their moisture primarily to the western coast of the Indian peninsula (Fig. 1), where the Sahyadri mountain range (Western Ghats) serves as an orographic barrier limiting the penetration of rains toward the interior. The Bay of Bengal monsoon branch brings rain to the Himalayas and the wider region of Southeastern Asia as well as the eastern and central regions of the Indian peninsula where most of the human population is concentrated (Gadgil, 2003). 


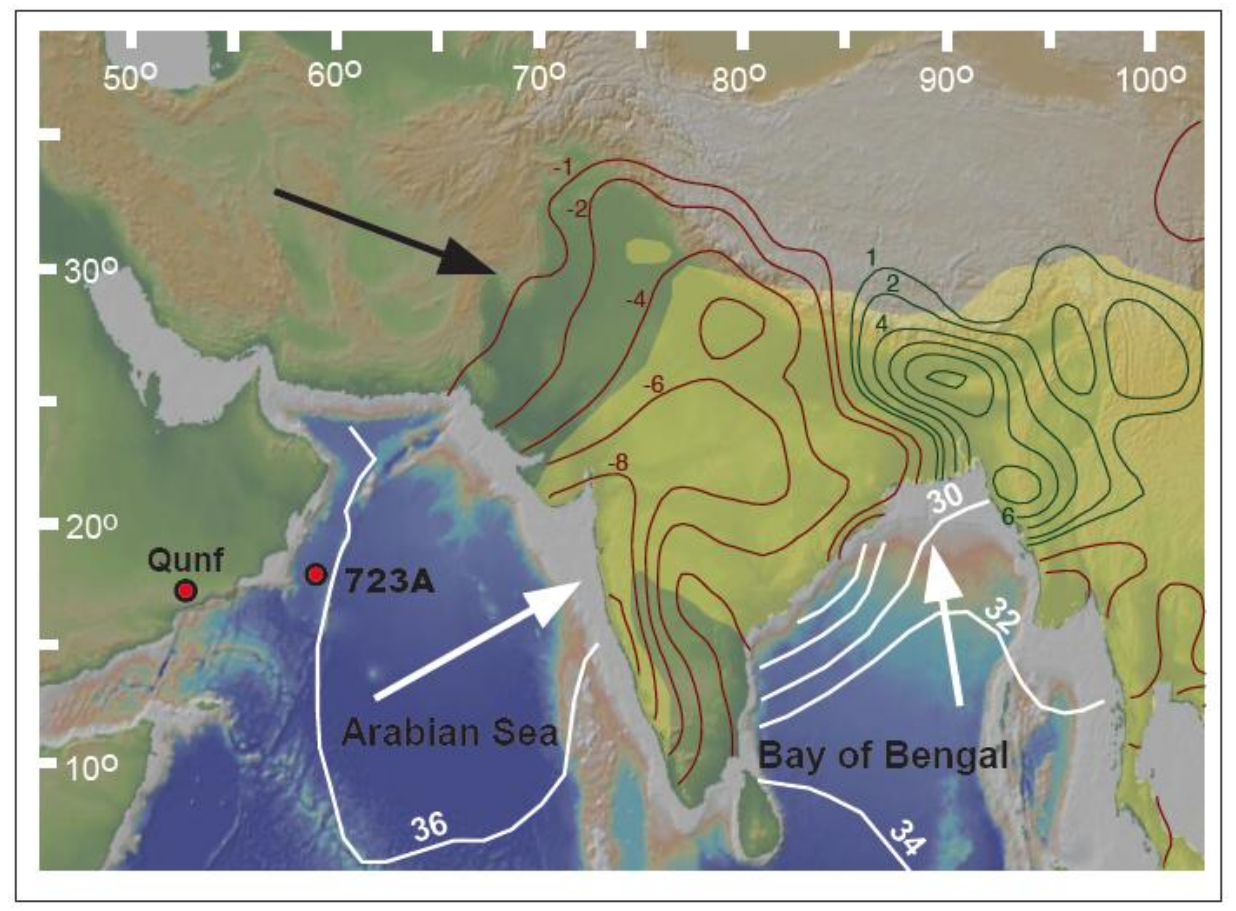

Figure 1. Physiographic map of the Indian peninsula and adjacent ocean regions with yellow shading for the region where precipitation rate is $4 \mathrm{~mm} /$ day or higher during JuneSeptember. Red dots indicate location of the Qunf cave (Fleitmann et al., 2003) and IODP hole 723A (Gupta et al., 2003). Black arrow is schematic for the incoming direction of the Westerly winds. White arrows indicate general incoming directions of the Arabian Sea and Bay of Bengal branches of the Indian summer monsoon. White contours are surface salinity for June-September in practical salinity scale (pss). Red and green contours indicate precipitation anomalies (mm/day) during monsoon break spells (Sinha et al., 2011a).

The large-scale systematics described above is responsible for the strong seasonal contrast in precipitation. However, intra-seasonal variations during the summer monsoon months can significantly affect the mean yearly rainfall. Instrumental records from the core monsoon zone $(\mathrm{CMZ})$, the region of central India that is considered representative for both the mean behavior as well as the fluctuations of the monsoon over the peninsula (Gadgil, 2003; Sinha et al., 2011a), show that the interannual variability of summer rainfall is strongly influenced by chaotic intra-seasonal oscillations leading to periods of increased (active) and reduced (break) precipitation (Gadgil, 2003). The competition 
between the continental and oceanic loci of the ITCZ (i.e., the Indian peninsula and the Equatorial Indian Ocean respectively) results in a characteristic increased/reduced precipitation dipole (Fig. 1) between the CMZ and northeast India/Bangladesh (Sinha et al., 2011a) as the system passes from active to break monsoon episodes and vice-versa. Although active and break spells of the monsoon are short lived, lasting from days to a few weeks (Gadgil, 2003; Sinha et al., 2011a), extended periods of break monsoon in the CMZ have been associated with most of the major droughts in the Indian subcontinent during the interval covered by the instrumental record (Joseph et al., 2009). The agrarianbased societies of south Asia have suffered relentlessly the profound effects from these droughts, strongly associated to migrations, famines and mass mortality.

\subsection{The last 1,000 years}

Sinha et al. (2011b) have recently used sub-annual precipitation reconstructions from stalagmites in the CMZ and northeast India extending over the last $\sim 700$ years to argue that the monsoon can persist in a predominantly active or break mode for decades to centuries. Although the mechanism for the multicentennial variability has yet to be clarified, migrations of the ITCZ in response to changes in the Northern Hemisphere temperatures (Sinha et al., 2011b; Tierney et al., 2010) and/or changes in the Indo-Pacific tropical climatology (Sinha et al., 2011b) are plausible external modulators of the monsoon system state (Sinha et al., 2011b). High resolution speleothem-based precipitation reconstructions in the CMZ (Sinha et al., 2011a) extend only for the late Holocene (i.e., last $\sim 1,400$ years), but they convincingly show that periods of drought (10\% less precipitation than the average monsoon) or even megadrought (20\% less precipitation than the average monsoon) that were at least as severe as historical events, but longer lasting, are common features during this time interval. Tree-ring-based reconstructions (e.g., Cook et al., 2010; Buckley et al., 2010) indicate a widespread spatial signature of some intense CMZ droughts at the scale of the entire Asian monsoon domain (Sinha et al., 2011a). 


\subsection{The last 10,000 years and beyond}

The monsoon picture becomes less clear for longer records as spatial variability and lower resolution limitations make it difficult to comprehensively describe changes in the Indian monsoon during the Holocene and last glacial age. Previous studies of the salinity variations in the Bay of Bengal (Cullen, 1981; Duplessy, 1982; Rashid et al., 2007) indicate that during the last glacial maximum (LGM) the riverine influx and precipitation over the area was lower than today. However, these studies could not address the millennial scale variability in hydrology, due to low sedimentation rates, since most of their cores were located in the southern reaches of the Bay of Bengal or in the Andaman Sea. In a recent study of Himalayan basin paleo-vegetation, Galy et al. (2008) suggest more arid conditions during the LGM than during the mid Holocene. Speleothem records from monsoon regions in China (i.e. Wang et al., 2008) and Oman (Fleitmann et al., 2007) generally agree with these marine sediment records but also show evidence for abrupt change in monsoon intensity during the mid-Holocene.

Detailed records of Holocene climate from the CMZ and particularly the Indian peninsula are conspicuously absent (Prasad and Enzel, 2006). High-resolution proxy records of precipitation (Fleitmann et al., 2003) and wind intensity (Gupta et al., 2003) during the Holocene are available for the Arabian Sea monsoon branch from the coastal and offshore regions of Oman respectively. These reconstructions, supported by other records (Sirocko et al., 1993; Overpeck et al., 1996; Schulz et al., 1998; Ivanochko et al., 2005), show a gradual decrease in precipitation during the Holocene associated with coeval weakening of summer monsoon winds, and have been interpreted (Fleitmann et al., 2007) as the result of the ITCZ southward migration (Haug et al., 2001). Foraminiferal oxygen isotopic records from the southeastern Arabian Sea suggest that monsoon intensified in late Holocene (Sarkar et al., 2000) as does reconstructed precipitation on the island of Socotra, offshore Yemen (Fleitmann et al., 2007), possibly responding to the same ITCZ southward retreat. Although implied, it is not certain if these records are coupled with climate in the Indian peninsula at all times. Holocene monsoon reconstructions from the 
NW Indian peninsula are limited to lower resolution lacustrine records and have not yielded clear evidence for increased precipitation in early Holocene corresponding to the interval of intensified summer monsoon winds (Prasad and Enzel, 2006).

Illustrating this uncertainty, an alternative hypothesis proposes that extended break monsoon conditions over the Indian peninsula are anti-correlated with monsoon wind intensity in the Arabian Sea during early Holocene (Staubwasser and Weiss, 2006). Under this scenario, the monsoon weakens only over the northernmost part of its domain over the Himalayas and their foothills, while the Indian peninsula experiences an increase in monsoon intensity, leaving no need for an ITCZ fluctuation to explain the spatial and temporal variability in monsoon proxy

records. However, because the intensification of the monsoon is evident primarily in records from southern India, it could reflect instead the orbital precession-forced southward migration of the ITCZ (Fleitmann et al., 2007).

In summary, from a survey of available data, it becomes evident that only an integrated record of the monsoon hydrology would generate a realistic picture of its variability. A comparison of available paleoclimate records reveals discrepancies between marine and continental records. While there is evidence for stronger monsoon winds during the early Holocene in the Arabian Sea branch of the Indian monsoon (Gupta, 2003) there is no corresponding evidence for increased precipitation in NW India (Prasad and Enzel, 2006). Furthermore, monsoon precipitation linked to the Bay of Bengal branch, the component that affects most of the population in India and neighboring Southeast Asian countries, has been reconstructed only for parts of the late Holocene (Sinha et al., 2007; Cook et al., 2010) or at low resolution (Kudras et al., 2001; Rashid et al., 2007). It should also be emphasized that paleoclimate proxies for upwelling are commonly related to the intensity of southwest Indian monsoon, but summer monsoon precipitation over India is not linearly correlated to wind strength. Rainfall depends more on the moisture content of the incoming winds, which is determined by sea surface temperature (SST) in 
the southern Hemisphere (Webster et al., 1998). Therefore, proxy records of summer monsoon rainfall and evaporation-precipitation (E-P) may better constrain monsoon intensity in the Bay of Bengal.

\section{River-dominated continental margins in monsoonal settings}

The Indian monsoon feeds some of the largest sediment-carrying rivers in the world (Syvitski and Saito, 2007) including the Ganges, Brahmaputra, Indus, Irrawady, Mahanadi, Krishna, and Godavari. These large sediment loads contribute to the development of river-dominated continental margins around the Bay of Bengal and the Arabian Sea that are characterized by high sediment accumulation rates. These high temporal resolution sedimentary records present the opportunity for a more detailed reconstruction of the Indian monsoon at the scale of entire river drainage basins.

Rivers play a central role in shaping the landforms that we see on Earth. They carve valleys on continents, transfer large amounts of sediment from uplands to lowlands, and deposit these sediments across the floodplains and at their mouths into standing bodies of water. Rivers bring approximately 20 petagrams $\left(\mathrm{Pg}=10^{15} \mathrm{~g}\right) / \mathrm{yr}$ of sediment to coastal environments (Meade, 1996) and are a major driving force controlling the shoreline and the morphology of the continental margins. On the coast, at the river mouth, when the river discharges sediment faster than it can be removed by waves and currents, a delta is formed. However, the actual delta-building process is the result of complex interactions between sediment discharge, basin morphology, tectonics, sea level changes, and coastal physical oceanography. Deltas have both subaerial and subaqueous components, are major sedimentary features along continental shelves, have a critical role in building siliciclastic continental margins. Since prehistoric times human civilizations have concentrated around the fertile soils of river floodplains and deltas. Today some of the largest and most important cities stand over deltas and $\sim 25 \%$ of the world's population lives within deltaic systems (Syvitsky and Saito, 2007). 
From an environmental context, river mouths have a disproportionate impact compared to their surface area because fluvial systems collect and integrate signals from surface processes over an extensive drainage area. Rivers are the source of dissolved and particulate materials entering into the ocean; they bring sediments, organic carbon, nutrients and a suite of chemical species as well as pollutants. The fluvial input of organic carbon into the oceans is estimated to be $\sim 0.4 \mathrm{PgC} / \mathrm{yr}$ (Schlünz and Schneider, 2000) with roughly $50 \%$ of this in particulate form (Hedges, 1992). River-dominated continental margins are major organic carbon repositories and one of the most important sites of active organic matter burial on Earth (Hedges and Keil, 1995). The fate of terrestrial materials in continental margins affects the global ocean and has the potential to influence global biogeochemical cycles (McKee et al., 2004). In addition, sediments deposited on river-dominated margins provide integrated records of both terrestrial and marine processes that can shed light on past environmental conditions, as well as on source-to-sink processes such as terrestrial OC cycling (Hedges et al. 1997; Weijers et al., 2007). The role of continental margin sediments in the carbon cycle as well as the use of these sedimentary archives for paleoenvironmental reconstructions rely upon a robust understanding of how organic matter is transferred from land to ocean, and how carbon signatures are ultimately recorded in marine sediments.

\section{Global Carbon Cycle}

The concentration of $\mathrm{CO}_{2}$ in the atmosphere plays a major role in regulating the global climate. Over geological timescales, the balance between natural processes that ultimately consume or produce $\mathrm{CO}_{2}$ modulates its concentration in the atmosphere. Weathering of silicates and burial of organic carbon (OC) in marine sediments are the two primary carbon sinks (Garrels et al., 1976; Berner, 2003). Volcanic activity, metamorphic decarbonation reactions, and weathering of carbonates and OC-rich sedimentary rocks represent sources of $\mathrm{CO}_{2}$ to the atmosphere (Berner, 2003; Hayes and Waldbauer, 2006). As centers of OC burial, continental margins play a major role in modulating Earth's atmospheric chemistry and therefore global climate over geological 
timescales (Berner, 1982). The continuous removal of OC from the biosphere and storage in margin sediments contributes significantly to the depletion of $\mathrm{CO}_{2}$ in the atmosphere. On shorter timescales, exchange between "intermediate" carbon reservoirs (Galy and Eglinton 2011) such as deep ocean waters and soils can modulate the $\mathrm{CO}_{2}$ concentration on the atmosphere. The atmospheric carbon reservoir $(750 \mathrm{PgC})$ is smaller than that held in soils (1,600 $\mathrm{PgC})$ and seawater $(38,000 \mathrm{PgC}$ as dissolved inorganic carbon (DIC); 600 $\mathrm{PgC}$ as dissolved organic carbon (DOC); Hedges, 1992), relatively small changes in the sizes and residence times between these carbon pools can significantly impact atmospheric $\mathrm{CO}_{2}$ concentrations.

The majority of sediment and organic matter eroded from the continents is deposited and stored on continental margins. It is estimated that as much as $85 \%$ of the global burial flux of terrestrial OC occurs on continental margins, underlining their disproportionate role in the global carbon cycle (Berner 1982, Hedges and Oades, 1997). In addition, sediments deposited on river-dominated margins provide integrated records of both terrestrial and marine processes that can shed light on past environmental conditions, as well as on source-to-sink processes (Hedges et al. 1997). The role of continental margin sediments in the carbon cycle as well as the use of these sedimentary archives for paleoenvironmental reconstructions rely upon a robust understanding of how organic matter is transferred from land to ocean, and how carbon signatures are ultimately recorded in marine sediments.

Terrestrial OC is transported to oceans mainly through rivers in the form of DOC and particulate organic carbon (POC); a smaller fraction may also be transported via aeolian processes. The present day discharge of riverine OC into the oceans constitutes $\sim 75 \%$ of the total exported terrestrial OC (Hedges et al. 1997) and it is estimated to be $0.43 \mathrm{PgC} / \mathrm{yr}$ (Schlünz and Schneider, 2000). The sources of this OC include a mixture of vascular plant debris, soils, OC eroded from sedimentary rocks, biological productivity within the river waters, and anthropogenic emissions (Blair et al., 2004, 2010). 


\section{Thesis outline}

This thesis provides new Holocene records of Indian monsoon variability using sediment cores with high accumulation rates from river-dominated margins in the Bay of Bengal and the Arabian Sea. Integrating marine and continental records, it presents regionally extensive paleoenvironmental reconstructions that have implications for landscape evolution, sedimentation, the terrestrial organic carbon cycle, and prehistoric human civilizations in the Indian subcontinent.

Chapter 2 presents a reconstruction of the Holocene paleoclimate in the core monsoon zone (CMZ) of the Indian peninsula using a sediment core recovered offshore from the mouth of the Godavari River in the Bay of Bengal. Carbon isotopes of the terrestrial plant leaf waxes that have been transported to, and preserved in, these margin sediments yield an integrated and regionally extensive record of the flora in the CMZ and provide evidence for a gradual increase in the proportion of aridity-adapted vegetation from $\sim 4,000$ until 1,700 years ago followed by the persistence of aridity-adapted plants after that as the drainage basin became increasingly perturbed by anthropogenic activity. The oxygen isotopic composition of planktonic foraminifer Globigerinoides ruber detects unprecedented high salinity events in the Bay of Bengal over the last 3,000 years, and especially after 1,700 years ago, which suggest that the CMZ aridification intensified in the late Holocene through a series of sub-millennial dry episodes. This chapter also considers archeological evidence from the Indian peninsula as a proxy for human population and reliance on early agricultural practices to assess correlations between major cultural and climatic changes in this region.

Chapter 3 also uses sediments from the same core described in the previous chapter, but focuses on the terrestrial carbon cycle as climatic conditions change in the Godavari River basin. It compares the ages of marine planktonic foraminifera with those of terrestrial plant waxes isolated from the same sediment horizons, and examines the 
relationships between hydroclimate and the mode and dynamics of terrestrial carbon discharge from the river drainage basin. Results show increasing age offsets from mid to late Holocene. Since $\sim 4,000$ yrs BP, higher plant fatty acids are on average $\sim 1,200$ yrs older than the foraminifera, indicating either increasing residence times of terrestrial carbon or increasing erosion and mobilization of pre-aged vascular plant-derived carbon as a consequence of a less humid climate. In addition to shedding light on past continental carbon cycle dynamics, these results also have important implications for the use of organic terrestrial proxies in paleoclimate reconstructions. They show that the temporal phasing of terrestrial and marine proxy signals may vary as a function of changes in hydroclimate.

Chapter 4 presents the first high-resolution seismic survey of the Indus River subaqueous delta on the Pakistani shelf in the northeastern Arabian Sea, and describes its morphology and Holocene sedimentation history. Seismic and core records are used to explore the suitability of using subaqueous deltaic sedimentary deposits from the Pakistani shelf to reconstruct the paleoclimate in the Indus drainage basin. Radiocarbon dates on mollusk shells from sediment cores show that sediment accumulation has been heterogeneous across the Indus shelf and the utility of sedimentary records for climate reconstruction appears strongly dependent on the stratigraphy of the cores.

A core recovered from a morphological depression is inferred to preserve an integrative paleoclimate record of the entire Indus River drainage basin. The carbon isotopic composition of sedimentary plant waxes suggests a remarkably stable climate over the arid regions of the Indus plain with a terrestrial biome dominated by $\mathrm{C}_{4}$ vegetation for the last 6,000 yrs. While reconstructions from the Arabian Sea and Bay of Bengal provide a consistent account of monsoon weakening over the Holocene, this reconstruction from the Indus River does not reflect these changes, and instead indicates that conditions in the drainage basin remained predominantly dry. 
Chapter 5 summarizes the most important findings of this thesis, highlights key new questions that this research has raised, and offers some directions for future research initiatives.

Overall this thesis provides new paleoclimate reconstructions of the Indian monsoon from river-dominated margins, contributing to the efforts of obtaining a more cohesive view of the Indian monsoon variability during the Holocene. It combines a wide range of observations and analytical techniques, and employs continental and marine climate proxies that integrate signals over extensive regions to present regional reconstructions. Results from this work have implications for the Indian monsoon system as whole, as well as vegetation cover, sedimentation, terrestrial carbon cycle and past human civilizations of the Indian subcontinent.

\section{References}

Ashfaq, M., Y. Shi, W. W. Tung, R. J. Trapp, X. J. Gao, J. S. Pal, and N. S. Diffenbaugh. 2009. Suppression of south Asian summer monsoon precipitation in the 21st century. Geophysical Research Letters 36 (1).

Berner, R. A. 1982. Burial of organic-carbon and pyrite sulfur in the modern ocean - its geochemical and environmental significance. American Journal of Science 282 (4):451473.

Berner, R.A. 2003. The long-term carbon cycle, fossil fuels and atmospheric composition. Nature 426 (6964):323-326.

Blair, N. E., E. L. Leithold, and R. C. Aller. 2004. From bedrock to burial: the evolution of particulate organic carbon across coupled watershed-continental margin systems. Marine Chemistry 92 (1-4):141-156.

Blair, N. E., K. Fournillier, E. L. Leithold, and L. B. Childress. 2010. Resolving organic carbon of differing diagenetic/catagenetic states in riverine and marine sediments. Geochimica Et Cosmochimica Acta 74 (12):A95-A95.

Boos, W. R., and Z. M. Kuang. 2010. Dominant control of the South Asian monsoon by orographic insulation versus plateau heating. Nature 463 (7278):218-U102. 
Buckley, B. M., K. J. Anchukaitis, D. Penny, R. Fletcher, E. R. Cook, M. Sano, C. N. Le, A. Wichienkeeo, T. M. Ton, and M. H. Truong. 2010. Climate as a contributing factor in the demise of Angkor, Cambodia. Proceedings of the National Academy of Sciences of the United States of America 107 (15):6748-6752.

Chao, W. C. 2000. Multiple quasi equilibria of the ITCZ and the origin of monsoon onset. Journal of the Atmospheric Sciences 57 (5):641-651.

Cook, E. R., K. J. Anchukaitis, B. M. Buckley, R. D. D'Arrigo, G. C. Jacoby, and W. E. Wright. 2010. Asian Monsoon Failure and Megadrought During the Last Millennium. Science 328 (5977):486-489.

Cullen, J. L. 1981. Microfossil evidence for changing salinity patterns in the Bay of Bengal over the last 20000 years. Palaeogeography Palaeoclimatology Palaeoecology 35 (2-4):315-356.

Duplessy, J. C. 1982. Glacial to interglacial contrasts in the northern Indian-ocean. Nature 295 (5849):494-498.

Fleitmann, D., S. J. Burns, M. Mudelsee, U. Neff, J. Kramers, A. Mangini, and A. Matter. 2003. Holocene forcing of the Indian monsoon recorded in a stalagmite from Southern Oman. Science 300 (5626):1737-1739.

Fleitmann, D., S. J. Burns, A. Mangini, M. Mudelsee, J. Kramers, I. Villa, U. Neff, A. A. Al-Subbary, A. Buettner, D. Hippler, and A. Matter. 2007. Holocene ITCZ and Indian monsoon dynamics recorded in stalagmites from Oman and Yemen (Socotra). Quaternary Science Reviews 26 (1-2):170-188.

Gadgil, S. 2003. The Indian monsoon and its variability. Annual Review of Earth and Planetary Sciences 31:429-467.

Galy, V., L. Francois, C. France-Lanord, P. Faure, H. Kudrass, F. Palhol, and S. K. Singh. 2008. C4 plants decline in the Himalayan basin since the Last Glacial Maximum. Quaternary Science Reviews 27 (13-14):1396-1409.

Galy, V., Eglinton, T.I. 2011. Protracted storage of biospheric carbon in the GangesBrahmaputra basin. Nature Geoscience 4:843-847.

Garrels, R. M., A. Lerman, and F. T. Mackenzie. 1976. Controls of atmospheric O2 and CO2 - past, present, and future. American Scientist 64 (3):306-315. 
Gupta, A. K., D. M. Anderson, and J. T. Overpeck. 2003. Abrupt changes in the Asian southwest monsoon during the Holocene and their links to the North Atlantic Ocean. Nature 421 (6921):354-357.

Halley, E. 1686. An historical account of the trade winds and monsoons observable in the seas between and near the tropics with an attempt to assign a physical cause of the said winds. $\dagger$. Philosophical Transactions of the Royal Society of London (16):153-168.

Haug, G. H., K. A. Hughen, D. M. Sigman, L. C. Peterson, and U. Rohl. 2001. Southward migration of the intertropical convergence zone through the Holocene. Science 293 (5533):1304-1308.

Hayes, J. M., and J. R. Waldbauer. 2006. The carbon cycle and associated redox processes through time. Philosophical Transactions of the Royal Society B-Biological Sciences 361 (1470):931-950.

Hedges, J.I.1992. Global biogeochemical cycles: progress and problems. Marine Chemistry 39: 67-93.

Hedges, J.I., Keil, R.G.1995. Sedimentary organic matter preservation: an assessment and speculative synthesis. Marine Chemistry 49:81-115.

Hedges, J. I., and J. M. Oades. 1997. Comparative organic geochemistries of soils and marine sediments. Organic Geochemistry 27 (7-8):319-361.

Hedges, J. I., R. G. Keil, and R. Benner. 1997. What happens to terrestrial organic matter in the ocean? Organic Geochemistry 27 (5-6):195-212.

Ivanochko, T. S., R. S. Ganeshram, G. J. A. Brummer, G. Ganssen, S. J. A. Jung, S. G. Moreton, and D. Kroon. 2005. Variations in tropical convection as an amplifier of global climate change at the millennial scale. Earth and Planetary Science Letters 235 (1-2):302314.

Joseph, S., A. K. Sahai, and B. N. Goswami. 2009. Eastward propagating MJO during boreal summer and Indian monsoon droughts. Climate Dynamics 32 (7-8):1139-1153.

Kudrass, H. R., A. Hofmann, H. Doose, K. Emeis, and H. Erlenkeuser. 2001. Modulation and amplification of climatic changes in the Northern Hemisphere by the Indian summer monsoon during the past 80 k.y. Geology 29 (1):63-66.

McKee, B.A., Aller, R.C., Allison, M.A., Bianchi, T.S. and Kineke, G.C. 2004. Transport and transformation of dissolved and particulate materials on continental margins influenced by major rivers: benthic boundary layer and seabed processes. Continental Shelf Research 24:899-926. 
Meade, R.H., 1996, River-sediment inputs to major deltas. In: Milliman, J., Haq, B. (Eds.), Sea-level rise and coastal subsidence. Kluwer: London, 63-85.

Overpeck, J., D. Anderson, S. Trumbore, and W. Prell. 1996. The southwest Indian Monsoon over the last 18000 years. Climate Dynamics 12 (3):213-225.

Prasad, S., and Y. Enzel. 2006. Holocene paleoclimates of India. Quaternary Research 66 (3):442-453.

Rashid, H., B. P. Flower, R. Z. Poore, and T. M. Quinn. 2007. A similar to 25 ka Indian Ocean monsoon variability record from the Andaman Sea. Quaternary Science Reviews 26 (19-21):2586-2597.

Sarkar, A., R. Ramesh, B. L. K. Somayajulu, R. Agnihotri, A. J. T. Jull, and G. S. Burr. 2000. High resolution Holocene monsoon record from the eastern Arabian Sea. Earth and Planetary Science Letters 177 (3-4):209-218.

Schott, F. A., and J. P. McCreary. 2001. The monsoon circulation of the Indian Ocean. Progress in Oceanography 51 (1):1-123.

Schlunz, B., and R. R. Schneider. 2000. Transport of terrestrial organic carbon to the oceans by rivers: re-estimating flux- and burial rates. International Journal of Earth Sciences 88 (4):599-606.

Schulz, H., U. von Rad, and H. Erlenkeuser. 1998. Correlation between Arabian Sea and Greenland climate oscillations of the past 110,000 years. Nature 393 (6680):54-57.

Sikka, D. R., and S. Gadgil. 1980. On the maximum cloud zone and the ITCZ over Indian longitudes during the southwest monsoon. Monthly Weather Review 108 (11):18401853.

Sinha, A., K. G. Cannariato, L. D. Stott, H. Cheng, R. L. Edwards, M. G. Yadava, R. Ramesh, and I. B. Singh. 2007. A 900-year (600 to 1500 A. D.) record of the Indian summer monsoon precipitation from the core monsoon zone of India. Geophysical Research Letters 34 (16).

Sinha, A., M. Berkelhammer, L. Stott, M. Mudelsee, H. Cheng, and J. Biswas. 2011 a. The leading mode of Indian Summer Monsoon precipitation variability during the last millennium. Geophysical Research Letters 38.

Sinha, A., L. Stott, M. Berkelhammer, H. Cheng, R. L. Edwards, B. Buckley, M. Aldenderfer, and M. Mudelsee. 2011b. A global context for megadroughts in monsoon Asia during the past millennium. Quaternary Science Reviews 30 (1-2):47-62. 
Sirocko, F., M. Sarnthein, H. Erlenkeuser, H. Lange, M. Arnold, and J. C. Duplessy. 1993. Century-scale events in monsoonal climate over the past 24,000 years. Nature 364 (6435):322-324.

Staubwasser, M., and H. Weiss. 2006. Holocene climate and cultural evolution in late prehistoric-early historic West Asia - Introduction. Quaternary Research 66 (3):372-387.

Syvitski, J. P. M. and Saito, Y. 2007. Morphodynamics of deltas under the influence of humans.

Global and Planetary Change 57:261-282.

Tierney, J. E., D. W. Oppo, Y. Rosenthal, J. M. Russell, and B. K. Linsley. 2010. Coordinated hydrological regimes in the Indo-Pacific region during the past two millennia. Paleoceanography 25.

Trenberth, K. E., D. P. Stepaniak, and J. M. Caron. 2000. The global monsoon as seen through the divergent atmospheric circulation. Journal of Climate 13 (22):3969-3993.

Wang, Yongjin, Hai Cheng, R. Lawrence Edwards, Xinggong Kong, Xiaohua Shao, Shitao Chen, Jiangyin Wu, Xiouyang Jiang, Xianfeng Wang, and Zhisheng An. 2008. Millennial- and orbital-scale changes in the East Asian monsoon over the past 224,000 years. Nature 451 (7182):1090-1093.

Webster, P. J., V. O. Magana, T. N. Palmer, J. Shukla, R. A. Tomas, M. Yanai, and T. Yasunari. 1998. Monsoons: Processes, predictability, and the prospects for prediction. Journal of Geophysical Research-Oceans 103 (C7):14451-14510.

Weijers, J. W. H., E. Schefuss, S. Schouten, and J. S. S. Damste. 2007. Coupled thermal and hydrological evolution of tropical Africa over the last deglaciation. Science 315 (5819):1701-1704. 


\section{CHAPTER 2}

\section{Holocene Aridification of India}

This work originally appeared as:

Ponton, C., L. Giosan, T.I. Eglinton, D.Q. Fuller, J.E. Johnson, P. Kumar, and T.S.

Collett. 2012. Holocene aridification of India. Geophysical Research Letters (39)

L03704, doi:10.1029/2011GL050722. Copyright, 2012, American Geophysical Union.

Reproduced by permission of the American Geophysical Union. 


\title{
Holocene aridification of India
}

\author{
Camilo Ponton, ${ }^{1,2}$ Liviu Giosan, ${ }^{2}$ Tim I. Eglinton, ${ }^{3,4}$ Dorian Q. Fuller, ${ }^{5}$ Joel E. Johnson, ${ }^{6}$ \\ Pushpendra Kumar, ${ }^{7}$ and Tim S. Collett ${ }^{8}$ \\ Received 21 December 2011; revised 10 January 2012; accepted 11 January 2012; published 14 February 2012.
}

[1] Spanning a latitudinal range typical for deserts, the Indian peninsula is fertile instead and sustains over a billion people through monsoonal rains. Despite the strong link between climate and society, our knowledge of the long-term monsoon variability is incomplete over the Indian subcontinent. Here we reconstruct the Holocene paleoclimate in the core monsoon zone (CMZ) of the Indian peninsula using a sediment core recovered offshore from the mouth of Godavari River. Carbon isotopes of sedimentary leaf waxes provide an integrated and regionally extensive record of the flora in the $\mathrm{CMZ}$ and document a gradual increase in aridity-adapted vegetation from $\sim 4,000$ until 1,700 years ago followed by the persistence of aridityadapted plants after that. The oxygen isotopic composition of planktonic foraminifer Globigerinoides ruber detects unprecedented high salinity events in the Bay of Bengal over the last 3,000 years, and especially after 1,700 years ago, which suggest that the CMZ aridification intensified in the late Holocene through a series of sub-millennial dry episodes. Cultural changes occurred across the Indian subcontinent as the climate became more arid after $\sim 4,000$ years. Sedentary agriculture took hold in the drying central and south India, while the urban Harappan civilization collapsed in the already arid Indus basin. The establishment of a more variable hydroclimate over the last ca. 1,700 years may have led to the rapid proliferation of waterconservation technology in south India. Citation: Ponton, C., L. Giosan, T. I. Eglinton, D. Q. Fuller, J. E. Johnson, P. Kumar, and T. S. Collett (2012), Holocene aridification of India, Geophys. Res. Lett., 39, L03704, doi:10.1029/2011GL050722.

\section{Introduction}

[2] From June to September, India receives over $80 \%$ of its annual precipitation [Gadgil, 2003]. The Arabian Sea branch of the monsoon delivers moisture primarily to the western Indian coast (Figure 1), where the Western Ghats range limits the penetration of rains toward the interior. The

${ }^{1}$ MIT/WHOI Joint Program in Oceanography/Applied Ocean Science and Engineering, Cambridge, Massachusetts, USA.

${ }^{2}$ Geology and Geophysics, Woods Hole Oceanographic Institution, Woods Hole, Massachusetts, USA.

${ }^{3}$ Marine Chemistry and Geochemistry, Woods Hole Oceanographic Institution, Woods Hole, Massachusetts, USA

${ }^{4}$ Geologisches Institut, Eidgenössische Technische Hochschule Zürich, Zürich, Switzerland.

${ }^{5}$ Institute of Archaeology, University College London, London, UK.

${ }^{6}$ Earth Sciences, University of New Hampshire, Durham, New Hampshire, USA.

${ }^{7}$ Institute of Engineering and Ocean Technology, Navi Mumbai, India

${ }^{8}$ U.S. Geological Survey, Denver, Colorado, USA.

Copyright 2012 by the American Geophysical Union. 0094-8276/12/2011GL050722
Bay of Bengal monsoon branch brings rain to most of the Indian peninsula (see auxiliary material). ${ }^{1}$ Historical records and reconstructions spanning the last millennium show that variability in summer monsoon precipitation led to droughts, some associated with widespread famine and social disturbances, that were significantly more severe and longer lasting than anything encountered in the measured record [Cook et al., 2010; Sinha et al., 2011a]. The strong relationship between climate and society in India provides impetus for developing a more predictive understanding of the monsoon [Ashfaq et al., 2009]. Long paleo-synoptic reconstructions would help explore the areal complexity of the monsoon, but high-resolution Holocene climate reconstructions for the Indian peninsula are conspicuously absent [Prasad and Enzel, 2006].

[3] Modern records from the core monsoon zone (CMZ), the region of central India that is considered representative for both the mean behavior as well as for fluctuations of the monsoon over the peninsula [Sinha et al., 2011a, and references therein], show that interannual variability of summer rainfall is negatively correlated with El Niño-Southern Oscillation (ENSO) indices and strongly influenced by chaotic intraseasonal oscillations, leading to periods of increased (active) and reduced (break) precipitation [Gadgil, 2003; Sinha et al., 2011a]. High resolution speleothem-based precipitation reconstructions in the $\mathrm{CMZ}$ covering the last $\sim 1,400$ years [Sinha et al., 2011a, 2011b] also suggest that extended periods of break monsoon in the CMZ have been associated with most of the major droughts in the Indian subcontinent. Sinha et al. [2011b] argue that the immediate cause for such extensive droughts is the monsoon's persistence in a predominantly active or break mode for decades to centuries. Longer Holocene monsoon reconstructions are available from the Arabian Sea region (Figure 2). Precipitation proxy data from a stalagmite in coastal Oman shows a gradual decrease in precipitation [Fleitmann et al., 2003] that is coeval with the weakening of summer monsoon winds reconstructed offshore Oman [e.g., Gupta et al., 2003] and has been interpreted to reflect the southward migration of the Intertropical Convergence Zone (ITCZ) [Fleitmann et al., 2007]. Although implied, it is not certain that these records can explain the hydroclimate of the Indian peninsula because of the heterogeneity of the monsoon expression at regional scales [see, e.g., Cook et al., 2010; Sinha et al., 2011a, 2011b].

[4] Complete Holocene monsoon reconstructions from the peninsula are limited to low resolution records and do not yield clear evidence for increased precipitation corresponding to stronger monsoon winds in the early Holocene [Prasad and Enzel, 2006]. Illustrating this uncertainty, an

\footnotetext{
Auxiliary materials are available at ftp://ftp.agu.org/apend/gl/ $2011 \mathrm{gl050722.}$
} 


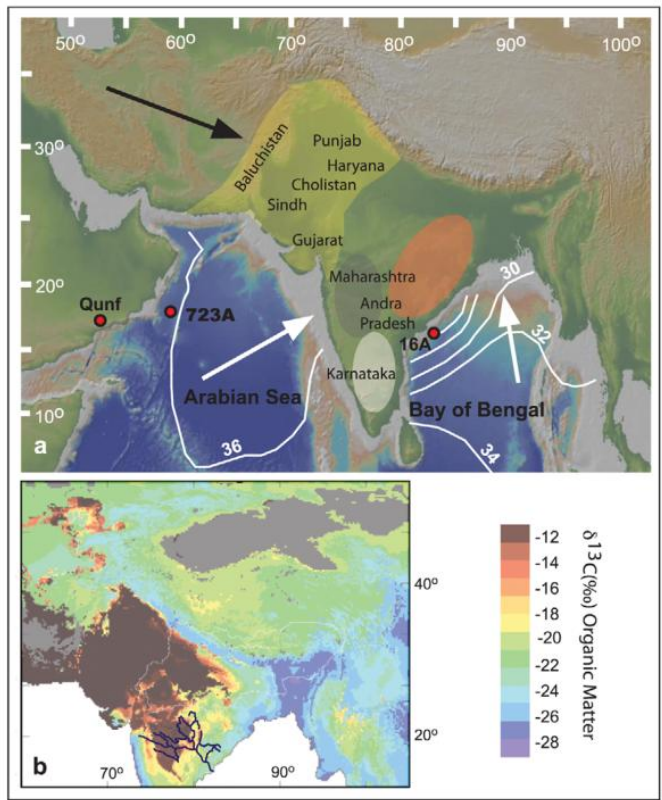

Figure 1. (a) Physiographic map of the Indian peninsula and adjacent ocean regions. Red dots show locations for core 16A, Qunf [Fleitmann et al., 2003] and site 723A [Gupta et al., 2003]. Black arrow is schematic for Westerly winds. White arrows indicate general directions of the Arabian Sea and Bay of Bengal branches of summer monsoon. White contours are surface salinity for June-September (in psu; see auxiliary material). Color shaded regions approximate the areal extent of past early cultures (see auxiliary material) with the corresponding modern provinces of India and Pakistan. The Indus Civilization domain is indicated by a yellow mask; Southern Neolithic is indicated by a white mask; Deccan Chalcolithic is indicated by a gray mask; and shifting cultivation domain is indicated by a red mask. (b) Average $\delta^{13} \mathrm{C}$ of bulk terrestrial biomass in modern-day India (reprinted from Galy et al. [2008], with permission from Elsevier).

alternative hypothesis [Staubwasser and Weiss, 2006] grounded in the analysis of modern intraseasonal activebreak monsoon dynamics proposes instead that the monsoon weakened only over the northernmost part of its domain over the Himalayas and their foothills, while the Indian Peninsula actually experienced an increase in monsoon intensity during the Holocene. However, an increase in precipitation is evident primarily in southern India and may reflect instead the Holocene progressive latitudinal southward shift of the summer ITCZ precipitation [Fleitmann et al., 2007].

[5] To constrain monsoon variability and its effects on the Indian peninsula, we produced Holocene climate records for both the continental and oceanic realms of the Bay of Bengal monsoon branch. Terrigenous and marine components were analyzed from sediment core NGHP-01-16A $\left(16^{\circ} 35.5986^{\prime} \mathrm{N}, 082^{\circ} 41.0070^{\prime} \mathrm{E} ; 1,268 \mathrm{~m}\right.$ water depth) recovered close to the Godavari River mouth, the largest non-Himalayan Indian river (see auxiliary material). The Godavari catchment $\left(312,812 \mathrm{~km}^{2}\right.$, maximum elevation 920 m, Figure 1; see auxiliary material) integrates monsoon rainfall from the $\mathrm{CMZ}$ at the interior of the Indian peninsula and is not affected by meltwater that augments the discharge of Himalayan rivers [Immerzeel et al., 2010]. We sampled hemipelagic sediments accumulating at rates higher than $0.3 \mathrm{~m} / 1000$ years throughout the Holocene (see auxiliary material for details on sedimentation). The cored region experiences a large seasonal range of salinity $(\sim 24-34$ psu and $\sim 2 \%$ change in $\delta^{18} \mathrm{O}$ of sea water) as the monsoon freshwater plume in the Bay of Bengal disperses after the summer (see auxiliary material).

\section{Methods}

[6] The age model for core NGHP-16A was based on ${ }^{14} \mathrm{C}$ Accelerator Mass Spectrometry (AMS) measurements on 11 samples of mixed planktonic foraminifera (see details in auxiliary material). Stable isotope analyses of oxygen were performed using standard techniques (see auxiliary material) on planktonic foraminifera Globigerinoides ruber (white) at a temporal resolution of $\sim 33$ years with an analytical reproducibility better than $0.1 \%$ based on replicate measurements of carbonate standard NBS-19. Compound-specific carbon isotope analyses were performed on $n$-alkanoic acids (see auxiliary material) at an average sampling interval of $\sim 220$ years. Solvent-soluble

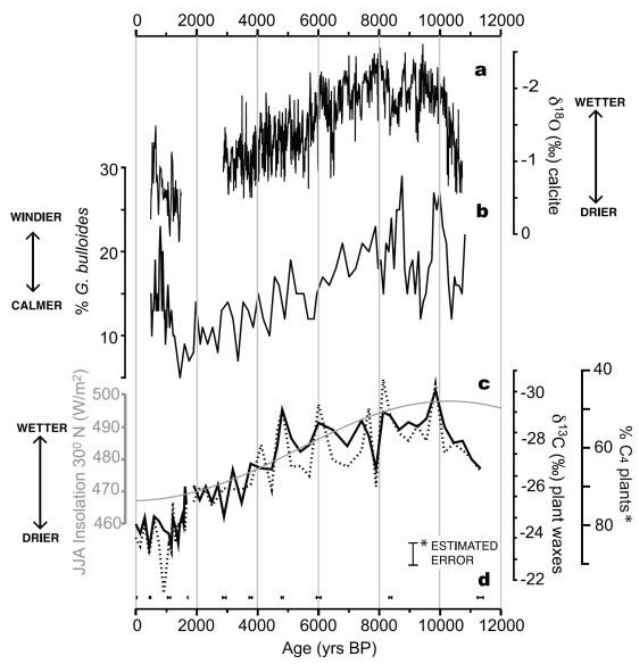

Figure 2. (a) Indian monsoon $\delta^{18} \mathrm{O}$ record from Qunf Cave, Oman [Fleitmann et al., 2003]. (b) Indian monsoon upwelling record [Gupta et al., 2003]. (c) The $\delta^{13} \mathrm{C}$ plant wax from core 16A. Black line is the weighted average of $n$-alkanoic acids $\mathrm{C}_{26}-\mathrm{C}_{32}$. Dashed line is $\mathrm{C}_{28}$, the most abundant homologue in most samples. Error bar represents the maximum propagated error ( $1 \sigma$ error; see auxiliary material) in the estimate of $\% \mathrm{C}_{4}$ plant cover (secondary axis on the far right). Grey line is the mean June-July-August insolation at $30^{\circ} \mathrm{N}$ [Laskar et al., 2004]. (d) Calibrated radiocarbon ages ( $1 \sigma$ error) in core 16A. 
organic matter was extracted from freeze-dried sediments using a microwave accelerated reaction system. The resulting total lipid extract was saponified and the acid fraction purified and then methylated using methanol of known isotopic composition. A Gas Chromatograph with isotope ratio monitoring Mass Spectrometer (GC-irMS) was used to obtain the $\delta^{13} \mathrm{C}$ measurements on the isolated n-alkanoic acids. All samples were analyzed in triplicate; $\delta^{13} \mathrm{C}$ values were determined relative to a reference gas $\left(\mathrm{CO}_{2}\right)$ of known isotopic composition, introduced in pulses during each run. GC-irMS accuracy and precision are both better than $0.3 \%$. Results were corrected for $\delta^{13} \mathrm{C}$ of the methyl derivative based on isotopic mass balance to derive $\delta^{13} \mathrm{C}$ values for the original $n$-alkanoic acids (see auxiliary material).

\section{Monsoon Variability in the Core Monsoon Zone}

[7] The carbon isotopic composition of terrestrial plant biomass is primarily a function of the plant's specific photosynthetic pathway and isotopic composition of atmospheric $\mathrm{CO}_{2}$ [Farquhar et al., 1989], with environmental conditions exerting a minimal influence. These isotopic signatures also manifest themselves in vascular plant epicuticular wax lipids [e.g., Tipple and Pagani, 2010]. Leaf wax $\delta^{13} \mathrm{C}$ records (i.e., for $\mathrm{C}_{26}$ to $\mathrm{C}_{32} n$-alkanoic acids; hereafter $\delta^{13} \mathrm{C}_{\mathrm{wax}}$; see auxiliary material) have been used extensively to reconstruct past changes in the balance of $\mathrm{C}_{3}$ vs. $\mathrm{C}_{4}$ vegetation [Feakins et al., 2005; Eglinton and Eglinton, 2008]. $\mathrm{C}_{4}$ vegetation is favored by aridity, high temperature, and low atmospheric $\mathrm{CO}_{2}$ conditions over $\mathrm{C}_{3}$ plants. Given the minimal variability in annual sea surface temperature in the northern Indian Ocean region [Govil and Naidu, 2010; Anand et al., 2008; Rashid et al., 2007; Govil and Naidu, 2011] and increasing $\mathrm{CO}_{2}$ over the Holocene, our leaf wax $\delta^{13} \mathrm{C}$ record reflects the integrated rainfall variations or aridity in the Godavari river catchment where natural vegetation cover is a mixture of savanna, tropical grassland, and tropical forest [Asouti and Fuller, 2008]. Modeled bulk organic carbon $\delta^{13} \mathrm{C}$ values corresponding to this modern biome mixture vary from ca. -12 to $-26 \%$ (Figure 1) [Galy et al., 2008]. In our core, $\delta^{13} \mathrm{C}_{\mathrm{wax}}$ (Figure 2) exhibits a large range of variation $(\sim-23 \%$ to $\sim-30 \%$ ).

[8] Based on prior $\delta^{13} \mathrm{C}$ measurements of $n$-alkanoic acids isolated from different plant species [Chikaraishi et al., 2004], we calculated isotopic end members of $-37.7 \pm 1.8 \%$ and $-21.1 \pm 1.4 \%$ for $\mathrm{C}_{3}$ and $\mathrm{C}_{4}$ plants (see auxiliary material), respectively. Using a simple isotopic mass balance we estimate that the proportion of $\mathrm{C}_{4}$ vegetation cover in central India increased from approximately $50 \%$ to more than $75 \%$ during the Holocene (Figure 2). The average error in the changes in abundance of $\mathrm{C}_{3}$ vs. $\mathrm{C}_{4}$ plants (see auxiliary material) based on the Chikaraishi et al. [2004] species survey amounts to $\pm 6.3 \%$, uncertainty which is considerably less than the changes in our record (Figure 2). Although there is significant carbon isotopic variability within $\mathrm{C}_{4}$ and especially $\mathrm{C}_{3}$ plants and their corresponding waxes [Freeman and Collarusso, 2001; Chikaraishi et al., 2004; Tipple and Pagani, 2010], which limits the ability to place tight constraints on changes in the proportion of $\mathrm{C}_{4}$ plants, the magnitude of change during the Holocene reflects a significant shift in vegetation type.
The range of variation for $\delta^{13} \mathrm{C}$ composition among individual $\mathrm{C}_{26}$ to $\mathrm{C}_{32} n$-alkanoic acid homologues also decreased from early to late Holocene (see auxiliary material). We speculate that this trend is also a response to increased aridity, and may reflect the narrower range of $\delta^{13} \mathrm{C}$ values expressed by $\mathrm{C}_{4}$ plants [Freeman and Collarusso, 2001] or a reduction in plant diversity [Rommerskirchen et al., 2003]. Crassulacean acid metabolism (CAM) plants, which can utilize both $\mathrm{C}_{3}$ and $\mathrm{C}_{4}$ carbon fixation pathways and have an intermediate $\delta^{13} \mathrm{C}$ range, are common in central India [Asouti and Fuller, 2008] and may lead to an underestimation of $\mathrm{C}_{4}$ cover, but also represent aridity-adapted vegetation. Additionally, anthropogenic contributions to the $\mathrm{C}_{4}$ signal through cultivation cannot be completely discounted but are likely to have been small until the 19th century when massive and permanent deforestation of the Eastern Ghats took place [Hill, 2008]. Prior to this large scale deforestation, the shifting cultivation style typical for the Eastern Ghats (Figure 1a) where most $\mathrm{C}_{3}$ flora occurs in the Godavari watershed, did not favor large changes in $\mathrm{C}_{3}$ vs. $\mathrm{C}_{4}$ plants (see auxiliary material). Early farming in the Deccan (Figure 1a) replaced $\mathrm{C}_{4}$-dominated savannah and adjacent woodland with $\mathrm{C}_{4}$ cultivated plants, but also affected the Western Ghats $\mathrm{C}_{3}$ forests, which comprise only a small part of the Godavari's headwaters. Rice, a $\mathrm{C}_{3}$ plant that was cultivated in coastal regions after 3,000 years ago, would have ameliorated rather than accentuated the trend toward $\mathrm{C}_{4}$ flora dominance in the late Holocene.

[9] The inferred change in vegetation structure is comparable in magnitude to a major glacial to interglacial ecosystem alteration (cf., $\sim 20 \%$ shift toward more $\mathrm{C}_{4}$ plants in the Himalayas from the Last Glacial Maximum to early Holocene [Galy et al., 2008]). Our own $\delta^{13} \mathrm{C}_{\mathrm{wax}}$ measurements on glacial-age samples at $\sim 26 \mathrm{ka} \mathrm{BP}$ show ${ }^{13} \mathrm{C}$-enriched values $(-22.3 \%$; see auxiliary material), implying that the vegetation cover in the Godavari catchment was similarly populated with $\mathrm{C}_{4}$ plants $(>85 \%)$. After a humid early Holocene when the proportion of $\mathrm{C}_{4}$ plants oscillated significantly, there was a marked change towards more positive $\delta^{13} \mathrm{C}_{\mathrm{wax}}$ values that persisted until ca. 1,700 years ago, reflecting the increasing aridification of central India. This increase in aridity is most evident after 4,000 BP (Figure 2) when the $\delta^{13} \mathrm{C}$ values for all $\mathrm{C}_{26}$ to $\mathrm{C}_{32} n$-alkanoic acid homologues shift to values beyond their previous range of variability. The last $\sim 1,700$ years appear to be anomalously arid with an apparent dominance of $\mathrm{C}_{4}$ vegetation. The Holocene aridification of central India supports the view that changes in the seasonality of Northern Hemisphere insolation associated with the orbital precession, led to progressively weaker monsoons [Fleitmann et al., 2007]. In concert with previous reconstructions in the Arabian Sea region [Fleitmann et al., 2003; Gupta et al., 2003] and northern Bay of Bengal [Kudrass et al., 2001], this aridification of the core monsoon zone shows that the Indian monsoon displayed a largely coherent response during the Holocene.

[10] We explored further the changes in aridity for the last 4,500 years by examining the oxygen isotope composition of planktonic foraminifer Globigerinoides ruber $\left(\delta^{18} \mathrm{O}_{\text {ruber }}\right)$ from core NGHP-01-16A (Figure 3). After applying a positive correction for the effects of post-glacial ice-sheet decay varying between 0 and $0.07 \%$ (see auxiliary material), $\delta^{18} \mathrm{O}_{\text {ruber }}$ should record surface water conditions in the Bay of Bengal. The relatively low $\delta^{18} \mathrm{O}$ 


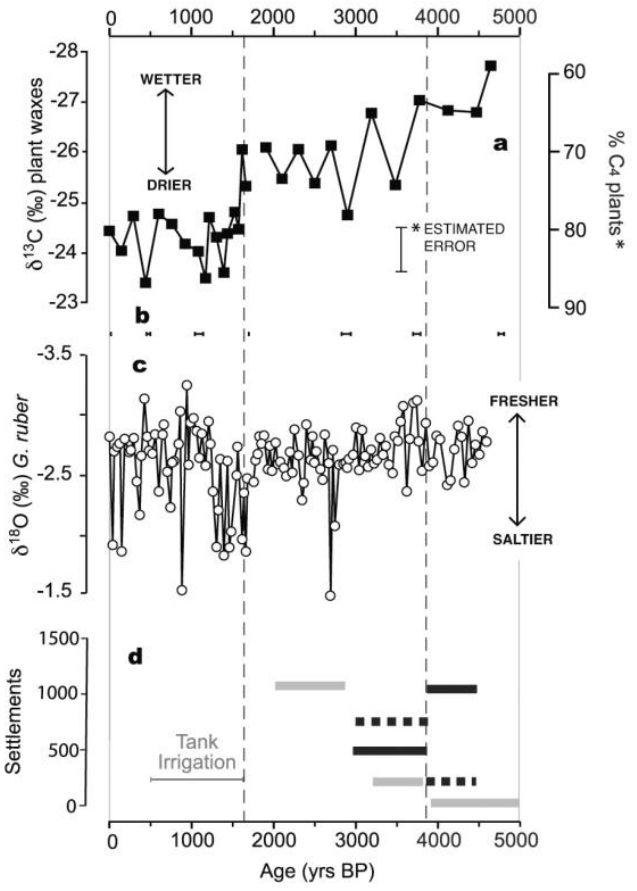

Figure 3. (a) $\delta^{13} \mathrm{C}$ plant wax record from core $16 \mathrm{~A}$ as the weighted average of $n$-alkanoic acids $\mathrm{C}_{26}-\mathrm{C}_{32}$. Error bar represents the maximum propagated error ( $1 \sigma$ error; see auxiliary material) in the estimate of $\% \mathrm{C}_{4}$ plant cover. Vertical black dashed lines identify steps in the aridification at ca. 4,000 and 1,700 years BP. (b) Calibrated radiocarbon ages $\left(1 \sigma\right.$ error) in core $16 \mathrm{~A}$. (c) $\delta^{18} \mathrm{O}$ measured on Globigerinoides ruber from core 16A; values are corrected for ice volume effects. (d) Number of settlements based on archaeological data expressed as totals over culturally defined time intervals (see auxiliary material). In solid gray, sites from the Deccan Plateau (Andhra Pradesh, Karnataka, Maharashtra). In solid black, Indus (Harappan) sites from the dry Baluchistan, Sindh, Gujarat, Cholistan and lower Punjab. In dashed black, sites from rainier upper Punjab and Haryana. The drought-prone regime in the late Holocene (after 1,700 years BP) coincides with the flourishing of water tank construction.

values of our record and the lack of a clear trend in the $\delta^{18} \mathrm{O}$ time series is not surprising for this region reflecting large fluvial discharge and the preformed waters of these fluvial sources [Breitenbach et al., 2010]. Freshwater from Godavari, augmented by several other large rivers, together with direct precipitation over the Bay and the water exchange with adjacent regions of the Indian Ocean act to buffer local variability [Schott and McCreary, 2001] (see auxiliary material). Relatively stable sea surface conditions characterize the interval between $\sim 4,500$ and 3,000 years $\mathrm{BP}$ (Figure 3 ) with variability between $\sim-2.3 \%$ and $-3.3 \%$. However, after 3,000 years BP, and especially over the last 1,700 years, $\delta^{18} \mathrm{O}_{\text {ruber }}$ values vary between $\sim-1.4 \%$ and $-3.3 \%$ exhibiting marked positive excursions. Similar to other tropical regions, Holocene sea surface temperature (SST) fluctuations in the northern Indian Ocean were small (up to $2.5^{\circ} \mathrm{C}$ ) after $\sim 8,000$ years BP (see Anand et al. [2008] and Govil and Naidu [2010] for eastern Arabian Sea, Rashid et al. [2007] for the Andaman Sea, and Govil and Naidu [2011] for the western Bay of Bengal) accounting for a maximum of $0.56 \%$ change in $\delta^{18} \mathrm{O}_{\text {ruber }}$ (see auxiliary material). Thirteen excursions of sub-millennial duration occurring in our late Holocene record are beyond the variance that can be explained by temperature variations. Simulations with a fully coupled atmosphere-ocean global climate model [LeGrande and Schmidt, 2009] also suggest that changes in precipitation sources over the Bay of Bengal were minimal in the last 6,000 years compared to earlier in the Holocene.

[11] In this context, we interpret the positive $\delta^{18} \mathrm{O}_{\text {ruber }}$ excursions after 3,000 years BP to reflect increased salinity events in the Bay of Bengal during drier intervals reminiscent of the extended droughts documented for the last millennium [Cook et al., 2010; Sinha et al., 2011a]. The lack of a corresponding increase in variance in the $\delta^{13} \mathrm{C}_{\mathrm{wax}}$ record over the late Holocene may reflect the buffering of short term terrestrial sedimentary signals within the Godavari watershed and/or sluggish recovery of $\mathrm{C}_{3}$ continental flora in a variable hydroclimatic regime. Records from cores with lower sedimentation rates from the northern Bay of Bengal and the Andaman Sea as well as eastern Arabian Sea also argue for higher salinities in the late Holocene [Kudrass et al., 2001; Rashid et al., 2007; Govil and Naidu, 2010]. The $\delta^{18} \mathrm{O}_{\text {ruber }}$ excursions are particularly prominent between $\sim 1,700$ and 1,300 years BP, coincident with the Holocene monsoon minimum in the wind proxy reconstruction in the Arabian Sea [Anderson et al., 2010] (Figure 3). Considering that the background $\delta^{18} \mathrm{O}_{\text {ruber }}$ over the last 1,300 years indicates surface salinities as low as in the middle Holocene or lower, it is reasonable to assume that the levels of precipitation were high outside these dry episodes, consistent with the increase in monsoon winds in the Arabian Sea during the same interval [Anderson et al., 2010]. In the eastern Arabian Sea, small annual mean SST variability (less than $1^{\circ} \mathrm{C}$ ) reconstructed on $G$. ruber contrasts with the increased seasonality indicated by coeval temperature record on G. bulloides over the past $\sim 4,000$ years [Anand et al., $2008]$, lending further support to the idea that $\delta^{18} \mathrm{O}_{\text {ruber }}$ excursions primarily reflect changes in monsoon variability. Recent foraminifer-based records of Govil and Naidu [2011] and Chauhan et al. [2010] suggests increased monsoon variability after ca. 3,500 and 2,200 years BP respectively whereas a speleothem record from NE India [Adkins et al., 2011; Breitenbach, 2010] shows increased monsoon variance in the last $\sim 2,000$ years. Taken together, these reconstructions suggest that monsoon variability increased coherently over the Indian peninsula in the late Holocene, although at sub-millennial timescale the variability may have been anti-phased between the peninsula and northeastern India [Sinha et al., 2011b].

[12] A recent reconstruction of the Australian-Indonesian monsoon shows a relatively dry early to middle Holocene and an increase in precipitation during the past $\sim 2,500$ years [Mohtadi et al., 2011]. The out-of-phase behavior of rainfall in central India in the Northern Hemisphere versus Indonesia in the Southern Hemisphere is in agreement with a primary orbital control on the monsoon in the Indian 
Ocean. Our terrestrial and oceanic records further suggest that aridification intensified in the CMZ in the late Holocene through a series of sub-millennial dry episodes. We note that these episodes occurred preferentially in late Holocene when the intensity of Northern Hemisphere summer insolation reached its minimum. El Niño frequency/intensity also increased in late Holocene [e.g., Moy et al., 2002]. However, understanding how the CMZ dry episodes relate to changes in Northern Hemisphere climatic state or to coupled ocean-atmosphere zonal modes, such as El Niño-Southern Oscillation, would require complete Holocene climate reconstructions from this region at subdecadal resolution.

\section{Aridification and Cultural Change}

[13] The dramatic effects of monsoon variability on the well-being of the peninsular population over the historical period are well-documented [Cook et al., 2010]. Regardless of the exact mechanisms leading to aridification of central India during the Holocene, our new data suggest that this symbiotic human-monsoon relationship may have existed since prehistory. The significant aridification recorded after ca. 4,000 years ago may have spurred the widespread adoption of sedentary agriculture in central and south India capable of providing surplus food in a less secure hydroclimate [Asouti and Fuller, 2008]. Archaeological site numbers and the summed probability distributions of calibrated radiocarbon dates from archaeological sites, which serve as proxies of agricultural population, increase markedly after 4,000 BP in peninsular India (Figure 3; see auxiliary material) for cultures of Southern India and the Deccan Plateau. In contrast, the same process of drying elicited the opposite response (Figure 3) in the already arid northwestern region of the subcontinent along the Indus River (Figure 1a). From $\sim 3,900$ to 3,200 years BP, the urban Harappan civilization entered a phase of protracted collapse. Late Harrapan rural settlements became instead more numerous in the rainier regions at the foothills of the Himalaya and in the Ganges watershed [Madella and Fuller, 2006]. During the Iron Age, after ca. 3,200 years BP, adaptation to semi-arid conditions in central and south India appears to have been well established with $\sim 60 \%$ of sites in areas with $<1000 \mathrm{~mm}$ of rainfall today and a significant number of sites $(18 \%)$ in areas with $<600 \mathrm{~mm}$ (see auxiliary material). Later, the rapid increase in rainwater harvesting structures that occurred after 1,700 BP in the semi-aric regions of south India [Gunnell et al., 2007] points to an expansion of the cultural adaptation to an additional increase in aridity (Figure 3). Although tentative, these correlations between hydroclimate and cultural changes in the Indian subcontinent suggest distinct societal responses to climate stress and underline the importance of understanding the history of the monsoon in a dynamic context at synoptic scales both for interpreting the past, but also for providing the long-term context for the short instrumentally observed variability.

[14] Acknowledgments. We thank colleagues and crew from the NGHP-01 expedition for intellectual interactions leading to this work. We also thank Daniel Montlucon, Carl Johnson and Allan Gagnon for their assistance in producing the lab data. We benefited from discussions with Valier Galy and Olivier Marchal and reviews by Mahyar Mohtadi, Max Berkelhammer and one anonymous reviewer. This study was supported by grants from the National Science Foundation (OCE-0841736 and OCE- 0623766) and Woods Hole Oceanographic Institution.

[15] The Editor thanks Max Berkelhammer, Mahyar Mohtadi and an anonymous reviewer for their assistance in evaluating this paper

\section{References}

Adkins, J. F., S. Breitenbach, B. Plessen, N. Marwan, D. C. Lund, P. Huybers, and G. H. Haug (2011), Holocene history of $\delta^{18} \mathrm{O}$ and grayscale from a stalagmite in NE India, with implications for monsoon and ENSO variability, Abstract PP22B-06, presented at 2011 Fall Meeting, AGU, San Francisco, Calif., 5-9 Dec.

Anand, P., D. Kroon, A. D. Singh, R. S. Ganeshram, G. Ganssen, and H. Elderfield (2008), Coupled sea surface temperature-seawater $\delta^{18} \mathrm{O}$ reconstructions in the Arabian Sea at the millennial scale for the last $35 \mathrm{ka}$, Paleoceanography, 23, PA4207, doi:10.1029/2007PA001564.

Anderson, D. M., C. K. Baulcomb, A. K. DuVivier, and A. K. Gupta (2010), Indian summer monsoon during the last two millennia, J. Quat. Sci., 25(6), 911-917, doi:10.1002/jqs.1369.

Ashfaq, M., Y. Shi, W. W. Tung, R. J. Trapp, X. J. Gao, J. S. Pal, and N. S. Diffenbaugh (2009), Suppression of south Asian summer monsoon precipitation in the 21 st century, Geophys. Res. Lett., 36, L01704, doi:10.1029/2008GL036500.

Asouti, E., and D. Q. Fuller (2008), Trees and Woodlands in South India. Archaeological Perspectives, Left Coast, Walnut Creek, Calif.

Breitenbach, S. (2010), Changes in monsoonal precipitation and atmospheric circulation during the Holocene reconstructed from stalagmites from Northeastern India, Sci. Tech. Rep. 10/06, Dtsch. GeoForschungsZent., Potsdam, Germany. doi:10.2312/GFZ.b103-10060.

Breitenbach, S. F. M., J. F. Adkins, H. Meyer, N. Marwan, K. K. Kumar, and G. H. Haug (2010), Strong influence of water vapor source dynamics on stable isotopes in precipitation observed in southern Meghalaya, Earth Planet. Sci. Lett., 292(1-2), 212-220, doi:10.1016/j.epsl.2010.01.038.

Chauhan, O. S., E. Vogelsang, N. Basavaiah, and U. S. A. Kader (2010), Reconstruction of the variability of the southwest monsoon during the past $3 \mathrm{ka}$, from the continental margin of the southeastern Arabian Sea, J. Ouat. Sci., 25, 798-807, doi:10.1002/jqs.1359.

Chikaraishi, Y., H. Naraoka, and S. R. Poulson (2004), Hydrogen and carbon isotopic fractionations of lipid biosynthesis among terrestrial (C3, C4 and CAM) and aquatic plants, Phytochemistry, 65(10), 1369-1381, doi:10.1016/j.phytochem.2004.03.036.

Cook, E. R., K. J. Anchukaitis, B. M. Buckley, R. D. D'Arrigo, G. C. Jacoby, and W. E. Wright (2010), Asian monsoon failure and megadrought during the last millennium, Science, 328(5977), 486-489, doi:10.1126/science. 1185188

Eglinton, T. I., and G. Eglinton (2008), Molecular proxies for paleoclimatology, Earth Planet. Sci. Lett., 275, 1-16, doi:10.1016/j.epsl.2008.07.012.

Farquhar, G. D., J. R. Ehleringer, and K. T. Hubick (1989), Carbon isotope discrimination and photosynthesis, Annu. Rev. Plant Physiol. Mol. Biol., 40, 503-537, doi:10.1146/annurev.pp.40.060189.002443

Feakins, S. J., P. B. deMenocal, and T. I. Eglinton (2005), Biomarker records of late Neogene changes in northeast African vegetation, Geology, 33(12), 977-980, doi:10.1130/G21814.1.

Fleitmann, D., S. J. Burns, M. Mudelsee, U. Neff, J. Kramers, A. Mangini, and A. Matter (2003), Holocene forcing of the Indian monsoon recorded in a stalagmite from southern Oman, Science, 300(5626), 1737-1739, doi: $10.1126 /$ science. 1083130

Fleitmann, D., et al. (2007), Holocene ITCZ and Indian monsoon dynamics recorded in stalagmites from Oman and Yemen, Quat. Sci. Rev., 26(1-2), 170-188, doi:10.1016/j.quascirev.2006.04.012.

Freeman, K. H., and L. A. Collarusso (2001), Molecular and isotopic records of $\mathrm{C} 4$ grassland expansion in the late Miocene, Geochim. Cosmochim. Acta, 65, 1439-1454, doi:10.1016/S0016-7037(00)00573-1.

Gadgil, S. (2003), The Indian monsoon and its variability, Annu. Rev. Earth Planet. Sci., 31, 429-467, doi:10.1146/annurev.earth.31.100901.141251. Galy, V., L. Francois, C. France-Lanord, P. Faure, H. Kudrass, F. Palhol, and S. K. Singh (2008), C4 plants decline in the Himalayan basin since the Last Glacial Maximum, Quat. Sci. Rev., 27(13-14), 1396-1409, doi:10.1016/j.quascirev.2008.04.005.

Govil, P., and P. D. Naidu (2010), Evaporation-precipitation changes in the eastern Arabian Sea for the last $68 \mathrm{ka}$ : Implications on monsoon variability, Paleoceanography, 25, PA1210, doi:10.1029/2008PA001687.

Govil, P., and P. D. Naidu (2011), Variations of Indian monsoon precipitation during the last $32 \mathrm{kyr}$ reflected in the surface hydrography of the western Bay of Bengal, Quat. Sci. Rev., 30, 3871-3879, doi:10.1016/j. quascirev.2011.10.004.

Gunnell, Y., K. Anupama, and B. Sultan (2007), Response of the south Indian runoff-harvesting civilization to northeast monsoon rainfall variability during the last 2000 years: instrumental records and indirect evidence, Holocene, 17(2), 207-215, doi:10.1177/0959683607075835. 
Gupta, A. K., D. M. Anderson, and J. T. Overpeck (2003), Abrupt changes in the Asian southwest monsoon during the Holocene and their links to the North Atlantic Ocean, Nature, 421(6921), 354-357, doi:10.1038 nature 01340 .

Hill, C. V. (2008), South Asia: An Environmental History, 329 pp., ABC-CLIO, Santa Barbara, Calif.

Immerzeel, W. W., L. P. H. van Beek, and M. F. P. Bierkens (2010), Climate change will affect the Asian water towers, Science, 328, 1382-1385, doi:10.1126/science.1183188.

Kudrass, H. R., A. Hofmann, H. Doose, K. Emeis, and H. Erlenkeuser (2001), Modulation and amplification of climatic changes in the Northern Hemisphere by the Indian summer monsoon during the past 80 k.y., Geology, 29(1), 63-66, doi:10.1130/0091-7613(2001)029<0063 MAAOCC $>2.0 . \mathrm{CO} ; 2$.

Laskar, J., P. Robutel, F. Joutel, M. Gastineau, A. C. M. Correia, and B. Levrard (2004), A long-term numerical solution for the insolation quantities of the Earth, Astron. Astrophys., 428(1), 261-285, doi:10.1051/0004-6361:20041335.

LeGrande, A. N., and G. A. Schmidt (2009), Sources of Holocene variability of oxygen isotopes in paleoclimate archives, Clim. Past, 5(3), 441-455, doi:10.5194/cp-5-441-2009.

Madella, M., and D. Q. Fuller (2006), Palaeoecology and the Harappan civilisation of South Asia: A reconsideration, Ouat. Sci. Rev., 25(11-12), 1283-1301, doi:10.1016/j.quascirev.2005.10.012.

Mohtadi, M., D. W. Oppo, S. Steinke, J.-B. W. Stuut, R. De Pol-Holz, D. Hebbeln, and A. Luckge (2011), Glacial to Holocene swings of the Australian-Indonesian monsoon, Nat. Geosci., 4, 540-544, doi:10.1038 Australian-

ngeo 1209.
Moy, C. M., G. O. Seltzer, D. T. Rodbell, and D. M. Anderson (2002), Variability of El Nino/Southern Oscillation activity at millennial timescales during the Holocene epoch, Nature, 420(6912), 162-165, doi:10.1038/nature 01194

Prasad, S., and Y. Enzel (2006), Holocene paleoclimates of India, Quat. Res., 66(3), 442-453, doi:10.1016/j.yqres.2006.05.008.

Rashid, H., B. P. Flower, R. Z. Poore, and T. M. Quinn (2007), A similar to 25 ka Indian Ocean monsoon variability record from the Andaman Sea, Quat. Sci. Rev., 26(19-21), 2586-2597, doi:10.1016/j.quascirev.2007.07.002.

Rommerskirchen, F., G. Eglinton, L. Dupont, U. Guntner, C. Wenzel, and

J. Rullkotter (2003), A north to south transect of Holocene southeas
Atlantic continental margin sediments: Relationship between aerosol transport and compound-specific $\delta^{13} \mathrm{C}$ land plant biomarker and pollen records, Geochem. Geophys. Geosyst., 4(12), 1101, doi:10.1029/ records, Geoche

Schott, F. A., and J. P. McCreary (2001), The monsoon circulation of the Indian Ocean, Prog. Oceanogr., 51(1), 1-123, doi:10.1016/S0079-6611 (01)00083-0

Sinha, A., M. Berkelhammer, L. Stott, M. Mudelsee, H. Cheng, and J. Biswas (2011a), The leading mode of Indian summer monsoon precipitation variability during the last millennium, Geophys. Res. Lett., 38, L15703, doi:10.1029/2011GL047713.

Sinha, A., L. Stott, M. Berkelhammer, H. Cheng, R. L. Edwards, B. Buckley, M. Aldenderfer, and M. Mudelsee (201 lb), A global context for megadroughts in monsoon Asia during the past millennium, Quat. Sci. Rev., 30(1-2), 47-62, doi:10.1016/j.quascirev.2010.10.005.

Staubwasser, M., and H. Weiss (2006), Holocene climate and cultural evolution in late prehistoric-early historic west Asia-Introduction, Quat. Res., 66(3), 372-387, doi:10.1016/j.yqres.2006.09.001.

Tipple, B. J., and M. Pagani (2010), A 35 Myr North American leaf-wax compound-specific carbon and hydrogen isotope record: Implications for C4 grasslands and hydrologic cycle dynamics, Earth Planet. Sci. Lett., 299, 250-262, doi:10.1016/j.epsl.2010.09.006.

T. S. Collett, U.S. Geological Survey, PO Box 25046, Denver, CO 80225, USA

T. I. Eglinton, Geologisches Institut, NO G 59, Sonneggstrasse 5, ETH, Zürich, 8092 Switzerland.

D. Q. Fuller, Institute of Archaeology, University College London, London WC1H OPY, UK.

L. Giosan and C. Ponton, Geology and Geophysics, Woods Hole Oceanographic Institution, 360 Woods Hole Rd., Woods Hole, MA 02543, USA. (lgiosan@whoi.edu)

J. E. Johnson, Earth Sciences, University of New Hampshire, 56 College Rd., Durham, NH 03824, USA.

P. Kumar, Institute of Engineering and Ocean Technology, Navi Mumbai 410221 , India. 


\section{Supplementary Material}

\section{Methods}

\subsection{Radiocarbon chronology}

Samples for radiocarbon dating from core NGHP-16A were disaggregated using distilled water and then sieved. Mixed planktonic foraminifera from the $>250 \mu \mathrm{m}$ size fraction were picked first, and supplemented by tests from the $>150 \mu \mathrm{m}$ size fraction when necessary. Radiocarbon measurements were performed at the National Ocean Sciences Accelerator Mass Spectrometry Facility (NOSAMS) in Woods Hole, MA, USA. Radiocarbon ages were converted to calendar ages using the CALIB 6.0 program [Stuiver and Reimer, 1993] and the Marine09 calibration curve [Reimer et al., 2009]. Available reservoir estimates for the Bay of Bengal surface waters are not substantially different than the standard marine reservoir correction [Dutta et al., 2001; Southon et al., 2002], which we used to calibrate our data. Ages for samples between calibrated dates were obtained by linear interpolation. Results are shown in Supplementary Table 1 and Supplementary Figure 1.

\subsection{Planktonic foraminifera oxygen isotopes}

Stable isotope analysis of oxygen were performed on planktonic foraminifera Globigerinoides ruber (white) from the first 5.0 meters of core NGHP-16A at an average sampling resolution of 3 samples per century. Sediment samples of $10 \mathrm{~cm}^{3}$ were wetwashed in a $63 \mu \mathrm{m}$ sieve and picked foraminifera were washed and sonicated in distilled water before processing. All samples contained between 8-10 tests from the $>150 \mu \mathrm{m}$ fraction and weighed between 100-150 $\mu \mathrm{g}$. Samples were processed using a VG Prism Mass Spectrometer at NOSAMS. Analytical reproducibility as determined from replicate measurements on carbonate standard NBS-19 is better than $0.1 \%$.

\subsection{Plant Wax Lipid Carbon Isotopes}

Compound-specific carbon isotope analyses of $n$-alkanoic acids were performed on 
samples from the upper 8.0 meters of core NGHP-16A at a sampling resolution of $20 \mathrm{~cm}$ corresponding to an average sampling interval of 220 years (from 440 years near the bottom of the core to $~ 125$ years near the top of the core). Lipid organic matter was extracted from 10-12 grams of the freeze-dried sediment samples using a dichloromethane (DCM):methanol $(\mathrm{MeOH})$ solution(9:1) in a CEM Microwave Accelerated Reaction System (MARS). Concentrated lipid extract was saponified with $0.5 \mathrm{~N} \mathrm{KOH}$ in methanol solution. Liquid/liquid extraction of the neutral fraction was done using pure hexane. Then the $\mathrm{pH}$ was adjusted to 2 by addition of $\mathrm{HCl}$ and liquid/liquid extraction of the acid fraction was performed using hexane:DCM (4:1). Lipids in the acid fraction, including leaf wax $n$-alkanoic acids, were methylated using $\mathrm{HCl} 5 \%$ in $\mathrm{MeOH}$ (70 ${ }^{\circ} \mathrm{C}$ for 12 hours). The resulting fatty acid methylesters (FAMEs) were extracted using hexane:DCM (4:1), then dried with anhydrous sodium sulfate, and then purified via silica gel chromatography. A FAMEs standard $\mathrm{C}_{13}-\mathrm{C}_{24}$ was added to each sample sequence prior to analysis by gas chromatography (GC). All samples were initially analyzed by GC using an HP 5890 Series II GC equipped with flame ionization detector (FID). Isotope ratio monitoring GC-MS (GC/irMS) was used to determine $\delta^{13} \mathrm{C}$ values of FAMEs.

Measurements were performed on a Finnigan Delta ${ }^{\text {Plus }}$ stable isotope mass spectrometer attached to an HP 6890 GC (DB5-MS column) and Finnigan GC combustion III interface. All analyses were performed in triplicate. $\delta^{13} \mathrm{C}$ values were determined relative to a reference gas $\left(\mathrm{CO}_{2}\right)$ of known isotopic composition, introduced in pulses during each run. GC/irMS accuracy and precision are both better than $0.3 \%$. The results were corrected for the $\delta^{13} \mathrm{C}$ composition of the methyl derivative $(\mathrm{MeOH}-39.56 \%$ o $\pm 0.2 \%$, measured at NOSAMS) based on isotopic mass balance in order to derive $\delta^{13} \mathrm{C}$ values for the original $n$-alkanoic acids.

\section{Geographical features of the Indian peninsula}

The Indian peninsula is bordered by the Arabian Sea to the west, the Bay of Bengal to the east, the Indian Ocean to the south and the Tibetan plateau on the north (Supplementary Fig. 2). Important geographic features include: the Thar dessert to the northeast, the Indo- 
Gangetic Plain to the south of the Himalayas, which lies between the Indus and Ganga (Ganges) rivers, and the Deccan Plateau, a large igneous province consisting of multiple layers of flood basalts; the coastal mountain range of Sahyadri (Western Ghats) along the western coast, and the Eastern Ghats range along the eastern coast of the peninsula [Washington, 1922]. The Godavari Basin covers an area of $312,812 \mathrm{~km}^{2}$, representing about $12 \%$ of the area of continental India (see fig.1b). The river headwaters lie on the northern end of the Western Ghats at an elevation of $920 \mathrm{~m}$. However the mean elevation of the basin is estimated at $420 \mathrm{~m}$ [Bikshamaiah and Subramanian, 1980].

\section{Hydroclimatology of the Indian peninsula and Bay of Bengal}

The Indian peninsula and the Bay of Bengal exhibit pronounced seasonality with marked wet and dry seasons. In June through September precipitation is brought in by the moist southwest winds. The Western Ghats affects the precipitation pattern over peninsular India. Monsoonal rains in western India fall preferentially on the strip of land between the coast and the Ghats. Consequently the region located inland of the Ghats receives less precipitation and is semi-arid to arid because of this particular orography [Gunnell et al., 2007].

The Western Ghats also form the drainage divide for peninsular India: main rivers within the Deccan plateau have their headwaters in the Western Ghats and flow east towards the Bay of Bengal. The Godavari River and its tributaries, drain most of the northern portion of the plateau, The Krishna River and its tributaries, drain the central portion of the plateau, and the southernmost portion of the plateau is drained by the Kaveri (Cauveri) River. There is a large seasonal variability in freshwater flux, with most of the total river runoff coming in during the summer monsoon. As a result, there is a strong freshening of surface waters in the coastal regions of the Bay of Bengal during/after the summer monsoon. The large impact of river discharge produces salinity changes on the order of 6 psu between summer and winter [Antonov et al., 2006]. Modern salinity patterns indicate that the strongest salinity variations in the western Bay of Bengal occur in front of the Godavari mouths (Supplementary Fig. 3). A persistent sediment plume extends $\sim 300 \mathrm{~km}$ 
offshore the Godavari river mouth [Sridhar et al., 2008]. During the Holocene, the Godavari delivered ample sediment quantities to the continental slope, giving rise to an expanded sedimentary sequence [Forsberg et al., 2007].

Supplementary Figure 3 shows the seasonal patterns for precipitation and sea surface salinity in the study region. Precipitation data is an average from 1948-2009 from NOAA Earth System Research Laboratory (ESRL). Precipitation maxima occur during Jul-Sep, and highest rainfall areas are located in the western and northeastern part of the Indian peninsula associated with the orographic effects of the Western Ghats and the Himalayan plateau respectively. Another region of high rainfall occurs in northeastern India and extends westward into the head of the Bay of Bengal, defining the core monsoon zone [Gadgil, 2003]. Salinity fluctuations occur simultaneously, with the appearance of a coastal freshwater plume fed by Indian rivers during the summer monsoon season and in the northwest margin of the Bay of Bengal. Sea surface salinity is from the Levitus database [Antonov et al., 2006] from IRI/Lamont-Doherty Earth Observatory Climate Data Library. Supplementary Figure 3 also includes the drainage area of the Godavari River in context with climatology.

\section{Archaeological evidence for subsistence, settlement and trends in human population in late prehistoric South India.}

Archaeological evidence provides a record of past populations and their subsistence strategies [Hassan, 1981]. Throughout most of the early and middle Holocene populations in peninsular India (Figure 1a in main text) continued the hunter-gatherer traditions of the Late Pleistocene, characterized by a Mesolithic technology that focused on composite tools using a complex of microlithic artefacts [Misra, 2002; Clarkson et al., 2009]. Such societies were predominantly mobile. Ceramics and groundstone tools are generally associated with food-producing societies of the past 5000 years in which population size is expected to have increased and mobility decreased. South India,

specifically the Southern Deccan Plateau, has been identified as a region of early cultivation of indigenous Indian millet began around 5000 years ago, while the Northern 
Deccan provides evidence for early farming based on a mixture of South Indian crops and those introduced from the Indus region, such as wheat and barley [Fuller, 2006; 2008; 2011]. Wheat and barley subsequently spread southwards after 4000 years ago. This early farming was focused initially on the drier savannah corridor and some dry deciduous woodland areas down the middle of the Indian peninsula [Asouti and Fuller, 2008; Fuller, 2011]. The indigenous crops of South India included minor millets as staple cereals, Brachiaria ramosa and Setaria verticillata, both $\mathrm{C}_{4}$ grasses, as well as $\mathrm{C}_{3}$ legumes Macrotyloma uniflorum and Vigna radiata. Thus early farming in the Deccan replaced $\mathrm{C}_{4}$ dominated savannah and adjacent woodland with cultivated flora with a similarly large $\mathrm{C}_{4}$ component. Later periods saw a broadening of the crop repertoire, much of this involved additional $\mathrm{C}_{4}$ crops, such as little millet (Panicum sumatense) and kodo millet (Paspalum scrobiculatum), native to other parts of India, and millets of African origin (Sorghum, Eleusine, Pennisetum). The adoption of rice, which is a C3 plant, took place after $1000 \mathrm{BC}$ and was more restricted towards coastal regions and the far south, especially near population centers [Fuller, 2006; Fuller et al., 2010]. After $1,500 \mathrm{BC}$ and increasingly over the subsequent 1,000-2,000 years, agricultural settlements encroached into the moister tropical forest zones in the Western Ghats [Kingwell-Banham and Fuller, 2011] introducing $\mathrm{C}_{4}$ anthropogenic vegetation into a zone with naturally higher proportions of $\mathrm{C}_{3}$ vegetation. In the Eastern Ghats region, which stores most of the $\mathrm{C}_{3}$ vegetation in the Godavari watershed, smaller scale shifting cultivation was typical until modern times; this type of agriculture replaces forest tracts used temporarily for agriculture with fast growing $\mathrm{C}_{3}$ forests after abandonment, notably sal (Shorea robusta) forests in the east and north with more teak (Tectona grandis) towards the west [Kingwell-Banham and Fuller, 2011]. Massive and permanent deforestation in the Eastern Ghats took place during British colonial times in the $19^{\text {th }}$ century [Hill, 2008], which led to a rapid expansion of the Godavari delta [Rao et al., 2005].

It has previously been suggested that the beginnings of agriculture in the Deccan region are associated with the beginnings of a trend towards increasing aridity, and 
declining monsoons across this region [Fuller and Korisettar, 2004; Fuller, 2008; 2011]. Given the new palaeoclimatic data reported in this paper, we wanted to consider the archaeological evidence as a proxy for human population and reliability of early agricultural practices to assess any correlations between major cultural and climatic changes in this region. There have been few systematic studies of prehistoric settlement patterns in south India, all restricted to small regions [e.g. Paddayya, 1973; Venkatasubbaiah, 1992; Shinde, 1998]. Nevertheless available archaeological data provides a record of past human population in the region, biased towards sedentary agriculturalists who would have lived at higher population densities than hunters or shifting cultivators [cf. Kingwell-Banham and Fuller 2011]. We therefore compiled counts of known archaeological sites from the third millennium BC (5,000 BP) through the first millennium BC (2,000 BP) for the states of Andhra Pradesh, Karnataka, and Maharashtra (Supplementary Table 2). For sites of the earlier period, referred to the Southern Neolithic in Karanataka and Andhra, and the Deccan Chalcolithic in Maharashtra, we followed the quasi-comprehensive map published in Asouti and Fuller [2008] (Supplementary Table 3). For the subsequent Iron Age, also known as the 'Megalithic Period' we used the site counts in Moorti [1994] (Supplementary Table 4), which provided a comprehensive compilation at the time of its publication. These data have a number of drawbacks. First, because of the vagaries of archaeological phasing based on material culture, chronological divisions are often potentially finer in periods that have been more heavily sampled, including the upper strata of deeply stratified sites, and archaeological phases are not all of equal length. Second, site numbers cannot be directly computed as population since site sizes may vary and the density of human populations of sites may vary systematically, nevertheless very few sites will represent less population than many sites, especially when difference are in orders of magnitude. Thirdly, the type of sites varies between the earlier Neolithic/Chalcolithic and the later Iron Age periods: in the Iron Age many sites consist of cemeteries, which have been easier to find because of monumental stone superstructures on tombs, whereas in the earlier period all sites represent occupation sites and burials when they do occur are 
found within those sites. Our tallies for the Iron Age therefore include both cemeteries (which are likely to have connected to nearby settlements even when these have not been found) and habitation sites, and this may lead to an over estimation (Iron Age versus earlier). Iron Age cemeteries have perhaps been easier to find too, so fieldwork may be biased towards finding these. For these reasons Iron Age numbers may be overestimated relative to earlier site numbers but the differences are so great as to suggest that some change is represented despite this.

An additional approach to estimating relative population sizes across regions is to use summed probability distributions of calibrated radiocarbon dates, which we have attempted here for the earlier Neolithic/Chalcolithic period for the southern and northern Deccan plateau. This approach has been used for example to look at population growth in Britain with the beginnings of agriculture [Collard et al., 2010a] and hunter-gatherers population dynamics in north American and northern Europe [e.g. Shennan and Edinborough, 2007; Collard et al., 2010b). This approach assumes that radiocarbon dates represent a more or less random sample of available archaeological evidence and therefore periods with higher population are more likely to have been dated more times. It also assumed than any regional biases, such as those due to research focuses on particular periods, will be insignificant by comparison to large chronological trends in the data. For south India the total number of radiocarbon dates is quite limited (Supplementary Table 3) by comparison to the thousands of dates in European databases for example. For example a recent study of the Neolithic of South India reports just 116 dates from 23 sites [Fuller et al., 2007]. This dataset was used to produce a summed distribution of all radiocarbon dates associated with the Southern Neolithic. In the North Deccan most dates have been associated with particular long excavation projects, mostly conducted in the 1970s and 1980s, and so the total number of dated sites with readily available data is limited to 83 dates and 11 sites [data from: Possehl and Rissman, 1992; Shinde, 1998]. Radiocarbon dates from the Iron Age are, by contrast, much more limited and dating has often been inferred from grave artefacts. Therefore we have not attempted to include radiocarbon data from this later period. While such data are an imperfect 
dataset, they still demonstrate that there is an apparent growth in population, which was based on agricultural villages, over the course of the Second Millennium BC, i.e., after 4,000 BP (Supplementary Table 4). Radiocarbon dates were summed with the OxCal 3.10 software [Bronk Ramsey, 2001; 2005]. The sums for the North Deccan and South Deccan have been run separately and each is scaled independently as the relative contribution of radiocarbon date contribution to the dataset at any given point in time. For ease of viewing, these two datasets have been plotted along the same time scale with one shown inverted below the timeline in Supplementary Figure 4.

The patterns in these data point to directional increases in archaeological population after 4,000 BP up to ca. 3,300 BP for South India and 3,200 BP for the North Deccan. While the declines after this time are to a large degree a product of the end of respective archaeological phases, it also does appear to represent a period of major social transformation. A great many sites of the Jorwe cultural phase in the North Deccan [Shinde, 1998] and at this stage many of the hilltop settlement sites of the Southern Neolithic cease to be occupied at this period [Fuller et al., 2007]. While the earliest dates for the Iron Age come from around this period, most of the Iron Age in the North Deccan indicates an eastward shift in settlement distribution to the somewhat wetter subzones of eastern Maharashtra. By contrast in South India there is continuity in the regions that were previously occupied and more regions came to be occupied after Neolithic. Nevertheless, as in the Neolithic period, Iron Age settlement seems to predominantly focus on savannah and dry-deciduous zone when judged by modern rainfall patterns (Supplementary Table 4). Nevertheless there are local shifts. For example, many more settlements are found on the plains in contrast to predominantly hilltop locations in the Neolithic. These changes with the transition to the Iron Age are increasingly seen as driven by social changes, as opposed to earlier ideas about new immigrants [Moorti, 1994; Fuller et al., 2007]. Nevertheless, there is clearly overall increase in agriculture and population in the Deccan as a whole after the 2,000 BP onset of highly arid conditions, which can be contrasted with some other parts of the South Asian subcontinent such as in the Indus valley [Madella and Fuller, 2006]. 


\section{Data Analysis}

\section{$5.1 \delta^{18} \mathrm{O}$ G. ruber}

G. ruber is abundant in the surface mixed layer $(\sim 100 \mathrm{~m})$ but its shell growth has been found to be restricted to the top $35 \mathrm{~m}$ of water [Fairbanks et al., 1982]. In sediment trap studies from the Arabian Sea and the Bay of Bengal, G. ruber has been found to be a year-round species with summer peak abundances [Curry et al., 1992; Unger et al., 2003]. The habitat of this species is ideal to record salinity and SST where and when fluctuations are highest. Our $\delta^{18} \mathrm{O}$ G. ruber record after 3000 years BP exhibits brief excursions of ca. 0.6 to over $1 \%$ heavier than the background values (between -2.9 and $2.5 \%$ ). According to the calcification equation for G. ruber [Mulitza et al., 2003], the temperature increase of $2.5^{\circ} \mathrm{C}$, the maximum Holocene variability in the Arabian Sea (Govil and Naidu, 2010) and Bay of Bengal (Govil and Naidu, 2011), can explain $0.56 \%$ of the amplitude of these positive excursions in $\delta^{18} \mathrm{O}$ ruber. We have also corrected the raw $\delta^{18} \mathrm{O}$ ruber data for ice volume effects using a glacio-eustatic sea level record for the Holocene [Fairbanks, 1989] and a sea level $-\delta^{18} \mathrm{O}$ water relationship of $0.0083 \% \mathrm{~m}$ [Adkins and Schrag, 2003].

\section{$5.2 \delta^{13} \mathrm{C}$ in $n$-alkanoic acids}

$\delta^{13} \mathrm{C}$ was measured on $n$-alkanoic acids $\left(\mathrm{C}_{26}-\mathrm{C}_{32}\right)$ from 42 sediment samples. All measurements were done in triplicate. Results are plotted on Supplementary Figure 5. The solid line represents the weighted average of $\delta^{13} \mathrm{C}$ measurements for $n$-alkanoic acids $\left(\mathrm{C}_{26}-\mathrm{C}_{32}\right)$. This weighted average was calculated by taking into account the concentration of each homologue and its $\delta^{13} \mathrm{C}$ value:

Wt. Average $=\left(\mathrm{C}_{1} \mathrm{X}_{1}+\mathrm{C}_{2} \mathrm{X}_{2}+\ldots \ldots+\mathrm{C}_{\mathrm{n}} \mathrm{X}_{\mathrm{n}}\right) /\left(\mathrm{C}_{1}+\mathrm{C}_{2}+\ldots .+\mathrm{C}_{\mathrm{n}}\right)$

where $\mathrm{X}$ is the measured $\delta^{13} \mathrm{C}$ average value for a particular $n$-alkanoic acid and $\mathrm{C}$ its concentration in the sample. 
A previous study [Chikaraishi et al., 2004] measured the $\delta^{13} \mathrm{C}$ of the different $n$-alkanoic acids directly extracted from $\mathrm{C}_{3}$ and $\mathrm{C}_{4}$ modern plants. From their reported values we extracted 52 measurements for $n$-alkanoic acids of $\mathrm{C}_{3}$ plants between $\mathrm{C}_{26}$ and $\mathrm{C}_{32}$ averaging $-37.7 \pm 1.8 \%$ and 16 measurements of the same compounds in $\mathrm{C}_{4}$ plants with an average of $-21.1 \pm 1.4 \%$. Using these values as end members [-37.7 $=0 \% \mathrm{C}_{4}$ plants; $21.1=100 \% \mathrm{C}_{4}$ ], we expressed our $\delta^{13} \mathrm{C}$ plant wax values as a percentage of $\mathrm{C}_{4}$ plants in the Godavari river catchment (Fig 2(e), secondary axis in black). We excluded from our analysis 2 samples measured in the core interval between 2.78 and $2.93 \mathrm{~cm}$ depth in core NGHP-16A due to anomalously high woody and charred organic matter visible under microscope as it may represent a direct and/or a redeposition event similar to events that are encountered deeper within core as organic-rich turbidites.

The measured $\delta^{13} \mathrm{C}$ value of a sample can be expressed as a mixture of pure $\mathrm{C}_{3}$ and $\mathrm{C}_{4}$ plants. Where $(f)$ is the fraction of $\mathrm{C}_{4}$ plants, $(1-f)$ the fraction of $\mathrm{C}_{3}$ plants in the mixture, and $\mathrm{f}$ is a number between 0 and 1 :

$$
\delta^{13} C_{\text {sample }}=f \cdot \delta^{13} C_{4}+(1-f) \cdot \delta^{13} C_{3}
$$

For simplicity in nomenclature, equation (1) can be written as:

$$
\delta=f \cdot \delta C_{4}+(1-f) \cdot \delta C_{3}
$$

Where $\delta$ is the $\delta^{13} \mathrm{C}$ value of the sample, $f$ the fraction of $\mathrm{C}_{4}$ plants, $\delta \mathrm{C}_{4}$ the $\delta^{13} \mathrm{C}$ value of a pure $\mathrm{C}_{4}$ plant, and $\delta \mathrm{C}_{3}$ the $\delta^{13} \mathrm{C}$ value of a pure $\mathrm{C}_{3}$ plant.

If we rearrange equation (1.1) to clear for $f$, then the fraction of $\mathrm{C}_{4}$ plants represented by a single $\delta^{13} \mathrm{C}$ value of a sample could be expressed as:

(1.2) $f=\frac{\delta-\delta C_{3}}{\delta C_{4}-\delta C_{3}}$

Using equation (1.2) and the previously calculated end member $\delta^{13} \mathrm{C}$ values for $\mathrm{C}_{3}$ and $\mathrm{C}_{4}$ plants we estimated the percent of $\mathrm{C}_{4}$ vegetation coverage in the central Indian peninsula 
during the Holocene, given that the recovered sediment samples represent an integrated signal of vegetation cover in the Godavari River catchment.

To quantify uncertainties associated with this estimate of $\mathrm{C}_{3} / \mathrm{C}_{4}$ ratios based on a simple end-member mixing model we propagate the errors introduced by instrumental uncertainties in the measurement of our samples, and the variability of measured $\delta^{13} \mathrm{C}$ values for different species of $\mathrm{C}_{3}$ and $\mathrm{C}_{4}$ plants used to calculate the end-member values. Based on the error propagation equation of Bevington and Robinson [1992] the variance (square of the standard deviation, $\sigma$ ) in the estimated fraction of $\mathrm{C}_{4}$ plants $(f)$ can be expressed as:

$$
\sigma_{f}{ }^{2}=\left(\frac{\partial f}{\partial \delta} \sigma_{\delta}\right)^{2}+\left(\frac{\partial f}{\partial \delta C_{3}} \sigma_{\delta C_{3}}\right)^{2}+\left(\frac{\partial f}{\partial \delta C_{4}} \sigma_{\delta C_{4}}\right)^{2}
$$

After solving the three partial derivatives of $f$ with respect to the $\delta^{13} \mathrm{C}$ values of the sample, and the $\mathrm{C}_{3}$ and $\mathrm{C}_{4}$ end-members, equation (2) can be expressed as:

$$
\sigma_{f}^{2}=\frac{f^{2}}{\left(\delta-\delta C_{3}\right)^{2}} \cdot \sigma_{\delta}{ }^{2}+\frac{f^{2} \cdot(f-1)^{2}}{\left(\delta-\delta C_{3}\right)^{2}} \cdot{\sigma_{\delta C_{3}}}^{2}+\frac{f^{2}}{\left(\delta C_{4}-\delta C_{3}\right)^{2}} \cdot \sigma_{\delta C_{4}}{ }^{2}
$$

And further simplified into:

$$
\left(\frac{\sigma_{f}}{f}\right)^{2}=\frac{\sigma_{\delta}{ }^{2}}{\left(\delta-\delta C_{3}\right)^{2}}+(f-1)^{2} \cdot \frac{\sigma_{\delta C_{3}}{ }^{2}}{\left(\delta-\delta C_{3}\right)^{2}}+\frac{\sigma_{\delta C_{4}}{ }^{2}}{\left(\delta C_{4}-\delta C_{3}\right)^{2}}
$$

Solving for the standard deviation in the calculated fraction of $\mathrm{C}_{4}$ plants $\left(\sigma_{f}\right)$ provides a way to quantify the propagated error in the application of the mixing model to estimate changes in vegetation cover: 


$$
\sigma_{f}=\sqrt{\left[\frac{\sigma_{\delta}{ }^{2}}{\left(\delta-\delta C_{3}\right)^{2}}+(f-1)^{2} \cdot \frac{\sigma_{\delta C_{3}}{ }^{2}}{\left(\delta-\delta C_{3}\right)^{2}}+\frac{\sigma_{\delta C_{4}}{ }^{2}}{\left(\delta C_{4}-\delta C_{3}\right)^{2}}\right]} \cdot f
$$

After solving equation (2.3) for all measured samples in this study, the maximum error in the calculation of the fraction of $\mathrm{C}_{4}$ plant cover $(f)$ is estimated to be 0.066 and the minimum 0.062 with an average of 0.063 . The propagated error estimate for $f$ (fraction of $\mathrm{C}_{4}$ plants) would correspond to one standard deviation $(\sigma)$, assuming no correlation between the errors in the different pools of $\delta^{13} \mathrm{C}$ measurements (sedimentary plant waxes, $\mathrm{C}_{3}$ plants, $\mathrm{C}_{4}$ plants). The calculated propagated error implies an uncertainty of $\pm 6.3 \%$ in the estimation of percent $\mathrm{C}_{4}$ plant cover. For comparison, the magnitude of the estimated changes in vegetation cover from mid Holocene to late Holocene is $\sim 30 \%$.

The main contributor to error in this mixing model is the variability in the end-members $\delta^{13} \mathrm{C}$ values. However, changes in plant biosynthesis in a stressed ecosystem are still poorly constrained. As more studies on plant biosynthesis become available and the survey for compound specific isotopic measurements of plant species diversifies, we will be able to better constrain the end-member values and decrease the uncertainty of the mixing model. 
Supplementary Table 1. Radiocarbon ages for mixed planktonic foraminifera and corresponding calendar age. Calendar ages were derived using the CALIB 6.0 radiocarbon calibration program (http://radiocarbon.pa.qub.ac.uk/calib) using the calibration data set Marine09. The standard marine reservoir correction was applied.

\begin{tabular}{lllllll}
\hline NOSAMS \# & Depth $(\mathbf{c m})$ & Raw $^{\mathbf{1 4}} \mathbf{C}$ Age & & Error & Calibrated Age (yrBP) & 1 $\sigma$ error \\
\hline 63284 & $0-2$ & 155 & \pm 55 & 0 & \pm & 0 \\
85606 & $62-64$ & 815 & \pm 30 & 460 & \pm 27 \\
79575 & $140-142$ & 1,520 & \pm 30 & 1,082 & \pm 50 \\
63285 & $280-282$ & 2,160 & \pm 40 & 1,704 & \pm 4 \\
65825 & $400-402$ & 3,120 & \pm 35 & 2,895 & \pm 54 \\
84036 & $460-462$ & 3,820 & \pm 30 & 3,769 & \pm 52 \\
80683 & $520-522$ & 4,580 & \pm 35 & 4,809 & \pm 39 \\
63286 & $600-602$ & 5,610 & \pm 50 & 5,996 & \pm 68 \\
63287 & $700-702$ & 7,890 & \pm 50 & 8,356 & \pm 46 \\
63287 & $800-802$ & 10,350 & \pm 75 & 11,319 & \pm 99 \\
63289 & $850-852$ & 33,000 & \pm 240 & 25,420 & \pm 257 \\
\hline
\end{tabular}


Supplementary Table 2. Tally of archaeological sites by period and region. For the period 3,200-2,200 BP, site counts are taken from Moorti [1994].

\begin{tabular}{|l|l|l|l|l|}
\hline $\begin{array}{l}\text { Period } \\
(\mathrm{BP})\end{array}$ & $\begin{array}{l}5000- \\
4500\end{array}$ & $\begin{array}{l}4500- \\
4000\end{array}$ & $\begin{array}{l}4000- \\
3400\end{array}$ & $\begin{array}{l}3200- \\
2200\end{array}$ \\
\hline S.Deccan & 3 & 8 & 180 & 91 \\
\hline N.Deccan & 0 & 15 & 75 & 965 \\
\hline total & 3 & 23 & 255 & 1056 \\
\hline
\end{tabular}


Supplementary Table 3. A tally of sites and radiocarbon dates for Neolithic/Chalcolithic Indian peninsula (Deccan Plateau). To fill out the cultural periods of the Northern Deccan some sites from Madhya Pradesh have been included. Citations provided here include secondary compilations of earlier data.

\begin{tabular}{|c|c|c|c|}
\hline State & Site & Number of dates & Source \\
\hline Maharashtra & Apegaon & 3 & Shinde 1994 \\
\hline Maharashtra & Chandoli & 2 & Shinde 1994 \\
\hline Maharashtra & Daimabad & 18 & Shinde 1994 \\
\hline Maharashtra & Inamgaon & 37 & Shinde 1994 \\
\hline Maharashtra & Kaothe & 1 & Shinde 1994 \\
\hline Maharashtra & Songaon & 5 & Shinde 1994 \\
\hline Madhya Pradesh & Dangwada & 6 & Sharma and Misra 2003 \\
\hline Madhya Pradesh & Eran & 11 & Sharma and Misra 2003 \\
\hline Madhya Pradesh & Kayatha & 22 & Sharma and Misra 2003 \\
\hline Madhya Pradesh & Navdatoli & 8 & Sharma and Misra 2003 \\
\hline Karnataka & Budihal & 15 & Fuller et al 2007 \\
\hline Karnataka & $\begin{array}{l}\text { Sannarachamma } \\
\text { (Sanganakallu) }\end{array}$ & 13 & Fuller et al 2007 \\
\hline Karnataka & Hiregudda & 13 & Fuller et al 2007 \\
\hline Karnataka & Hallur & 11 & Fuller et al 2007 \\
\hline Karnataka & Tekkalakota & 8 & Fuller et al 2007 \\
\hline Karnataka & Piklihal & 8 & Fuller et al 2007 \\
\hline Karnataka & Watgal & 7 & Fuller et al 2007 \\
\hline Andhra Pradesh & Veerapuram & 5 & Fuller et al 2007 \\
\hline Andhra Pradesh & Ramapuram & 5 & Fuller et al 2007 \\
\hline Karnataka & Birappa & 5 & Fuller et al 2007 \\
\hline Andhra Pradesh & Hanumantaraopeta & 4 & Fuller et al 2007 \\
\hline Andhra Pradesh & Utnur & 3 & Fuller et al 2007 \\
\hline Andhra Pradesh & Sanyasula Gavi & 3 & Fuller et al 2007 \\
\hline Karnataka & Terdal & 2 & Fuller et al 2007 \\
\hline Karnataka & Banahalli & 2 & Fuller et al 2007 \\
\hline Karnataka & Narsipur & 2 & Fuller et al 2007 \\
\hline Andhra Pradesh & Palavoy & 2 & Fuller et al 2007 \\
\hline Andhra Pradesh & Velpumudugu & 2 & Fuller et al 2007 \\
\hline Karnataka & Kurugodu & 1 & Fuller et al 2007 \\
\hline Karnataka & Kodekal & 1 & Fuller et al 2007 \\
\hline Andhra Pradesh & Biljapalle & 1 & Fuller et al 2007 \\
\hline Andhra Pradesh & Hattibelagallu, & 1 & Fuller et al 2007 \\
\hline
\end{tabular}


Supplementary Table 4. A tally of Iron Age ("megalithic") sites in South India in relation to rainfall zone [Moorti, 1994]. Note that this tally includes sites from Kerala and Tamil Nadu, and therefore has greater total number than Table D1, which considers a more restricted region.

\begin{tabular}{|l|l|l|l|l|}
\hline $\begin{array}{l}\text { Rainfall zone } \\
\text { (modern) }\end{array}$ & $\begin{array}{l}\text { Habitation } \\
\text { site }\end{array}$ & $\begin{array}{l}\text { Habitation } \\
\& \text { burial site }\end{array}$ & Burial site & Total \\
\hline$<600 \mathrm{~mm}$ & 19 & 96 & 201 & 316 \\
\hline $600-1000 \mathrm{~mm}$ & 61 & 103 & 559 & 723 \\
\hline $1000-1500 \mathrm{~mm}$ & 19 & 57 & 343 & 419 \\
\hline $1500-3000 \mathrm{~mm}$ & & 2 & 188 & 190 \\
\hline$>3000 \mathrm{~mm}$ & & 1 & 94 & 95 \\
\hline
\end{tabular}




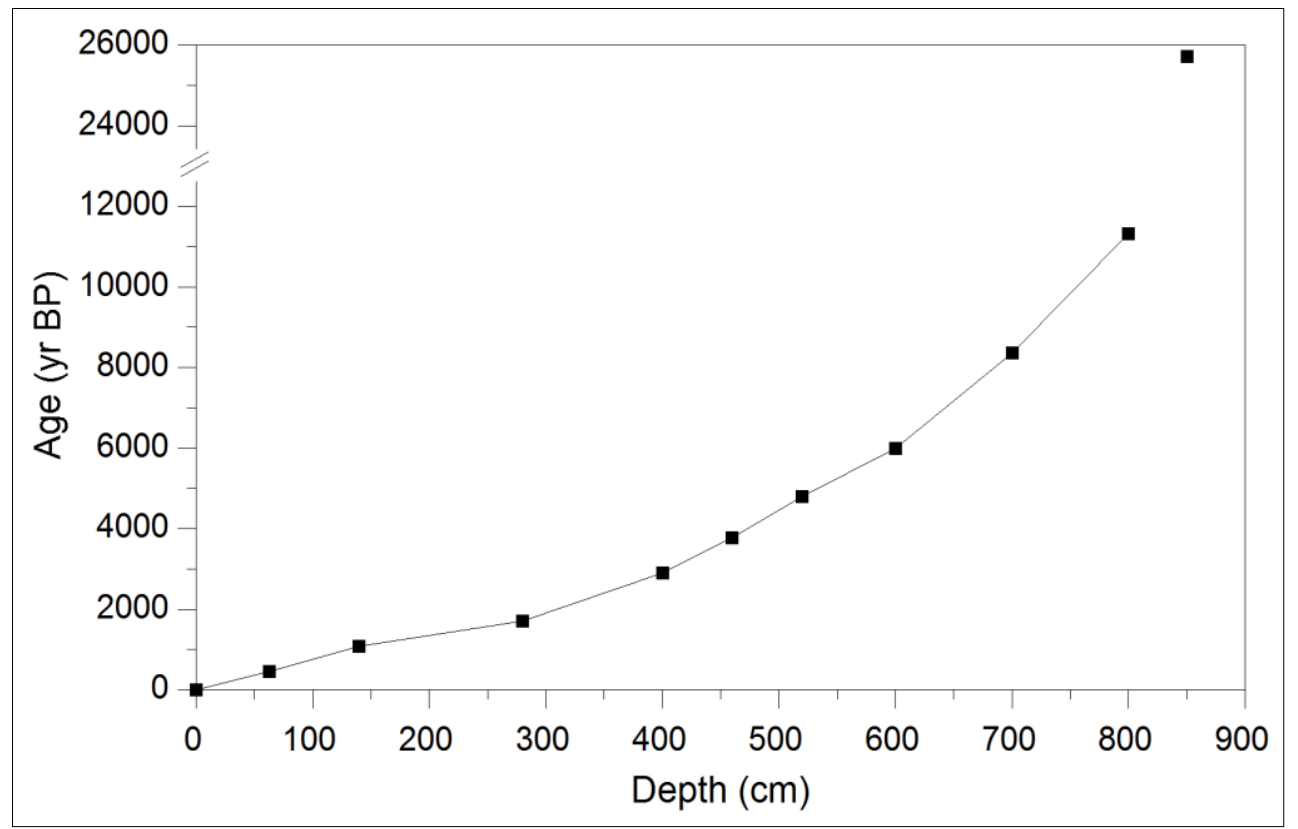

Supplementary Figure 1. Age-depth relationship for core NGHP-16A. Error bars (Supplementary Table 1) are smaller than symbols denoting data points (black squares). 


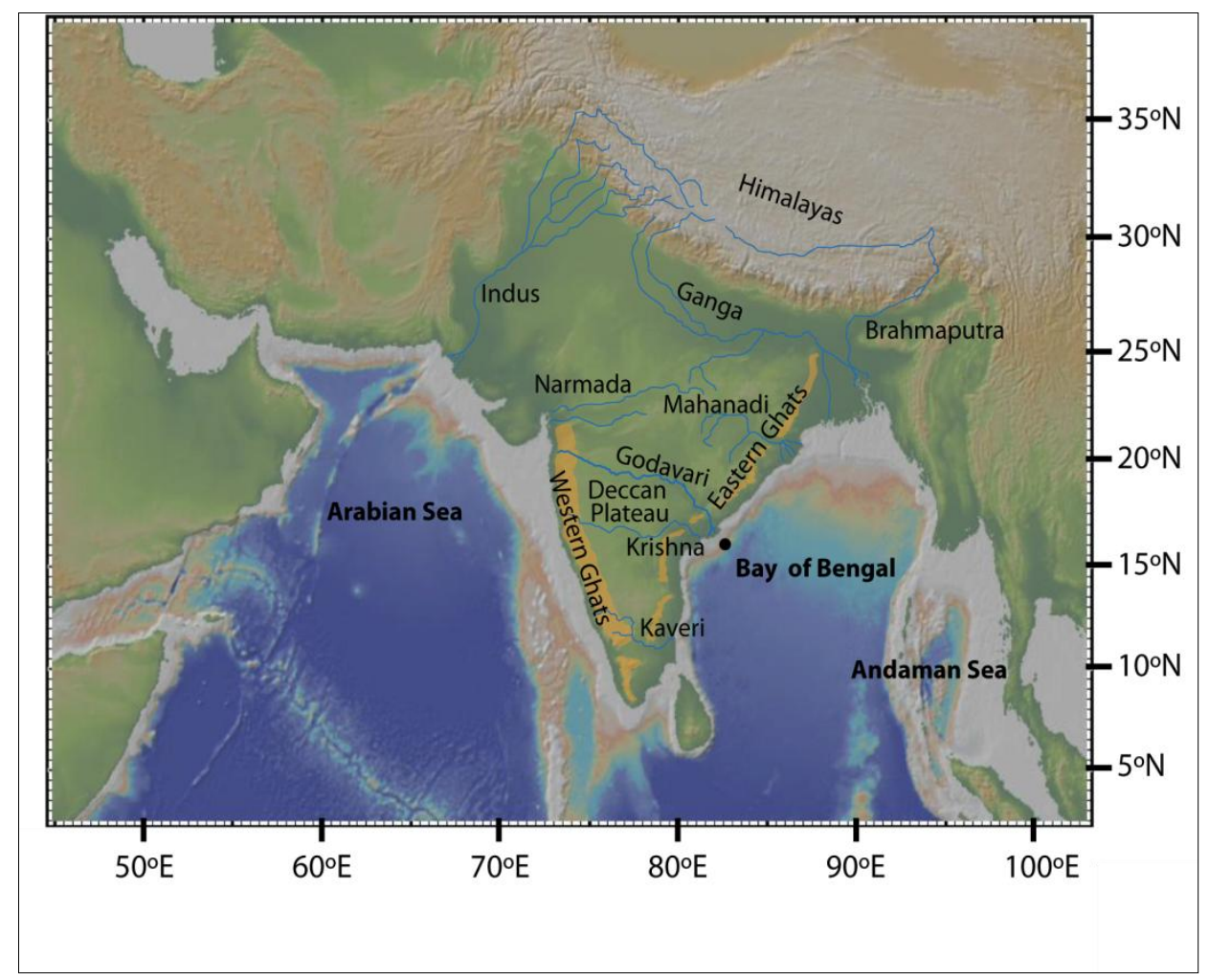

Supplementary Figure 2. Geography of the Indian Peninsula. Schematic outline of the Western and Eastern Ghats are shown in orange. NGHP-16A core location indicated by black dot. Bathymetry of Indian Ocean and Asian topography is from GMRT database [Ryan et al., 2009]. 


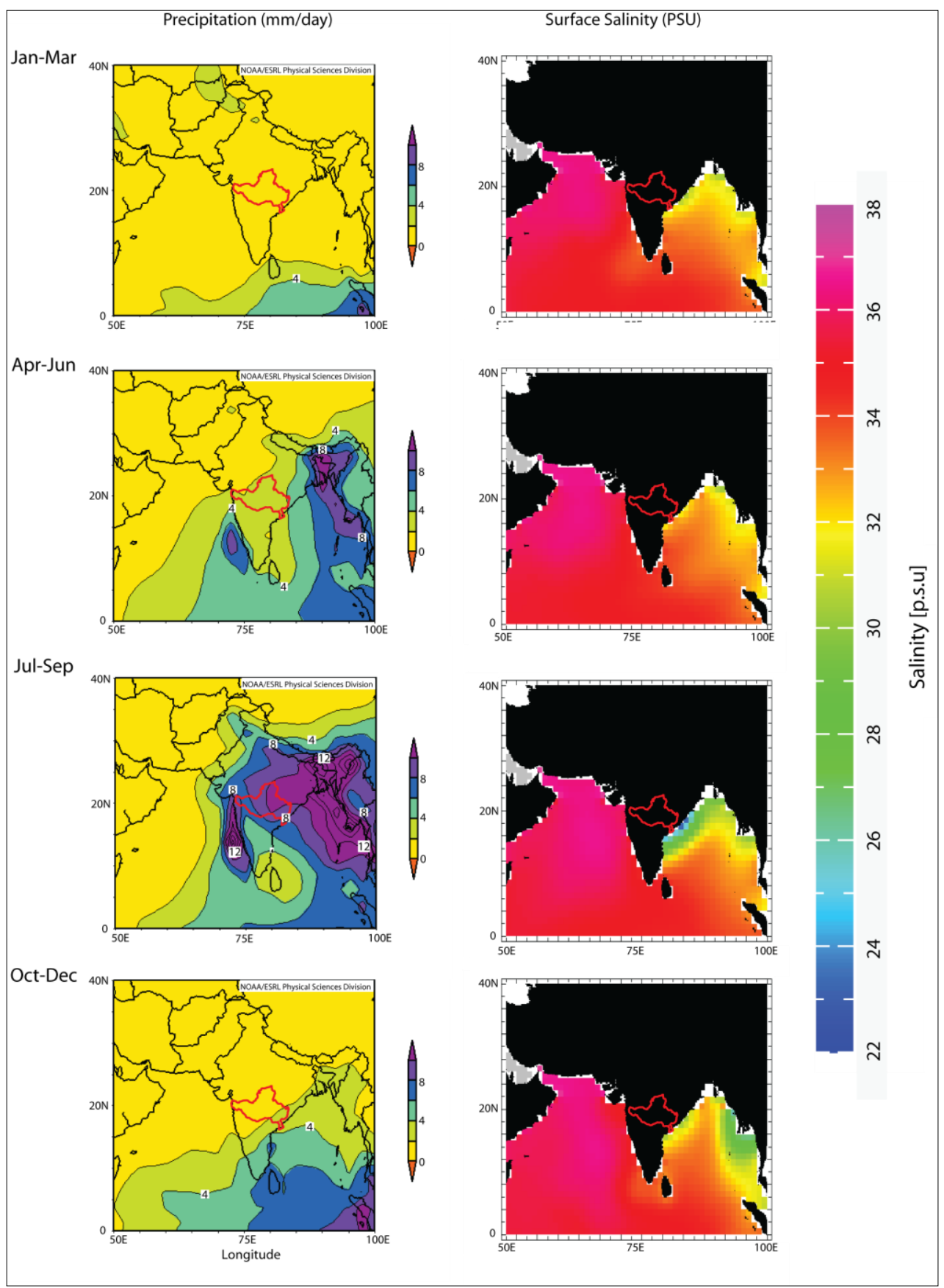

Supplementary Figure 3. Hydro-climatology of the Indian peninsula and Bay of Bengal. Panels on the left are precipitation average 1948-2009 from NOAA/ESRL GPCP http://www.esrl.noaa. gov/psd/data/gridded/data.gpcp.html. Panels on the right are sea surface salinity [Antonov et al., 2006]. Godavari River catchment outline in red. 


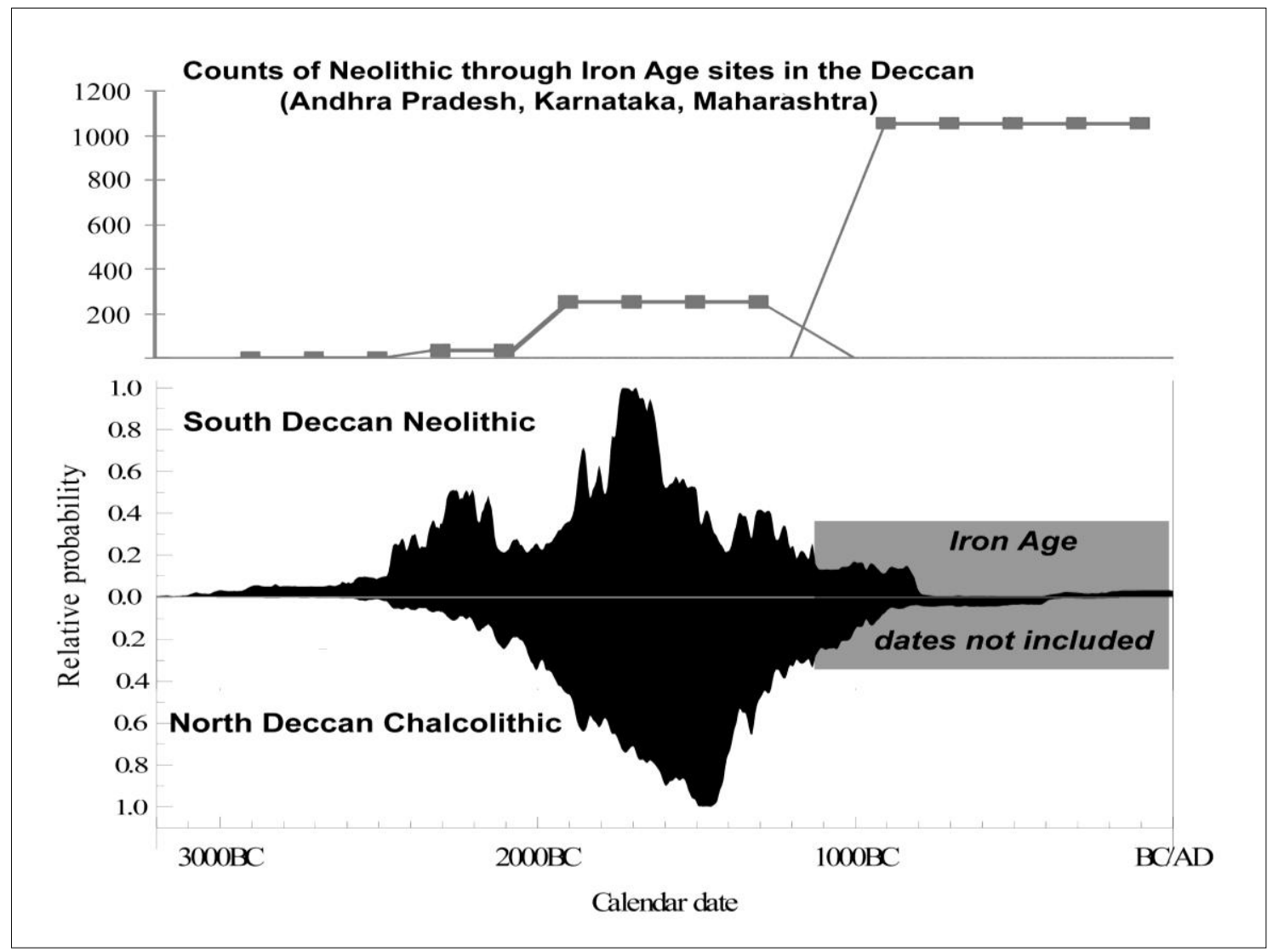

Supplementary Figure 4. Proxies for population dynamics in peninsular India between 5,000 and 2,000 years ago. The top chart is a count of known archaeological sites that plausibly relate to the farming societies. The lower chart represents the summed probability of the calibrated radiocarbon ages for the Neolithic/Chalcolithic, with the North and South Deccan as separate plots on the same time scale. 


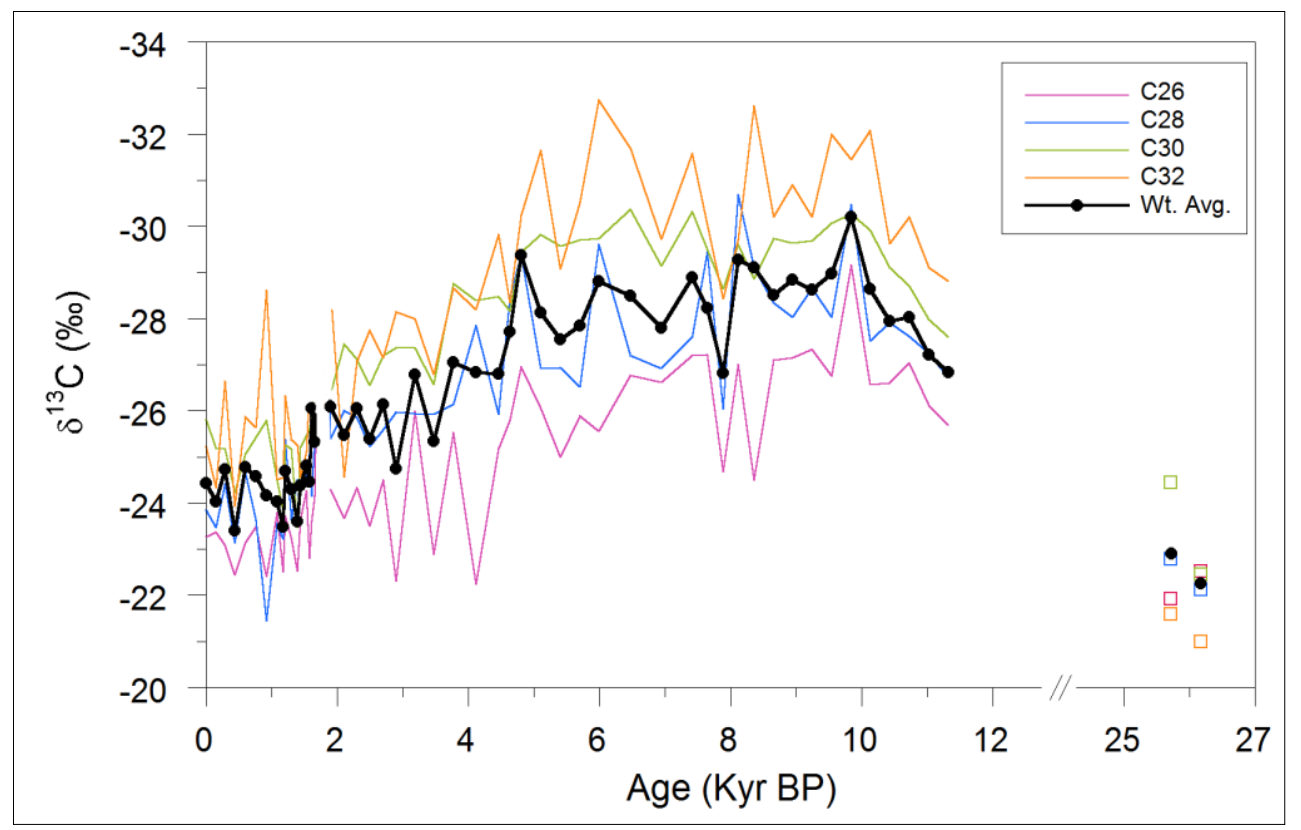

Supplementary Figure 5. $\delta^{13} \mathrm{C}$ values of $n$-alkanoic acids from core NGHP-16A. The black curve is the weighted average, and solid black circles representing data points. Colored curves are the different homologues $\left(\mathrm{C}_{26}-\mathrm{C}_{32}\right)$. Open squares represent homologues of the last glacial period samples according to the same color conventions. Changes in $\delta^{13} \mathrm{C}$ represent integrated rainfall variations in the Godavari basin expressed as changes in the relative proportions of $\mathrm{C}_{3} \mathrm{vs}_{\mathrm{C}} \mathrm{C}_{4}$ plant cover. 


\section{References}

Adkins, J. F., and D. P. Schrag (2003), Reconstructing Last Glacial Maximum bottom water salinities from deep-sea sediment pore fluid profiles, Earth and Planetary Science Letters, 216(1-2), 109-123.

Antonov, J.I., R.A. Locarnini, T.P. Boyer, A.V. Mishonov, and H.E. Garcia (2006), Sea Surface Salinity, in World Ocean Atlas 2005, Vol. 2: Salinity, edited by S. Levitus, Ed., NOAA, Washington, D.C.

Asouti, E. and D.Q. Fuller, (2008) Trees and Woodlands in South India. Archaeological Perspectives, Left Coast Press, Walnut Creek, Calif.

Bevington, P.R. and D.K. Robinson, (1992) Data Reduction and Error Analysis for the Physical Sciences, $2^{\text {nd }}$ edition, WCB/McGraw-Hill, USA.

Bikshamaiah, G., and V. Subramanian (1980), Chemical and sediment mass-transfer in the Godavari River Basin in India, Journal of Hydrology, 46(3-4), 331-342.

Bronk Ramsey, C. ( 2001), Development of the radiocarbon calibration program OxCal, Radiocarbon, 43(2A), 355-63.

Bronk Ramsey, C. (2005), OxCal version 3.10. Computer Program. Available at: http://c14.arch.oxoac.uk/.

Chikaraishi, Y., H. Naraoka, and S. R. Poulson (2004), Hydrogen and carbon isotopic fractionations of lipid biosynthesis among terrestrial (C3, C4 and CAM) and aquatic plants, Phytochemistry, 65(10), 1369-1381.

Clarkson, C., et al. (2009), The oldest and longest enduring microlithic sequence in India: 35000 years of modern human occupation and change at the Jwalapuram Locality 9 rockshelter, Antiquity, 83(320), 326-348.

Collard, M., B. Buchanan, M. J. Hamilton, and M. J. O'Brien (2010a), Spatiotemporal dynamics of the Clovis-Folsom transition, Journal of Archaeological Science, 37(10), 2513-2519.

Collard, M., K. Edinborough, S. Shennan, and M. G. Thomas (2010b), Radiocarbon evidence indicates that migrants introduced farming to Britain, Journal of Archaeological Science, 37(4), 866-870.

Curry, W. B., D. R. Ostermann, M. V. S. Guptha, and V. Ittekkot (1992), Foraminiferal production and mosoonal upwelling in the Arabian Sea: evidence from sediment trap, in Upwelling Systems: Evolution since the Early Miocene, edited by E. A. Se, pp. 93-106, Geological Society Special Publication. 
Dutta, K., R. Bhushan and B.L. Somayajulu (2001), Delta R correction values for the northern Indian Ocean, Radiocarbon, 43, 483-488.

Fairbanks, R. G. (1989), A 17,000-year glacio-eustatic sea-level record - influence of glacial melting rates on the Younger Dryas event and deep-ocean circulation, Nature, 342(6250), 637-642.

Fairbanks, R. G., M. Sverdlove, R. Free, P. H. Wiebe, and A. W. H. Be (1982), Verticaldistribution and isotopic fractionation of living planktonic-foraminifera from the Panama Basin, Nature, 298(5877), 841-844.

Forsberg, C. F., A. Solheim, T.J., Kvalstad, R. Vaidya, and S. Mohanty (2007), Slope instability and mass transport deposits on the Godavari river delta, east Indian margin from a regional geological perspective, Submarine Mass Movements and Their Consequences 27, 19-27.

Fuller, D.Q. (2006), Agricultural Origins and Frontiers in South Asia: A Working Synthesis. Journal of World Prehistory, 20, 1-86.

Fuller, D.Q. (2008). Asia, South: Neolithic Cultures, in Encyclopedia of Archaeology, edited by D. Pearsall, pp.756-768, Elsevier, Amsterdam.

Fuller, D.Q. (2011), Finding Plant Domestication in the Indian Subcontinent. Current Anthropology, 52(S4), S347-S362

Fuller, D.Q. and R. Korisettar, (2004), The Vegetational Context of Early Agriculture in South India, Man and Environment XXIX(1), 7-27.

Fuller, D. Q., N. Boivin, and R. Korisettar (2007), Dating the Neolithic of South India: new radiometric evidence for key economic, social and ritual transformations, Antiquity, 81(313), 755-778.

Gadgil, S. (2003), The Indian monsoon and its variability, Annual Review of Earth and Planetary Sciences, 31, 429-467.

Govil, P., and P. D. Naidu (2010), Evaporation-precipitation changes in the eastern Arabian Sea for the last $68 \mathrm{ka}$ : Implications on monsoon variability, Paleoceanography, 25.

Govil, P., and P. D. Naidu (2011), Variations of Indian monsoon precipitation during the last 32 kyr reflected in the surface hydrography of the Western Bay of Bengal, Quaternary Science Reviews, 30, 3871-3879.

Gunnell, Y., K. Anupama, and B. Sultan (2007), Response of the South Indian runoffharvesting civilization to northeast monsoon rainfall variability during the last 2000 
years: instrumental records and indirect evidence, Holocene, 17(2), 207-215.

Hassan, F.A. (1981), Demographic Archaeology, Academic Press, New York.

Hill, C.V., 2008, South Asia: An Environmental History, ABC-CLIO Press, 329 p.

Kingwell-Banham E. and D.Q. Fuller (2011), Shifting cultivators in South Asia: expansion, marginalisation and specialisaton over the long term. Quaternary International [on-line/in press]: DOI: 10.1016/j.quaint.2011.05.025.

Madella, M., and D. Q. Fuller (2006), Palaeoecology and the Harappan Civilisation of South Asia: a reconsideration, Quaternary Science Reviews, 25(11-12), 1283-1301.

Misra, V.N. (2002), Mesolithic culture in India, in Mesolithic India, edited by V.N. Misra and J.N. Pal, pp. 1-66, Department of Ancient History, Culture and Archaeology, University of Allahbad, Allahbad, India.

Moorti, U.S. (1994), Megalithic Culture of South India. Socio-economic Perspectives, Ganga Kaveri Publishing House, Varanasi.

Mulitza, S., D. Boltovskoy, B. Donner, H. Meggers, A. Paul, and G. Wefer (2003), Temperature: delta O-18 relationships of planktonic foraminifera collected from surface waters, Palaeogeography Palaeoclimatology Palaeoecology, 202(1-2), 143-152.

Paddayya K. (1973), Investigations into the Neolithic Culture of the Shorapur Doab, South India, Brill, Leiden.

Possehl, G.L. and P. Rissman (1992). The chronology of prehistoric India from earliest times to the Iron Age, in Chronologies in old world archaeology, edited by R.W. Ehrich, pp. 1, 465-490; 462, 447-474, University of Chicago Press, Chicago.

Rao, K.N., Sadakata, N., Malini, B.H., Takayasu, K., 2005, Sedimentation processes and asymmetric development of the Godavari delta, India, in River Deltas: Concepts, Models, and Examples, edited by L. Giosan, and J.P. Bhattacharya, pp. 435-452, SEPM Special Publication 83.

Reimer, P. J., et al. (2009), INTCAL09 and MARINE09 radiocarbon age calibration curves, 0-50,000 years cal BP, Radiocarbon, 51(4), 1111-1150.

Ryan, W. B. F., et al. (2009), Global Multi-Resolution Topography synthesis, Geochemistry Geophysics Geosystems, 10.

Sharma R.K. and O.P. Misra (2003), Archaeological Excavations in Central India (Madhya Pradesh and Chhattisgarh), Mittal Publications, New Delhi.

Shennan, S., and K. Edinborough (2007), Prehistoric population history: from the late 
glacial to the late neolithic in central and northern Europe, Journal of Archaeological Science, 34(8), 1339-1345.

Sridhar, P. N., M. M. Ali, P. Vethamony, M. T. Babu, I. V. Ramana, and S. Jayakumar (2008), Seasonal Occurrence of Unique Sediment Plume in the Bay of Bengal, EOS Trans. AGU 89, 22-23.

Shinde, V.S. (1994), The Deccan Chalcolithic: a recent perspective, Man and Environment 19, 1-2.

Shinde, V.S. (1998), Early Settlements in the Central Tapi Basin, Munshiram Manoharlal, New Delhi.

Southon, J., M. Kashgarian, M. Fontugne, B. Metivier, and W. W. S. Yim (2002), Marine reservoir corrections for the Indian Ocean and southeast Asia, Radiocarbon, 44(1), 167180.

Stuiver, M., and P. J. Reimer (1993), Extended C-14 data-base and revised calib 3.0 C-14 age calibration program, Radiocarbon, 35(1), 215-230.

Unger, D., V. Ittekkot, P. Schafer, J. Tiemann, and S. Reschke (2003), Seasonality and interannual variability of particle fluxes to the deep Bay of Bengal: influence of riverine input and oceanographic processes, Deep-Sea Research Part II-Topical Studies in Oceanography, 50(5), 897-923.

Venkattasubbaiah, P.C. (1992), Protohistoric investigation in the Central Pennar Basin, Cuddapah, Andhra Pradesh, PhD Thesis, University of Poona, Pune, India.

Washington, H. S. (1922), Deccan traps and other plateau basalts, Bulletin of the Geological Society of America, 33, 765-803. 


\title{
CHAPTER 3
}

\section{Climate Controls Residence Time of Organic Carbon in a Monsoonal River Basin}

\begin{abstract}
This study compares radiocarbon age relationships between planktonic foraminifera and higher (terrestrial) plant wax fatty acids isolated from the same depth horizons in a sediment core off the mouth of the Godavari River in the Bay of Bengal. The Godavari drainage basin has been experiencing aridification over the Holocene and provides a good opportunity to examine relationships between hydroclimate and the dynamics of terrestrial carbon discharge to the sea. Radiocarbon measurements of long-chain fatty acids compared to planktonic foraminifera show an increase in age offset from mid to late Holocene, suggesting that increased aridity either slowed carbon cycling and/or transport rates, or resulted in mobilization of older (soil) organic carbon, the net result being an apparent increase of terrestrial storage times of vascular plants carbon. Since $\sim 4,000 \mathrm{yrs}$ BP the fatty acids are on average $\sim 1,200$ yrs older than the foraminifera, indicating either increasing residence times of terrestrial carbon or increasing erosion and mobilization of pre-aged vascular plant-derived carbon as a consequence of a less humid climate. At the core top, the age discrepancy between depositional age and plant wax fatty acids is approximately $\sim 5,000 \mathrm{yrs}$, which we attribute to enhanced exhumation of old soil organic matter as a consequence of anthropogenic activity.

The findings of this study show that there are key facets of organic matter transfer from the continents to the oceans that remain poorly understood, and demonstrate a direct link between climate dynamics and carbon cycling within river drainage basins. In addition to their pertinence to carbon cycle studies, these results also have implications for the use of terrestrial proxies preserved in continental margin sediments in paleoclimate reconstructions; in particular the temporal phasing of terrestrial and marine proxy signals in the context of a variable hydroclimate deserves closer scrutiny.
\end{abstract}

\subsection{Introduction}

\subsubsection{Terrestrial organic carbon: from source to sink}

Once a $\mathrm{CO}_{2}$ molecule is captured by a terrestrial plant and incorporated into tissue through photosynthesis it can take several paths before being transported by a river into the ocean and then buried within continental margin sediments. A conceptual model with different transport pathways for terrestrial biospheric carbon and other continental OC sources is presented in Figure 1 (modified from Blair et al., 2004). The model includes a 
series of interconnected reservoirs where terrestrial OC resides and is transformed/degraded before moving to the next compartment and eventually being discharged to, and preserved in, receiving marine sedimentary basins. From Figure 1 it is clear that the resulting sedimentary terrestrial OC is likely to comprise a mixture of material from different carbon pools that can make its way to the ocean sediments with different transit times. While some of the terrestrial OC may have been transported to the continental margin almost instantaneously, other portions of it may have resided in soils or in the flood plains for thousands of years before being eroded and transported. We have an understanding of the different pathways carbon can take from land into the oceans, but we do not have tight constraints on the time elapsed between the production of terrestrial biomass via photosynthetic fixation of a $\mathrm{CO}_{2}$ and its burial in marine sediments or its continental "residence time". Furthermore, terrestrial OC turnover and residence times are expected to vary with other environmental properties such as climate (aridity, temperature), soil type, and topography of the river catchment (e.g. Schimel et al., 2011; Trumbore 1997; Quideau et al., 2001). In addition to this, anthropogenic activities including deforestation, agricultural practices, and river damming (e.g. Wang et al. 1999; Fisher et al. 2003) have shifted the type and discharge rate of terrestrial OC into the oceans (Syvitski et al., 2005).

Environmental signatures encoded in terrestrial OC exported by rivers result from complex processes occurring at various spatial and temporal scales. One of the caveats in using sedimentary records for paleoclimatic reconstructions based on terrestrial organic proxies is the uncertainty in the timescales over which terrestrial organic matter is synthesized, transferred and stored in marine sediments. In fact, several studies have shown a significant storage time for OC on land prior to deposition in continental margins (Drenzek, 2007; Drenzek et al., 2009; Kusch et al., 2010a, Gustafsson et al., 2011; Galy and Eglinton 2011). 
In order to improve our understanding on the burial of OC in marine sediments, as well as to accurately interpret signals of continental climate embedded in terrestrial proxies, it is important to better constrain the residence or storage time of terrestrial OC associated with its transfer from the continental river drainage basins to marine sediments, as well as to identify the key factors that control timescales of terrestrial carbon transfer. These aspects provide motivation for the present study and we explore here the effect of aridification on the dynamics of terrestrial organic carbon transfer from biological source to sedimentary sink.

\subsubsection{Residence times of terrestrial organic carbon}

One approach in addressing climatic effects on the dynamics of terrestrial carbon is to examine radiocarbon age relationships between terrestrial and marine components codeposited in sedimentary sequences proximal to the mouths of river systems, in our case higher plant wax biomarker compounds and marine planktonic foraminifera. While marine planktonic foraminiferal tests are expected to settle quickly through the water column and deposit on the ocean floor not far away from the organism's surface water habitat, carbon derived from the terrestrial biosphere must travel from its source of production within continental drainage basins, and move through multiple reservoirs (soils, floodplains, etc., Fig. 1) before deposition on the ocean floor. Excluding the marine "reservoir effect" (Stuiver and Ostlund, 1983; Stuiver et. al., 1986; Southon et al., 2002), terrestrial organic matter would therefore be anticipated to be of an older radiocarbon age than the planktonic foraminiferal shells deposited on the same sediment horizon. Previous radiocarbon studies by Drenzek (2007) and Drenzek et al. (2009) show that higher plant wax fatty acids deposited in marine shelf sediments proximal to river mouths can predate the depositional age by several thousand years. However, no comparison to foraminifera age was attempted in these prior studies. Coupled biomarkerspecific and planktonic foraminiferal ${ }^{14} \mathrm{C}$ measurements have been made before (e.g., Ohkouchi et al. 2002; Kusch et al. 2010b) but with a focus on marine sediment redistribution processes and not supply of continentally-derived OC. Mollenhauer and 
Eglinton (2007) report alkenone, foraminifera and fatty acid ages in California Borderland core top and pre-bomb sediments and show that long-chain fatty acids are systematically depleted in ${ }^{14} \mathrm{C}$ (older) than the planktonic formanifera. The authors calculate residence times for long-chain fatty acids and report values of 380 - 1,200 yrs. However, for simplification, they assumed terrigenous compounds were delivered to the ocean immediately after production and did not considered intermediate carbon reservoirs.

A recent biomarker ${ }^{14} \mathrm{C}$ study indicates that the residence time of vascular plant $\mathrm{OC}$ supplied to surface sediments near the mouths of rivers flowing into the Black Sea varies from between 900 and 4,400 years (Kusch et al., 2010a), indicating a significant storage time in intermediate carbon reservoirs within continental drainage basins. The radiocarbon ages of vascular plant biomarkers in river sediments along the GangesBrahmaputra river system suggest an overall residence time of the OC in the basin of approximately 50 - 1,300 years (Galy and Eglinton, 2011). There is also evidence of the potential influence of climate change on the age of terrestrial OC discharged from the Arctic rivers. Gustaffson et al. (2011) show that the vascular plant biomarkers extracted from surface sediments from Eurasian Arctic rivers are older on those rivers most heavily affected by warming and destabilization of permafrost soils. While prior studies have examined links between river drainage basin properties and ${ }^{14} \mathrm{C}$ residence times, there have been no reported studies that explore links between past climate variability and residence time.

In this study we compare the radiocarbon age relationships between planktonic foraminifera and higher (terrestrial) plant wax fatty acids isolated from the same depth horizons in a sediment core off the mouth of the Godavari River. The core, which spans the entire Holocene, provides an opportunity to examine the effect of long-term aridification on the residence time of terrestrial organic carbon as it is transferred from source to sedimentary sink. 


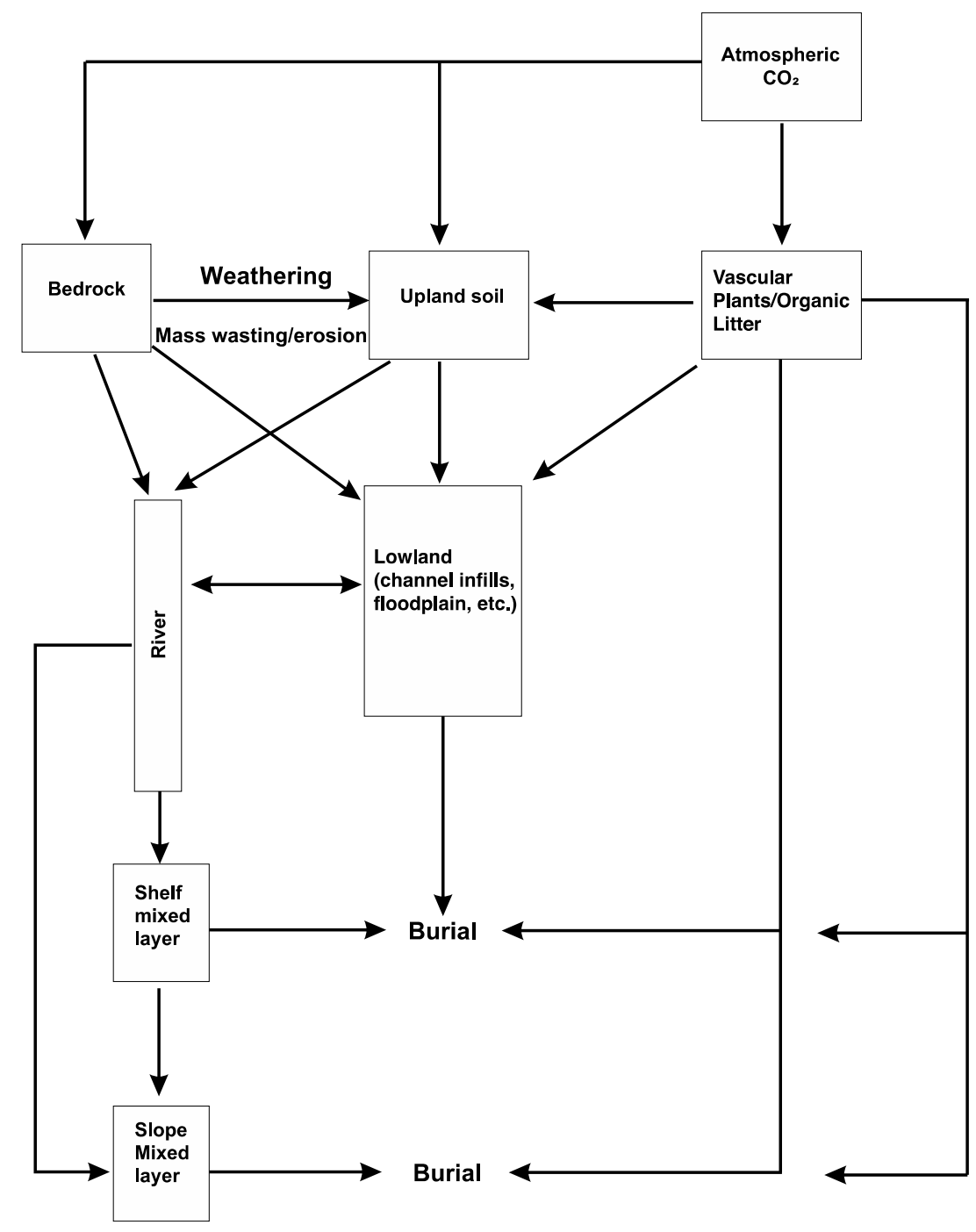

Figure 1. Conceptual model for the transport of riverine terrestrial $\mathrm{C}$ into the oceans: source to sink. While we have an understanding of the different pathways carbon can take from land into the oceans, we do not have tight constraints on the residence times within reservoirs (Modified from Blair et al. 2004).

\subsection{Study Area}

The Godavari, the largest non-Himalayan Indian river, drains central India and discharges into the Bay of Bengal. This region has experienced significant aridification as a consequence of weakening of the Indian monsoon over the Holocene (Ponton et al., 
2012) and therefore provides an excellent candidate to examine relationships between climate and the dynamics of terrestrial carbon discharge from river drainage basins. The Godavari catchment has its headwaters in the Deccan Plateau in west-central India, and most of its floodplain occurs over the old continental craton formations in the east-central Indian peninsula (Figure 2). In the Godavari river catchment, modern-day natural vegetation cover is a mixture of savannah, tropical grassland, and tropical forest (Asouti and Fuller, 2008). The Godavari headwaters on the Deccan plateau are dominated by $\mathrm{C}_{4}$ plant savannah, whereas the floodplains are mostly covered by tropical grasslands (mixture of $\mathrm{C}_{3} / \mathrm{C}_{4}$ vegetation) and $\mathrm{C}_{3}$-flora forests towards the Eastern Ghats (Figure 2). Anthropogenic changes in vegetation cover through cultivation are likely to have been small until the $19^{\text {th }}$ century when massive and permanent deforestation of the Eastern Ghats took place (Hill, 2008). Rice, a $\mathrm{C}_{3}$ plant, was cultivated in coastal regions beginning $~ 3,000$ years ago.

To investigate the transport time of terrestrial biospheric carbon through the Godavari River catchment and into Bay of Bengal sediments, we produced radiocarbon dates for exclusively terrigenous and marine components from sediment core NGHP-01-16A (16 ${ }^{\circ}$ $35.5986^{\prime} \mathrm{N}, 082^{\circ} 41.0070^{\prime} \mathrm{E}$; $1,268 \mathrm{~m}$ water depth) recovered approximately $40 \mathrm{~km}$ from the Godavari River mouth. We sampled hemipelagic sediments accumulating at rates higher than $30 \mathrm{~cm} / \mathrm{Kyr}$ throughout the Holocene (Figure 3). Chronology has been constructed based on $16{ }^{14} \mathrm{C}$ AMS dates of planktonic foraminifera spanning the last $\sim 11,000$ yrs BP. Our previous work analyzed the $\delta^{13} \mathrm{C}$ composition of terrestrial epicuticular plant wax lipids $\left(\mathrm{C}_{26-32} n\right.$-alkanoic acids) and $\delta^{18} \mathrm{O}$ of marine planktonic foraminifer G. ruber $\left(\delta^{18} \mathrm{O}_{\text {ruber }}\right)$ for this interval, and showed that conditions in the Godavari basin became progressively drier from the middle Holocene to late Holocene, with a strong aridification trend taking off after $\sim 5 \mathrm{ka}$ ago. Unprecedented positive excursions of $\delta^{18} \mathrm{O}_{\text {ruber }}$ suggest that the monsoon entered a drought-prone regime at $\sim 3 \mathrm{ka}$ ago that intensified in the last 1,700 years (Figure 4). 

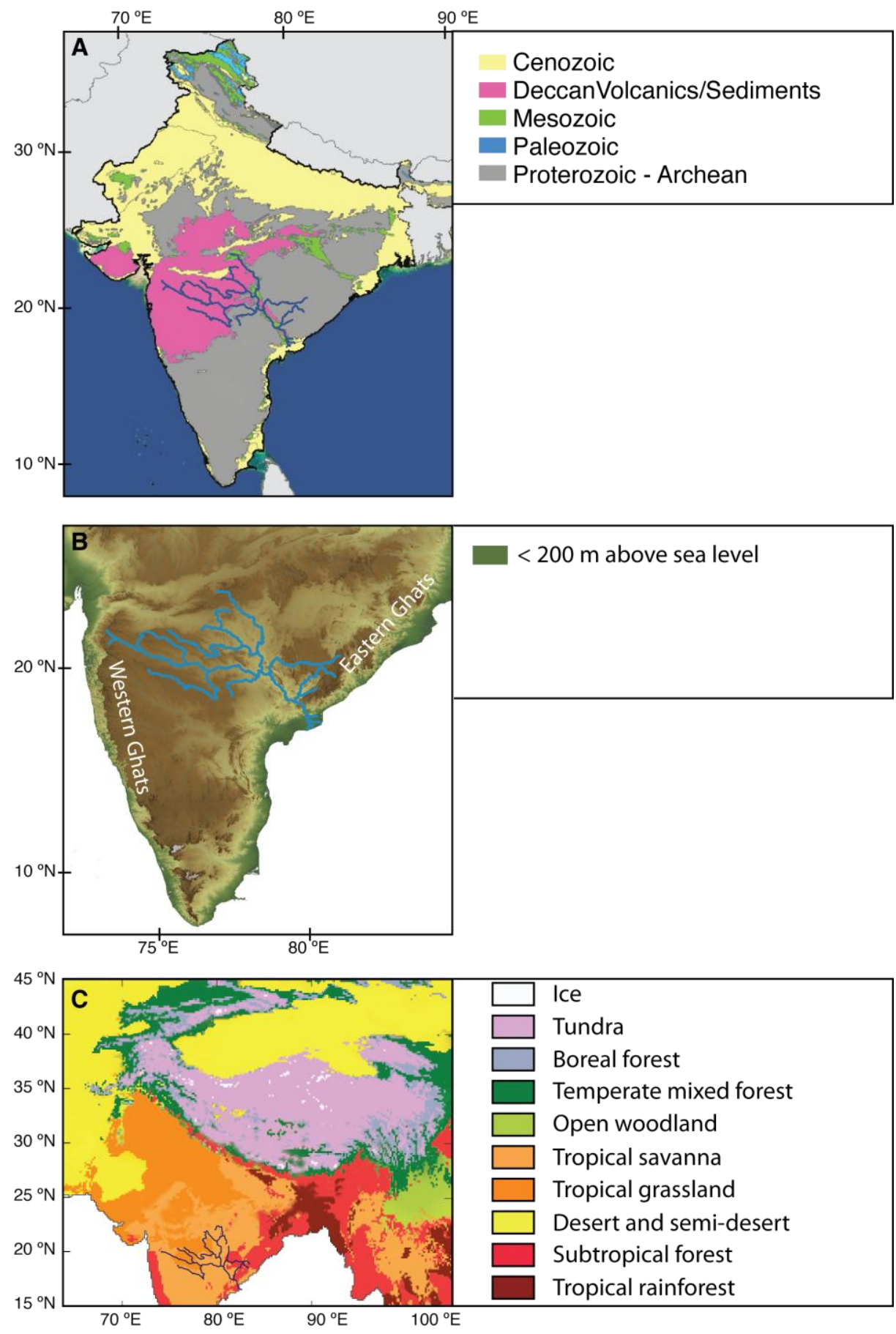

Figure 2. Godavari River drainage basin in its geological, physiographical, and ecological context A. Geological map modified from NASA Remote Sensing - Goddard Space flight Center: rst.gsfc.nasa.gov/. B. Digital elevation model courtesy of S. Constantinescu. C. Vegetation model results for present day biome distribution modified from Galy et al., (2008.) 


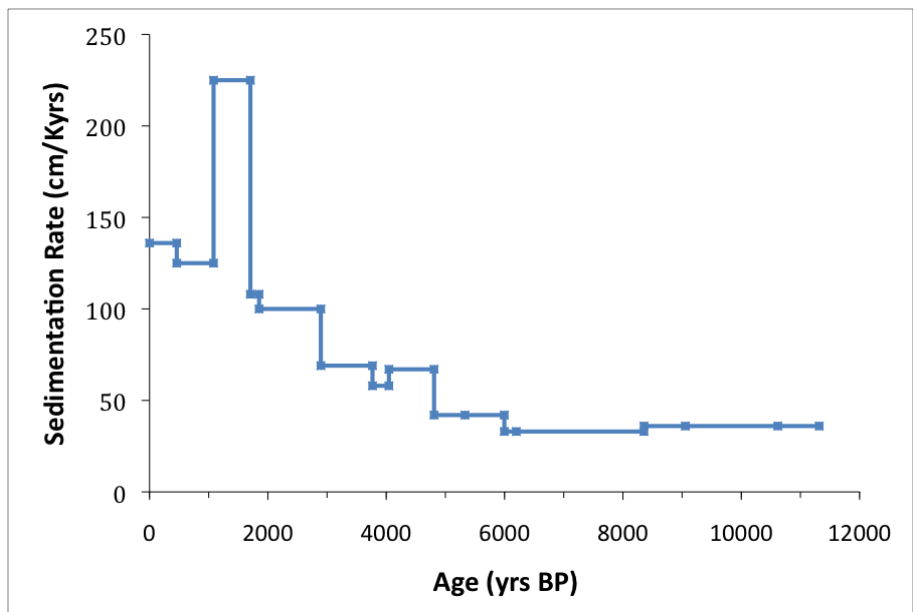

Figure 3. Sedimentation rates from core NGHP-16A.

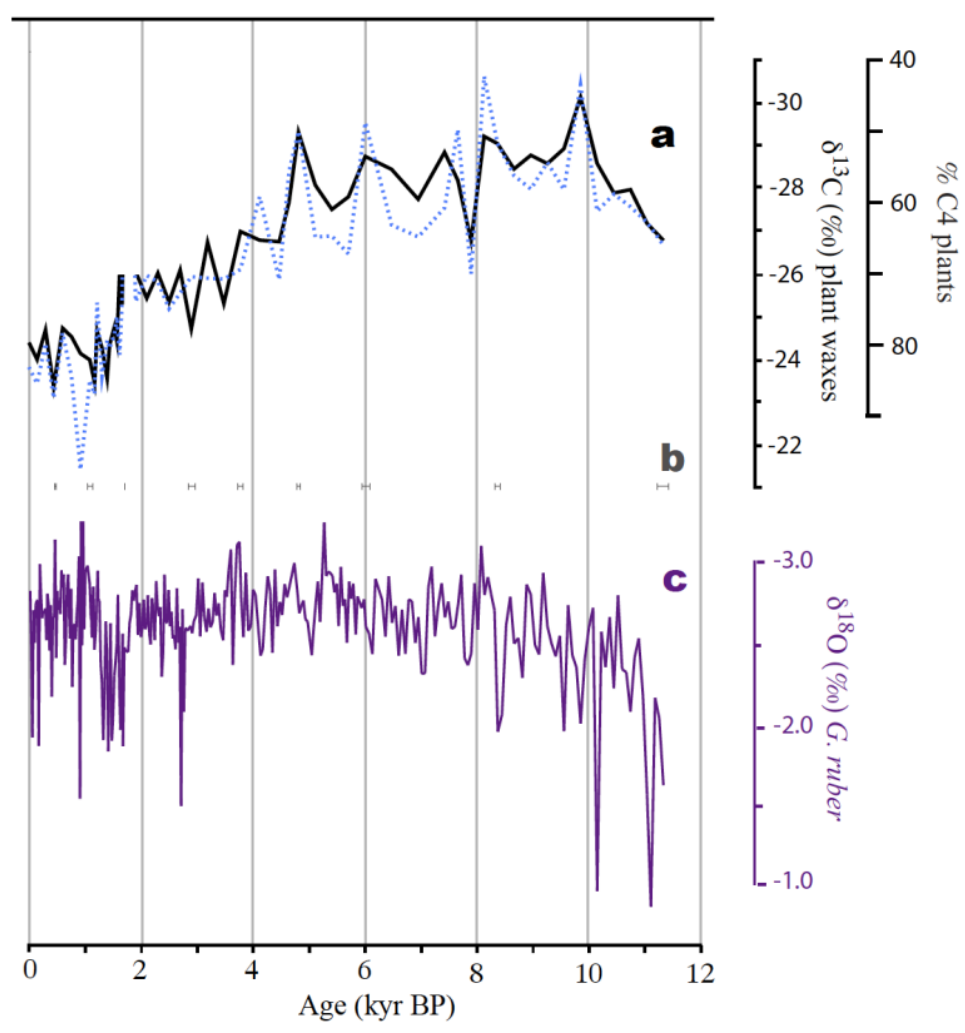

Figure 4. a) $\delta^{13} \mathrm{C}_{\mathrm{wax}}\left(n\right.$-alkanoic acids $\mathrm{C}_{26-32}$ ) from core 16A. b) calibrated radiocarbon ages in core $16 \mathrm{~A} \mathrm{c)} \delta^{18} \mathrm{O}$ measured on Globigerinoides ruber from core $16 \mathrm{~A}$, values are corrected for ice volume effects. 


\subsection{Methods}

Twelve samples ( $3 \mathrm{~cm}$ thick) of bulk sediment were taken from the top $8.0 \mathrm{~m}$ of core with the intention to achieve a sampling resolution of $~ 1000$ yrs. These samples were processed for total organic carbon (TOC), $\delta^{13} \mathrm{C}_{\mathrm{org}}$, and $\mathrm{C} / \mathrm{N}$ ratio. In addition to this, radiocarbon measurements were obtained on TOC, $\mathrm{C}_{24-32} n$-alkanoic acids (as fatty acid methyl esters (FAMEs)) and planktonic foraminifera. Planktonic foraminifera ages have been calibrated applying a standard reservoir age and the Marine09 curve (see Ponton et al., 2012 for details). TOC and FAME ages are presented as conventional (uncalibrated) ${ }^{14} \mathrm{C}$ ages.

\subsubsection{Bulk elemental and isotopic analysis}

Aliquots of every sampled core horizon were freeze-dried, homogenized with mortar and pestle and measured in duplicate for total carbon and total nitrogen by high temperature combustion on a Carlo Erba 1108 elemental Analyzer. TOC was measured in duplicate by the same method after carbonate removal by exposure to $\mathrm{HCl}$ vapor for $60-72$ hours followed by addition of a drop of $2 N \mathrm{HCl}_{(\mathrm{aq})}$ directly onto the sample. If any effervescence was noticed, an additional drop was added after drying overnight at $60^{\circ} \mathrm{C}$. TOC generated from additional dry sediment sample aliquots was measured for bulk ${ }^{13} \mathrm{C}$ and ${ }^{14} \mathrm{C}$ content at the National Ocean Sciences Accelerator Mass Spectrometry (NOSAMS) facility at WHOI. Results are reported as conventional radiocarbon ages according to Stuiver and Polach (1977).

\subsubsection{Fatty acid extraction}

Lipid organic matter was extracted from 25-30 grams of the freeze-dried sediment samples using a dichloromethane (DCM):methanol $(\mathrm{MeOH})$ solution (9:1) in a CEM Microwave Accelerated Reaction System (MARS). Concentrated lipid extract was saponified with $0.5 \mathrm{~N} \mathrm{KOH}$ in methanol solution. Liquid/liquid extraction of the neutral fraction was done using pure hexane. Then the $\mathrm{pH}$ was adjusted to 2 by addition of $\mathrm{HCl}$ and liquid/liquid extraction of the acid fraction was subsequently performed using 
hexane:DCM (4:1). Lipids in the acid fraction, including leaf wax $n$-alkanoic acids, were methylated using $\mathrm{HCl} 5 \%$ in $\mathrm{MeOH}\left(70{ }^{\circ} \mathrm{C}\right.$ for 12 hours). The resulting fatty acid methylesters (FAMEs) were extracted using hexane:DCM (4:1), dried over anhydrous sodium sulfate, and then purified via silica gel chromatography. A FAME external standard $\left(\mathrm{C}_{18}\right.$ and $\left.\mathrm{C}_{28}\right)$ was included each run sequence prior to sample analysis by gas chromatography with flame ionization detection (GC/FID) for initial quantification.

\subsubsection{Compound specific $\Delta^{14} C$ analysis}

For isolation of the individual FAMEs, preparative capillary gas chromatography (PCGC) was used following (Eglinton et al., 1996). FAME samples were blown to dryness and re-dissolved in $50-150 \mu \mathrm{L}$ of iso-octane to achieve concentrations in the range of 100 - $200 \mathrm{ng} / \mu \mathrm{L}$ per compound. The samples were repeatedly injected (24-45 times) into an Agilent 7890 gas chromatograph equipped with a Gerstel PTV injection system and coupled to a Gerstel preparative fraction collector (PFC). The target was to have 300 - $500 \mathrm{ng}$ of each individual compound on column on every injection. Separation was achieved on a Varian VF-1ms fused silica capillary column $(30 \mathrm{~m}, 0.53 \mathrm{~lm}$ i.d., 0.5 $\mathrm{lm})$. The PTV injector temperature program was $50^{\circ} \mathrm{C}(0.05 \mathrm{~min}), 12^{\circ} \mathrm{C} / \mathrm{s}$ to $320^{\circ} \mathrm{C}(5$ $\mathrm{min}), 12^{\circ} \mathrm{C} / \mathrm{s}$ to $340^{\circ} \mathrm{C}(4 \mathrm{~min})$. For FAMEs, the $\mathrm{GC}$ oven was programmed $50^{\circ} \mathrm{C}(1$ $\min ), 6^{\circ} \mathrm{C} / \mathrm{min}$ to $320^{\circ} \mathrm{C}(20 \mathrm{~min})$. Hydrogen was used as carrier gas $(10 \mathrm{~mL} / \mathrm{min})$. The transfer line and $\mathrm{PFC}$ were heated at $320^{\circ} \mathrm{C}$. Individual $n \mathrm{C}_{16}, n \mathrm{C}_{24}, n \mathrm{C}_{26}, n \mathrm{C}_{28}, n \mathrm{C}_{30}, n \mathrm{C}_{32}$ homologues were isolated into 6 clean glass PFC traps kept at $5^{\circ} \mathrm{C}$. PFC traps were eluted with hexane and brought up to a known volume for purity check and quantification for recovery calculations on a GC-FID. Recoveries averaged 64\% (54\% min and 78\% max), which is typical for this process. After isolation, FAMEs were eluted over a silica gel column using hexane:DCM $(2: 1)$ to remove potential column bleed contamination. In order to obtain sample yields large enough for radiocarbon measurements some isolates were re-combined $\left(n \mathrm{C}_{24}-n \mathrm{C}_{32}\right)$. 
For combustion, purified FAMEs were transferred into pre-combusted quartz tubes, the hexane evaporated, and $\sim 150 \mu \mathrm{g}$ pre-combusted copper oxide was added for oxygen supply. The tubes were evacuated while kept chilled in a dry-ice/isopropanol slurry, then flame-sealed and subsequently combusted at $850^{\circ} \mathrm{C}$ for $5 \mathrm{~h}$. After cooling, the quartz tubes were cracked under vacuum; the escaping $\mathrm{CO}_{2}$ gas was stripped of water, trapped and quantified manometrically. The $\mathrm{CO}_{2}$ was further transferred into evacuated pyrex tubes which were flame-sealed for storage before AMS measurement.

Compound-specific AMS radiocarbon measurements were performed at ETH Zurich using the MICADAS system equipped with a gas-ion source (Ruff et al., 2007). Results are reported as conventional radiocarbon ages (years BP) and $\Delta^{14} \mathrm{C}$ referring to Stuiver and Polach (1977). The radiocarbon ages of the individual $n$-alkanoic acids were corrected for the addition of one methyl group during derivatization using isotopic mass balance. In addition, internal corrections for additional modern and dead carbon that can be introduced as contamination in the combustion, vacuum line work, and AMS analytical procedures have been applied before reporting final $\Delta^{14} \mathrm{C}$ values, based on quantitative measurements of OX-I and coal standards as well as the long-term blank average of the facility.

Possible contamination derived from sample preparations steps before combustion have been recognized to be significant when measuring $\mathrm{C}$ samples smaller than $100 \mu \mathrm{gC}$ (Drenzek 2007; Santos et al. 2010). This contamination can derive from carbon in the lab environment, or from sample preparatory techniques like gas chromatography that via column bleed or carry over from previous injections can introduce external carbon into the sample. Drenzek (2007) running a standard of $n$-alkanoic acids of known $\Delta^{14} \mathrm{C}$ composition through a very similar methodology as we describe here, determined that contamination of fossil carbon due to pre-combustion lab procedures for small $\mathrm{C}$ samples was $0.75+/-0.4 \mu \mathrm{g}$ of $\mathrm{C}$. Using this value, we assess that pre-combustion fossil carbon contamination on our samples $(9-36 \mu \mathrm{g}$ of $\mathrm{C}$ ) can overestimate the age of the samples 
by 124 - 380 yrs. This error is significant; we acknowledge it in our interpretations, but do not incorporate it into our sample age measurements given we did not perform the quantitative standard analysis at our facility. In addition, Drenzek (2007) did not perform a final purification of isolated compounds prior to combustion, whereas a clean-up step by passage of isolated compounds through pre-combusted $\mathrm{SiO}_{2}$ gel was adopted in the present study.

\subsection{Results and Discussion}

Radiocarbon dates on mixed planktonic foraminifera provide the chronology for the core, and show that the top $8 \mathrm{~m}$ of sediment yield a record spanning the last $\sim 11,000$ years (Figure 5). Planktonic foraminifera, TOC and long-chain $\left(\mathrm{C}_{24-32}\right)$ fatty acid fractions of 12 sediment samples were radiocarbon-dated. The ages of each of the measured fractions generally increase with depth, as expected in sediments with limited or no postdepositional reworking (Table 1; Figure 5).

Table 1. ${ }^{14} \mathrm{C}$ Ages of individual sedimentary fractions: long-chain fatty acids $\left({ }_{n} \mathrm{C}_{24-32}\right)$, total organic carbon, and mixed planktonic foraminifera.

\begin{tabular}{|c|c|c|c|c|c|c|c|}
\hline \multicolumn{2}{|c|}{$\begin{array}{c}\text { Depth interval } \\
(\mathrm{m})\end{array}$} & \multirow{2}{*}{$\begin{array}{c}\begin{array}{c}\text { Fatty acid } \Delta^{14} \mathrm{C} \\
(\% \circ)^{*}\end{array} \\
-478.8\end{array}$} & \multirow{2}{*}{$\begin{array}{c}\text { Fatty acid age } \\
(\mathrm{y})\end{array}$} & \multirow{2}{*}{$\begin{array}{c}\text { TOC } \Delta^{14} \mathrm{C} \\
(\%) \\
-299.3\end{array}$} & \multirow{2}{*}{$\begin{array}{c}\text { TOC age } \\
(\mathrm{y})\end{array}$} & \multirow{2}{*}{$\begin{array}{c}\begin{array}{c}\text { Uncalibrated } \\
\text { foram age } \\
\text { (y) }\end{array} \\
155 \pm 55\end{array}$} & \multirow{2}{*}{$\begin{array}{r}\begin{array}{r}\text { Calibrated } \\
\text { foram age } \\
(y)^{\star *}\end{array} \\
0 \pm 0\end{array}$} \\
\hline 0.06 & $\begin{array}{ll}- & 0.09\end{array}$ & & & & & & \\
\hline 1.46 & 1.49 & -288.7 & $2677 \pm 132$ & -314.0 & $2970 \pm 30$ & $1542 \pm 35$ & $1104 \pm 50$ \\
\hline 2.96 & 2.99 & -337.1 & $3243 \pm 116$ & -362.0 & $3560 \pm 30$ & $2308 \pm 55$ & $1852 \pm 25$ \\
\hline 4.03 & 4.06 & -380.2 & $3783 \pm 111$ & -399.2 & $4040 \pm 30$ & $3120 \pm 55$ & $2895 \pm 54$ \\
\hline 4.76 & 4.79 & -453.8 & $4799 \pm 146$ & -460.8 & $4910 \pm 30$ & $4097 \pm 35$ & $4046 \pm 50$ \\
\hline 5.34 & 5.37 & -459.2 & $4878 \pm 119$ & -475.9 & $5130 \pm 30$ & $4960 \pm 55$ & $5331 \pm 78$ \\
\hline 6.00 & 6.03 & -514.1 & $5739 \pm 259$ & -541.1 & $6200 \pm 40$ & $5230 \pm 35$ & $5996 \pm 50$ \\
\hline 6.42 & 6.45 & -572.4 & $6766 \pm 157$ & -558.0 & $6500 \pm 35$ & $5755 \pm 35$ & $6198 \pm 50$ \\
\hline 6.85 & 6.88 & -549.7 & $6351 \pm 125$ & -431.8 & $4490 \pm 30$ & $4940 \pm 35$ & $5276 \pm 45$ \\
\hline 7.20 & 7.23 & -670.1 & $8849 \pm 170$ & -675.2 & $8980 \pm 35$ & $8455 \pm 35$ & $9056 \pm 53$ \\
\hline 7.64 & 7.67 & -709.1 & $9860 \pm 264$ & -698.8 & $9580 \pm 40$ & $9765 \pm 50$ & $10314 \pm 57$ \\
\hline 7.87 & $\begin{array}{l}-\quad 7.90 \\
\end{array}$ & -707.9 & $9827 \pm 190$ & -718.0 & $10100 \pm 40$ & $9775 \pm 40$ & $10619 \pm 50$ \\
\hline
\end{tabular}

${ }^{*}$ Corrected for methylation

** error is $\pm 1 \sigma$ 
The sample at $6.85 \mathrm{~m}$ yielded anomalous results showing an age reversal on all three dated fractions. The ages of the foraminifera, TOC, and fatty acids are $922 \mathrm{yrs}, 2010 \mathrm{yrs}$, and 415 yrs younger than those for the sample immediately above $(6.42 \mathrm{~m})$. The coherence in younger-than-expected ages for foraminifera, plant waxes and TOC suggest that this is not an analytical problem as these components were processed and analyzed independently. Furthermore, the TOC ages and the plant wax ages were measured at different laboratories. There is no evidence for large-scale bioturbation in the core that could have brought material from above into this horizon. The remaining possibility of entrainment of younger carbon during coring or sampling remains the most likely. We treat this sample as an outlier.

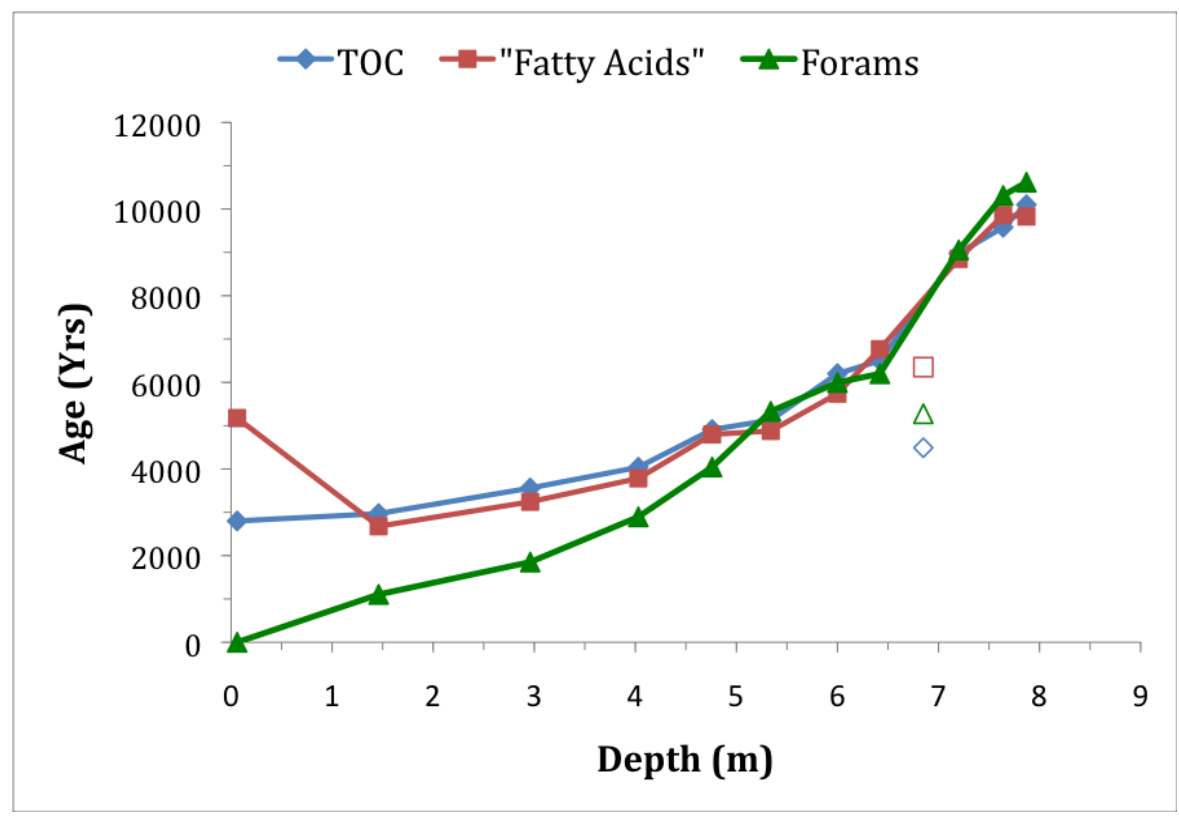

Figure 5. Comparative ages of planktonic foraminifera, TOC, and long-chain fatty acids. Open symbols represent an age reversal at $6.85 \mathrm{~m}$. This sample is considered an outlier. 
The remarkable correspondence between the ages of the TOC and the long-chain fatty acid fractions (Figure 5), implies that, at least at this location, the age of the long-chain fatty acids is representative of a broader suite of organic constituents that collectively form a major fraction of the TOC. The coherent behavior of all organic fractions suggest further that they undergo the same set of physical and chemical processes during their transfer from the source to the continental slope sink. However, there is a discrepancy at the core top where the age of the long-chain fatty acids is $\sim 2,300 \mathrm{yrs}$ older than the TOC, which could be the result of a core top enriched with freshly produced labile marine carbon that is drawing bulk carbon to younger age values. In contrast, towards the top of the core the long-chain fatty acids are significantly pre-aged, presumably as a result of protracted storage on the continents (see below).

The ${ }^{14} \mathrm{C}$ age difference between planktonic foraminifera and long-chain fatty acids decreases with increasing core depth (Figure 5) and the ages of the long-chain fatty acids show no statistical difference from those of planktonic foraminifera deeper than $5.3 \mathrm{~m}$. Above this depth there is a step change and the age of these fractions start to diverge. The same relations between dated fractions can be observed in Figure 6 where ${ }^{14} \mathrm{C}$ data are expressed as age offsets vs. depth. From this figure it is also evident that the core top values display the largest age offsets between fractions, with the organic material being extensively aged. We anticipate that anthropogenic perturbations of the drainage basin, and in particular exhumation and erosion of aged organic carbon stored in soils due to intensive deforestation and agricultural practices - particularly since the $19^{\text {th }}$ century (Hill, 2008), are instrumental in explaining this age offset (Syvitstki et al., 2005). 


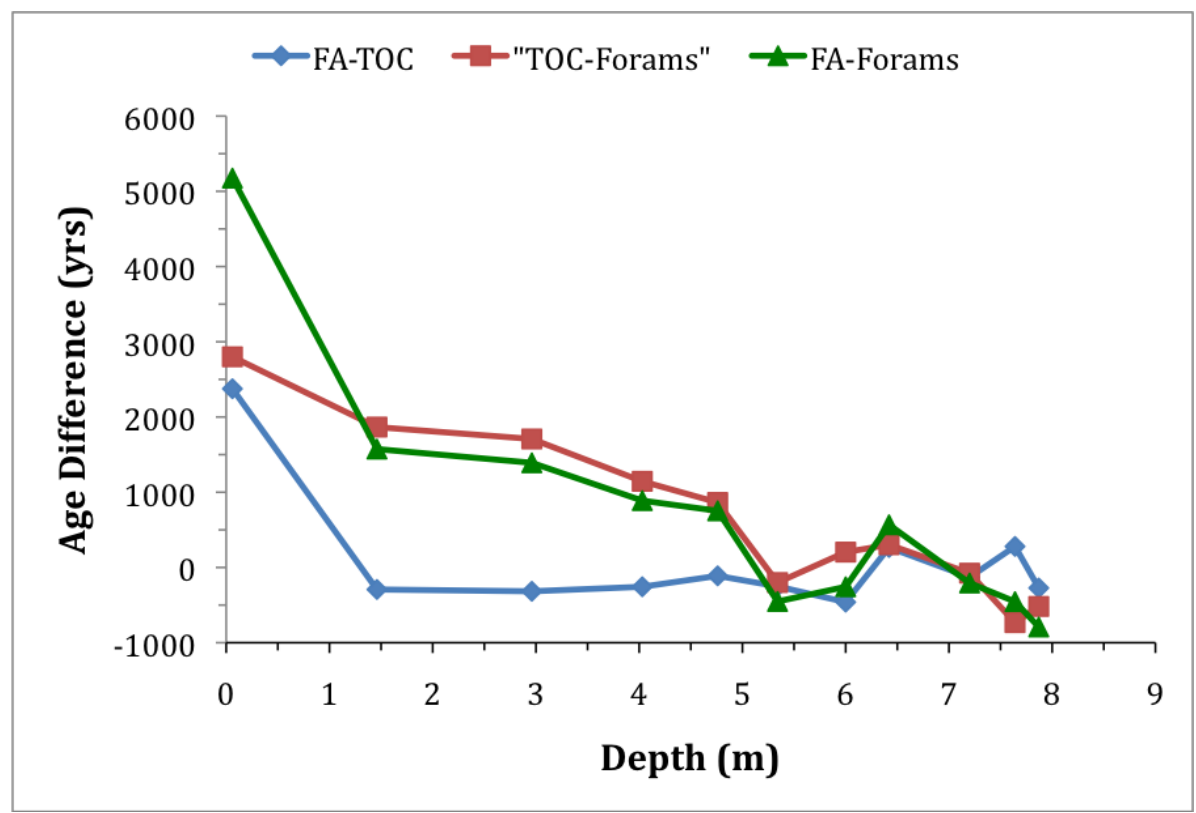

Figure 6. Age offsets between different dated fractions (FA = long-chain fatty acids).

Comparison with the aridification record (Figure 4a; Ponton et al., 2012) reveals that the age offset between dated fractions (long-chain fatty acids vs. foraminifera) is contemporaneous with changes in hydroclimate of the Godavari basin (Figure 7). For the last $\sim 4,000$ years the long-chain fatty acids are consistently older than the foraminifera. As the aridification progressed during the second half of the Holocene, the age offset between long-chain fatty acids and foraminifera increases. This is particularly pronounced in the last 2,000 years; until then the maximum age offset remained below 1,000 years. This implies that either a pool of older terrestrial carbon is accessed as aridity increases and/or that the length of storage or "residence time" of terrestrial carbon on the continents is longer during arid intervals. For clarity, the TOC ages were not plotted in Figure 7 since they mostly agree with the fatty acids, except when noted above, and may be influenced by a more complex suite of inputs and pre- and post-depositional processes. 


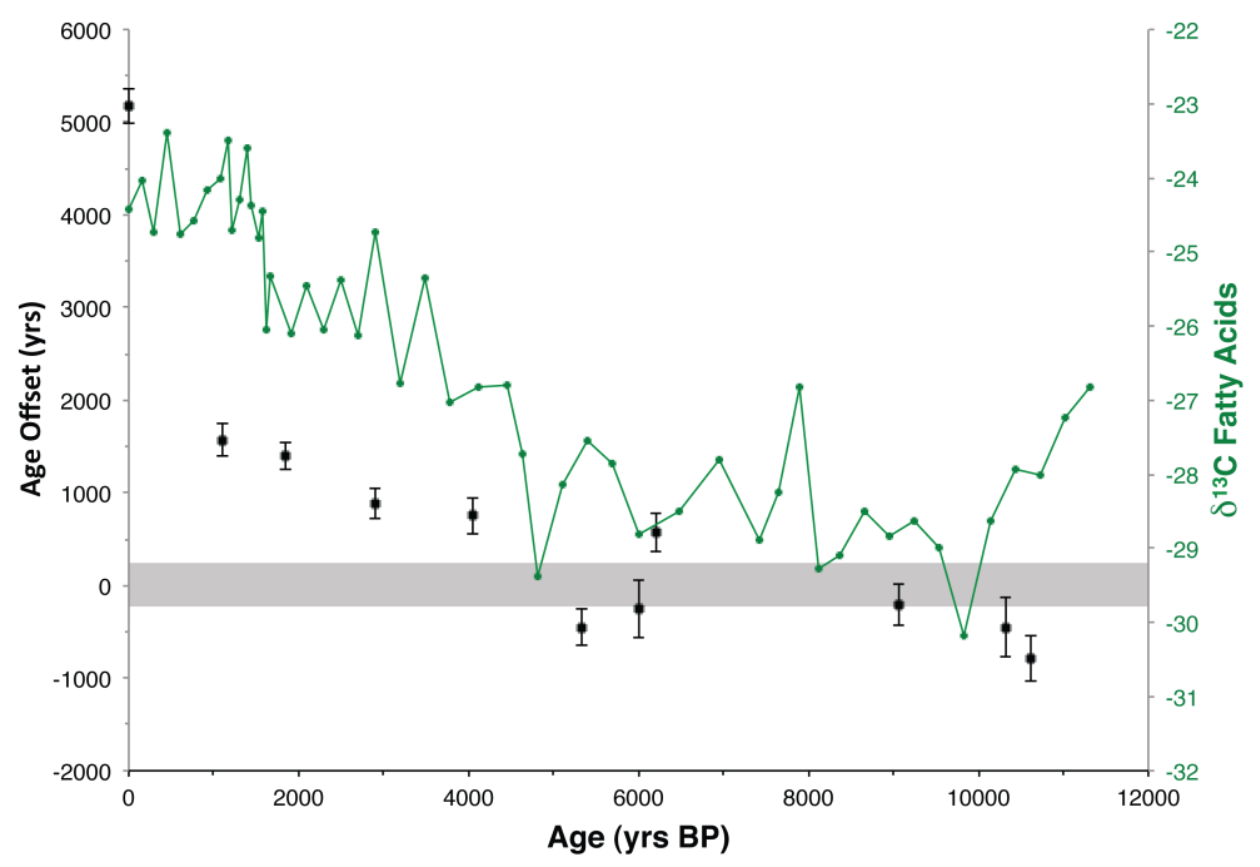

Figure 7. Age offset between long-chain fatty acids and foraminifera. Error bars represent dating uncertainties for compound specific ${ }^{14} \mathrm{C}$ dating methods and foraminifera age calibrations. Zero-age difference region in gray shade. In green, the $\delta^{13} \mathrm{C}$ values for the weighted average $\left(\mathrm{C}_{26-32}\right)$ fatty acids.

In the early Holocene, the three fatty acid samples have ages on average 450 years younger than the planktonic foraminifera ages. Since it is hard to envision a carbon source fresher than directly fixed biospheric $\mathrm{CO}_{2}$, it is possible these age offsets are caused by overestimates in the calibrated age of planktonic foraminifera. $\mathrm{All}{ }^{14} \mathrm{C}$ foraminifera samples were corrected for the standard ventilation surface water age of 400 years. Available reservoir age estimates for the Bay of Bengal surface waters are not substantially different than the standard marine reservoir correction (Dutta et al., 2001; Southon et al., 2002), but if ventilation age increased during the late Holocene, the foraminifera ages will become younger and the estimated age offsets reduced. Among the possible explanations for an increased ventilation age at this location is a freshwater lens of old DIC water from the Godavari River sitting above the core site. To our knowledge such measurements on the Godavari river waters are not available. 


\subsubsection{Storage time vs. availability of aged carbon}

As discussed previously, there are several pathways and loops that an organic molecule originally produced by a vascular plant can take before being buried in marine continental margin sediments (Fig 1; e.g. Blair et al. 2004). It is also evident that the terrestrial organic matter buried in marine sediments is a mixture from different carbon pools that come from different reservoirs (e.g. Drenzek, 2007). The results of this study reveal an increasing age offset between long-chain fatty acid ages and planktonic foraminifera ages starting at $\sim 5,000 \mathrm{yr} \mathrm{BP}$. This implies that the age of the long-chain fatty acids being deposited by the river is increasing. There are two possibilities to explain this progressive aging: 1) the storage time of $\mathrm{OC}$ is increasing in the river basin or 2) a source, or sources, of older OC have become available and older fatty acids are mixing with freshly produced ones increasing the resulting ages.

The measured increased age offsets appear to be synchronous with the onset of aridification in central India, implying a climate-driven forcing of terrestrial carbon residence times. Recent studies have attempted to describe the effect of climatic changes in OC turnover times in soils (Schimel, et al., 2011; Yang et al., 2011; Butzer et al., 2008). These studies show that dry/wet cycles affect the turnover times of carbon removal or storage and supporting results from previous model simulations suggest rates of carbon turnover can be much larger in recently disturbed ecosystems than in more mature (climatically stable) ecosystems (Trumbore, 1997). In the following sections we incorporate other available data from the same core in order to evaluate different scenarios that may favor increased storage time or variations in age populations to explain the observed increase in age offsets.

\subsubsection{Seasonality}

Decreases in monsoon precipitation responsible for the increasing aridity translate to lower average discharges for the Godavari River and its tributaries as the monsoon is 
their sole moisture source. This could lead to an increase in residence time of organic carbon due to increased storage time in soils and/or decreased erosion. Lower average water discharges should also result in more sluggish transport of sediments, including OC, in the bed load fraction (Tucker, 2004; Molnar, 2006), which may in turn increase the age of the organic carbon discharged at the river mouth (Galy et al., 2011). The sediment load decline and potentially a decrease in vegetation cover that accompanies aridification may also lead to incision of the floodplain (Bookhagen et al., 2006), allowing the river to tap into a pool of older organic carbon.

All these possible routes of aging the organic matter delivered at the mouth of the river change further when we take into consideration seasonal as well as sub-millennial variability in the monsoon precipitation and river discharge. Seasonality in precipitation may have two basic expressions. The first is a change in precipitation between seasons, while the length of the seasons remain the same. Assuming that erosion increases linearly with precipitation, this type of change would only redistribute erosion between seasons with effects no different than the ones discussed in the previous paragraph. Assuming that increases in precipitation lead to increases in flood magnitude, which is a more plausible scenario, erosion will increase instead. The second expression of seasonality involves a change in the length of monsoon seasons. An increase in the summer monsoon length would result in a decrease in average erosional power if total precipitation remains unchanged but it is distributed over a longer season. The corollary is that a shortening of the summer monsoon season may augment the erosional power by increasing the maximum annual discharge. It becomes apparent that insights from additional lines of evidence (i.e., sediment sources and accumulation rates) are needed to better understand the observed age discrepancies in this drainage basin.

\subsubsection{Sedimentation rates}

The sediment accumulation rate in the core increases over the last 5,000 yrs (Figure 3), similar to the trend observed in increasing age offset between long-chain fatty acids and 
foraminifera (Figure 8). Increases in sedimentation rates suggest that a more sluggish transport from the continent is not responsible for the offset. Instead, this could imply that the age of the fatty acids increases with respect to the foraminifera because of an increased proportion of aged terrigenous material is mobilized from previously unavailable sources within the continent. Between $\sim 6,000$ and 10,000 yrs BP, when the sedimentation rates are relatively low for this site, the age offsets are minimal. Since the average error for the estimate of age offset is $215 \mathrm{yrs}$, samples are within error of the zero-age difference region (gray shaded area; Figure 8).

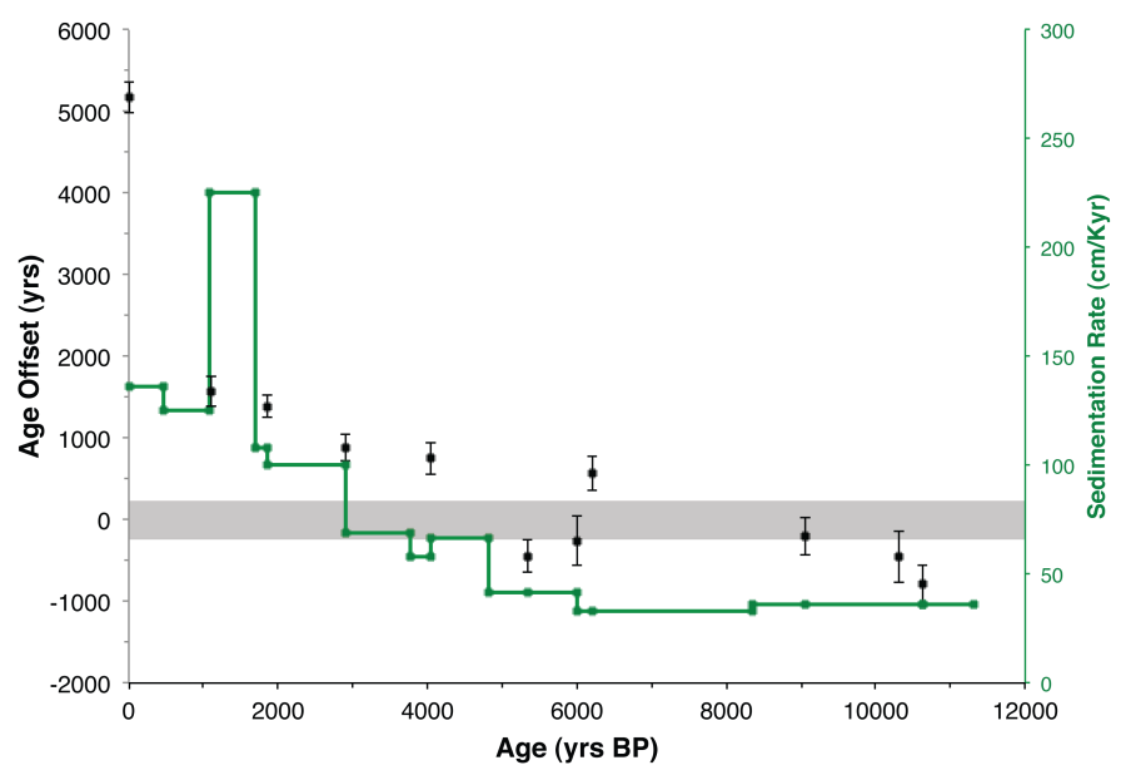

Figure 8. Sedimentation rates (green line) and age offsets between long-chain fatty acids and foraminifera (black squares). Error bars represent dating uncertainties for compound specific ${ }^{14} \mathrm{C}$ dating methods and foraminifera age calibrations. Zero-age difference region in gray shade.

With fluctuating sedimentation rates or under stable conditions, what changes the age of the sedimentary plant waxes is not necessarily the flux of terrestrial material, but its provenance and transport pathways from source to sink. There are several scenarios that could explain the changes in input of terrestrial OC from a diverse set of reservoirs into 
the basin. In this context, it is important to bear in mind that even at the molecular level, mixed (age) populations of a source-specific biomarker compound are encountered in sedimentary environment as a consequence of the multiple storage points and transport

routes (see Figure 1). Therefore, the measured ${ }^{14} \mathrm{C}$ age for a specific biomarker is a composite of these different populations (e.g., fatty acids from fresh leaf litter vs. from soils; Drenzek, 2007). Consequently, observed changes in apparent age of long-chain fatty acids could reflect changes in the overall storage/residence time of these compounds or changes in the proportions of fresh vs. pre-aged (soil) fractions.

\subsubsection{Sediment provenance}

Sedimentation rates provide evidence of the amount of material being exported by the river at different times, but do not provide information regarding the provenance of that sediment within the drainange basin. Evidence on signal provenance was derived from the sediment's inorganic fraction using detrital $\mathrm{Nd}$ isotopic ratios (L. Giosan, unpublished data). Very low, negative $\varepsilon N d$ values are generally found in continental crusts, whereas positive $\varepsilon N d$ values are commonly found in mantle derived melts (DePaolo, 1988), such as those of large igneous provinces. The bedrock in the Godavari drainage basin is composed of two distinct geological provinces: flood basalts from the Deccan Plateau in the upper basin and crystalline igneous/metamorphic rocks from the Indian craton in the lower basin (Murthy et al., 2011; Figure 2). These two geological provinces have very distinct $\mathrm{Nd}$ isotopic signatures: The Deccan basalts have an average $\varepsilon \mathrm{Nd}$ of $\sim+1 \pm 5$ while the average craton $\varepsilon \mathrm{Nd}$ is $\sim-35 \pm 8$. Sediments preserve the $\mathrm{Nd}$ isotopic signal of the weathered bedrock from which they originated, and $\mathrm{Nd}$ isotope analyses on bulk sediments constitute a robust provenance indicator (e.g., Clift and Blusztajn, 2005; Colin et al., 1999).

$\varepsilon \mathrm{Nd}$ values of bulk sediment samples from core 16A show that there is clearly a stronger input of Deccan-derived sediments in the last 2,000 yrs, when conditions are driest in the drainage basin and sedimentation rates are highest (Figure 9). Adopting the average $\varepsilon \mathrm{Nd}$ 
values for the two main geological provinces we can generate a mixing model and estimate the relative sedimentary inputs from the upper and lower drainage basins of Godavari system over time. From 2,000 - 10,000 yrs BP the Deccan basalts sedimentary input is $\sim 46 \%$ while in the last 1,600 yrs BP the input increased to $\sim 62 \%$. This increase in Deccan contribution relative to craton-derived sediments seems to come as a lagged response to the onset of aridification (Figure 9). Notably, the $C_{4}$ vegetation in the Godavari catchment today is concentrated on the Deccan plateau (Asouti and Fuller, 2008), which supports the measured increase of $\mathrm{C}_{4}$-derived higher plant waxes during the last $\sim 2,000$ yrs.

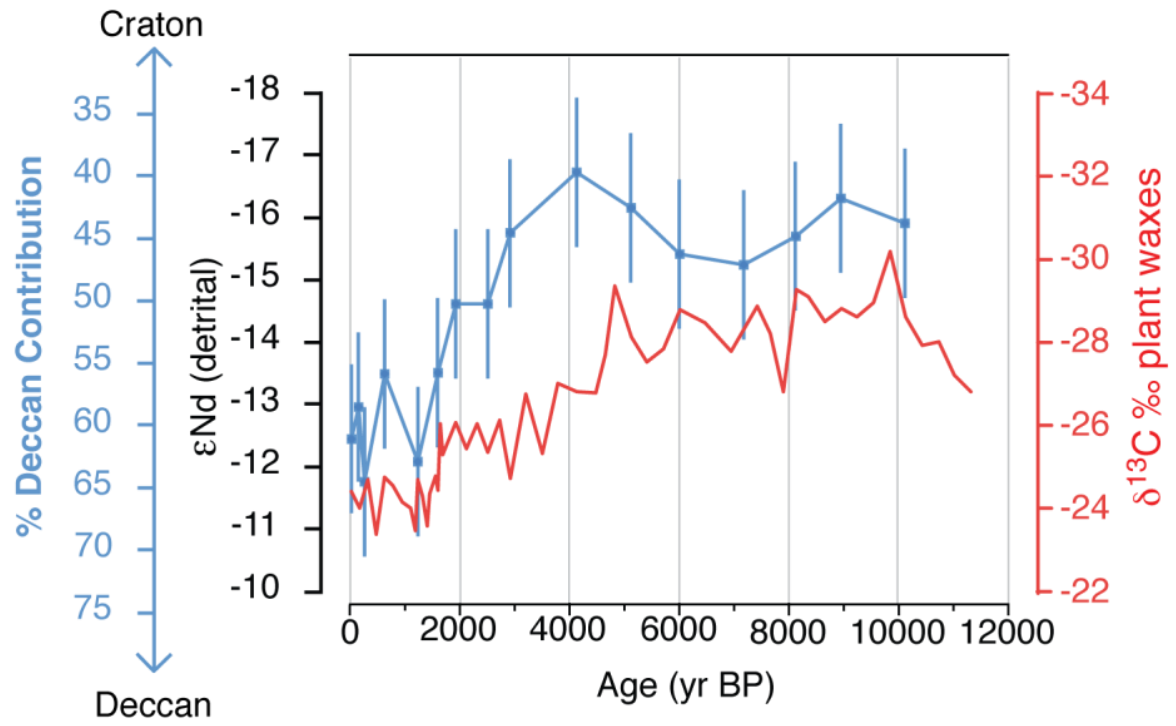

Figure 9. $\varepsilon \mathrm{Nd}$ values in blue (provenance proxy) and $\delta^{13} \mathrm{C}_{\mathrm{wax}}$ in red (proxy for aridity). Error bars on the $\varepsilon \mathrm{Nd}$ curve apply only to the "\% Deccan contribution" axis on the far left in blue, and result from an error propagation analysis based on the end-member $\varepsilon \mathrm{Nd}$ estimates for the Deccan Plateau and the Indian craton.

While the observation of an increase in age offset between plant wax fatty acids and foraminifera with the onset of aridification is unequivocal, increased sedimentation rates and $\mathrm{Nd}$ isotopic data on bulk sediments showing a higher proportion of detrital material originating in arid parts of the upper drainage basin indicate that terrigenous material is 
more efficiently transferred and exported through the river drainage basin under drier conditions. Therefore, it is not clear that an increase in storage times of OC in the drainage basin produced the increased in age offsets. Instead, re-mobilization of aged carbon from the arid upper basin may be a more influential factor. Nevertheless, mobilization of aged carbon from the upper basin, together with the strong $\mathrm{C}_{4}$ signal, implies that the aged soils must also contain a predominantly $\mathrm{C}_{4}$ vegetation signal. In other words, the Deccan Plateau must have been $\mathrm{C}_{4}$ dominated for some extended period of time prior to the inferred aridification. This does not necessarily contradict the interpretation that vegetation in the entire drainage basin shifts in response to climate, but rather implies the Deccan Plateau has been a relatively arid region within the basin through time.

\subsubsection{Climate control on organic carbon transport}

The scenarios discussed above clearly have different but profound implications in terms of our understanding of climate-driven impacts on the terrestrial carbon cycle and on interpretations of terrestrial proxy records embedded in continental margin sediments. During the early Holocene the OC is transported efficiently through the drainage basin at a time when precipitation and therefore water discharge is relatively high. In the mid Holocene the age offsets between planktonic foraminifera and long-chain fatty acids start to increase at the same time that the climate starts turning arid in central India. Changes in fluxes from different reservoirs within the system cannot be precisely constrained, but it becomes apparent that increased residence time of terrestrial carbon within the system can have the same effects. During the last 2,000 yrs the measured age offsets are the largest during a time when the climate turned arid, the monsoon entered in a droughtprone regime - potentially causing a decrease in the size of the plant biomass reservoir (fresh OC flux) and an increase in erosion rates (aged OC flux) - and when the impacts of human intervention on the landscape are most acutely felt through mobilization and loss of soil OC. These conditions can occur simultaneously exacerbating the increase in storage times of OC due to aridity. While further work is clearly needed to resolve 
underlying processes, the present study clearly demonstrates that changing climate in monsoonal regions markedly affects the nature and dynamics of terrestrial carbon transfer to the marine environment. Variations in either storage time or the proportions of fresh versus aged carbon both indicate climate-driven controls on the overall flow of terrestrial carbon through drainage systems.

\subsubsection{Implications for increased carbon storage time}

If the reason for the observed age offsets between long-chain fatty acids and planktonic foraminifera is an increase in storage time, this will have implications for the terrestrial carbon cycle and for paleoclimate reconstructions. An increased storage time implies that under arid conditions the system is more sluggish and it takes longer to transport carbon from the continents to the oceans, prolonging the stay in the intermediate carbon reservoirs on land. For paleoclimate reconstructions the increasing age of long-chain fatty acids poses a problem when interpreting the organic proxy data using a chronology based on marine sedimentary components (e.g. planktonic foraminifera). Figure 10 illustrates this problem by presenting the $\delta^{13} \mathrm{C}$ record of the weighted average of long-chain fatty acids $\left(n \mathrm{C}_{26-32}\right)$ using two different chronologies based on planktonic foraminifer and plant wax fatty acid ${ }^{14} \mathrm{C}$ ages. In this context, reconstructing fatty acid records using an independent age model based on fatty acid ${ }^{14} \mathrm{C}$ measurements would only be valid when dealing with variations in storage time, and would be in appropriate for multimode age populations. Given that there is compelling evidence for the presence of terrestrial carbon with mixed age populations in river and continental margin sediments (Drenzek, 2007; Blair 2010, Galy \& Eglinton, 2011) it may prove difficult to reconcile chronologies for terrestrial and marine proxy records in marine sedimentary sequences. It is also important to note that this issue my be pertinent to other terrestrial proxies recorded in river-proximal marine sediments. For example, pollen, titanium, $\delta^{15} \mathrm{~N}$, and even $\mathrm{Nd}$ isotope records may all exhibit varying lags and unique transmission times. 


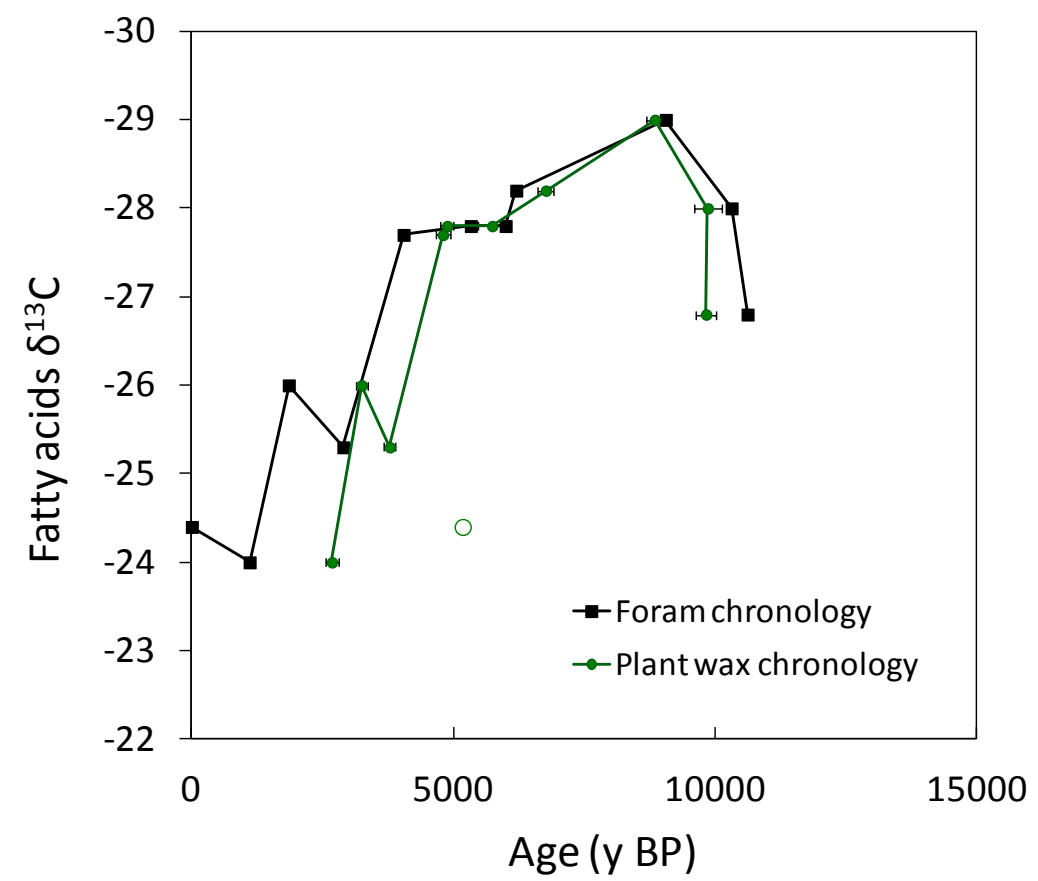

Figure 10. $\delta^{13} \mathrm{C}$ of long-chain fatty acids $\left(n \mathrm{C}_{26-32}\right)$ for samples on which ${ }^{14} \mathrm{C}$ ages were measured, plotted on a planktonic foraminifera-based chronology (black line) and a fatty acid- based chronology (green line). The lags are caused by age offset between fatty acids and foraminifera. The open green circle represents the core top sample which, due to its large age offset, appears as an age reversal on the fatty acid-based chronology.

\subsubsection{Implications of mixing fresh biospheric carbon with aged carbon}

If the reason for the observed age offsets between long-chain fatty acids and planktonic foraminifera is an increase in the input of aged OC there are implications for the terrestrial carbon cycle and for paleoclimate reconstructions. Previously stored OC made available by aridity in the basin can cause an increase in the atmospheric $\mathrm{CO}_{2}$ reservoir as a result of old OM degradation. This represents a feedback mechanism by which climatic change can affect the terrestrial carbon cycle. Similarly, when increased age offsets between long-chain fatty acids and planktonic foraminifera result from enhanced exhumation of old soil OM, only a portion of the $\delta^{13} \mathrm{C}_{\mathrm{wax}}$ signal will reflect vegetation responses, posing a problem for paleoclimatic reconstructions. 
In order to further explore this scenario, we calculated the percentage of older carbon required to mix with fresh biospheric carbon to generate the observed age offsets of 1000 and 5000 years. Although a myriad of different combinations and mixing models with different age populations are possible to generate a pre-established age offset, we present here four examples of simple mixing between a fresh carbon pool $\left(\Delta^{14} \mathrm{C}=0\right.$ per mil $)$ and older carbon pools with ages of 50000, 20000, 10000, and 5000 years $\left(\Delta{ }^{14} \mathrm{C}=-998,-917\right.$, -712, and -464 per mil respectively). Aged carbon pools roughly represent carbon from the last glacial maximum ( 20000 yr BP), early Holocene ( 10000 yr BP) and mid Holocene $(\sim 5000 \mathrm{yr} \mathrm{BP})$. The $50000 \mathrm{yr}$ old carbon is almost radiocarbon dead and represents fossil carbon. This information is presented in Table 2 and was obtained applying the following equation:

(i) Radiocarbon age $=-8033 \ln \left[1+\left(\mathrm{f}\left(\Delta^{14} \mathrm{C}_{\text {modern }}\right)+(1-\mathrm{f})\left(\Delta^{14} \mathrm{C}_{\text {aged }}\right)\right) / 1000\right]$

where $\mathrm{f}$ is the fraction of modern carbon, and the radiocarbon age was replaced by the predetermined age offset (either 1000 or 5000 in this case).

Table 2. Percent of aged and fresh carbon required to yield 1000 and $5000 \mathrm{yr}$ age offsets.

\begin{tabular}{lcccr} 
Age offset $(\mathrm{y})$ & $\begin{array}{c}\text { Age of old } \\
\text { carbon }(\mathrm{y})\end{array}$ & $\Delta^{14} \mathrm{C}(\%)$ & $\begin{array}{c}\text { \% old carbon } \\
\text { required }\end{array}$ & $\begin{array}{c}\text { \% fresh carbon } \\
\text { required }\end{array}$ \\
\hline \hline 1000 & 50,000 & -998 & 12 & 88 \\
5000 & 50,000 & -998 & 47 & 53 \\
1000 & 20,000 & -917 & 13 & 87 \\
5000 & 20,000 & -917 & 50 & 50 \\
1000 & 10,000 & -712 & 18 & 82 \\
5000 & 10,000 & -712 & 65 & 35 \\
1000 & 5,000 & -464 & 74 & 26 \\
5000 & 5,000 & -464 & 100 & 0 \\
\hline
\end{tabular}


The selected ages for the old carbon pools represent possible carbon mixing scenarios in this basin, and give an estimate of how much carbon of a specific age is needed to generate the observed age offsets. Mixing with pools of 10000 and $5000 \mathrm{yr}$ old carbon represent the likely scenarios that early and mid Holocene soils are being eroded during the late Holocene. To increase the age of sedimentary long-chain fatty acids by 1000 years with respect to the planktonic foraminifera, $74 \%$ of the carbon must be from the 5000 yr pre-aged pool, which implies significant erosion of relatively young soils across the drainage basin. On the other hand, only $18 \%$ of the total carbon must come from a $10000 \mathrm{yr}$ old pool to create the same age offset suggesting that deeper erosion of soils would be more effective in generating age offsets. Similarly, to generate the same 1000 years offset, $13 \%$ of the carbon from the $20000 \mathrm{yr}$ old pool is needed, and $50 \%$ of this last glacial carbon is required to generate a $5000 \mathrm{yr}$ offset. Thus, the erosional style within the drainage basin whether uniformly surficial or deeper more localized in e.g., gullies or fluvial incision would be important to assess via additional proxies to understand processes of organic carbon recycling and transfer. Our mixing estimates show that fluctuations in the availability of aged carbon pools caused by climatic variability can change the residence times of organic carbon in the drainage system and therefore have implication for the terrestrial carbon cycle. Furthermore, mixing with aged carbon also affects paleoclimate reconstructions. For example given than during the last glacial maximum conditions were much drier in the Indian subcontinent with respect to present (e.g. Galy et al., 2008; Ponton et al., 2012) soils from this age have a strong $\mathrm{C}_{4}$ biomass isotopic signature. If mixing with $50 \%$ carbon from the last glacial period causes the observed $5000 \mathrm{yr}$ offset at the core top, the measured $\delta^{13} \mathrm{C}$ values should be corrected for the strong pre-aged carbon input prior to interpretation.

Mixing with radiocarbon dead or fossil carbon should also be considered given its common occurrence in river basins and soils (e.g. Drenzek, 2007; 2009; Hedges and Oades, 1997; Galy et al., 2008; Gustafsson et al., 2011). Table 2 also provides information on the percent of $50000 \mathrm{yr}$ old carbon required to yield the observed age 
offsets. While only $12 \%$ percent of $50000 \mathrm{yr}$ old carbon is required to create a $1000 \mathrm{yr}$ age offset by mixing with modern carbon, $47 \%$ is required to generate a $5000 \mathrm{yr}$ offset. Age-depth soil profiles within the basin or soil sedimentation rates will be needed to determine the age and proportion of older carbon pools within the erodible reservoirs in the Godavari river catchment and to test if the estimated values are reasonable.

So far we have examined mixing of modern biospheric carbon with aged carbon pools representing specific geologic stages. Now we examine mixing of different proportions of fossil carbon $\left(\Delta{ }^{14} \mathrm{C}=-999\right.$ per mil) with carbon pools of all age ranges $\left(\Delta^{14} \mathrm{C}\right.$ between 0 -999). Results are reported in Table 3 and show what the age offsets of samples of different ages will be when mixed with 10, 20, 50 and 70\% of dead carbon. Equation (i) was used to calculate the different sample ages, and age offsets represent the difference between the age of the sample with mixed dead carbon and what the age of a pure sample ( $0 \%$ dead carbon) will be.

Our mixing scenarios show that a mixture with the same proportion of dead carbon creates the same offset regardless of the real sample age and that increasing the amount of dead carbon in the mixture rapidly increases the age offset. A mixture with $20 \%$ dead carbon produces an age offset of $\sim 1790$ years while a mixture with $50 \%$ dead carbon produces an age offset of $\sim 5560$ years. Assuming that dead carbon is widely available, these calculations show the potential of relatively small amounts of very old carbon to have strong impacts on the residence time of carbon in the system. 
Table 3. Age offsets for mixing with dead carbon.

\begin{tabular}{|c|c|c|c|c|c|c|c|c|c|}
\hline \multirow{3}{*}{$\begin{array}{l}\Delta^{14} \mathrm{C} \\
(\% \circ)\end{array}$} & \multirow{3}{*}{$\begin{array}{c}\text { Real } \\
\text { age }(y)^{*}\end{array}$} & \multicolumn{8}{|c|}{ Age with } \\
\hline & & \multicolumn{2}{|c|}{$10 \%$ dead C } & \multicolumn{2}{|c|}{$20 \%$ dead C } & \multicolumn{2}{|c|}{$50 \%$ dead C } & \multicolumn{2}{|c|}{$70 \%$ dead $\mathrm{C}$} \\
\hline & & age $(\mathrm{y})$ & offset $(\mathrm{y})$ & age $(\mathrm{y})$ & offset $(\mathrm{y})$ & age $(\mathrm{y})$ & offset $(\mathrm{y})$ & age $(\mathrm{y})$ & offset $(y)$ \\
\hline 0 & 0 & 845 & 845 & 1791 & 1791 & 5560 & 5560 & 9653 & 9653 \\
\hline-100 & 846 & 1692 & 845 & 2637 & 1790 & 6405 & 5559 & 10497 & 9651 \\
\hline-200 & 1793 & 2638 & 845 & 3583 & 1790 & 7351 & 5558 & 11441 & 9648 \\
\hline-300 & 2865 & 3710 & 845 & 4655 & 1790 & 8422 & 5557 & 12510 & 9645 \\
\hline-400 & 4103 & 4948 & 845 & 5893 & 1789 & 9658 & 5555 & 13744 & 9640 \\
\hline-500 & 5568 & 6413 & 845 & 7357 & 1788 & 11120 & 5552 & 15202 & 9634 \\
\hline-600 & 7361 & 8205 & 844 & 9148 & 1787 & 12909 & 5548 & 16985 & 9625 \\
\hline-700 & 9672 & 10515 & 843 & 11457 & 1786 & 15213 & 5541 & 19281 & 9609 \\
\hline-800 & 12929 & 13771 & 842 & 14711 & 1782 & 18457 & 5528 & 22507 & 9578 \\
\hline-900 & 18497 & 19334 & 837 & 20269 & 1772 & 23985 & 5488 & 27983 & 9486 \\
\hline-950 & 24065 & 24893 & 829 & 25817 & 1752 & 29474 & 5409 & 33370 & 9305 \\
\hline-975 & 29633 & 30444 & 811 & 31345 & 1713 & 34886 & 5253 & 38587 & 8955 \\
\hline-999 & 55490 & 55490 & 0 & 55490 & 0 & 55490 & 0 & 55490 & 0 \\
\hline
\end{tabular}

calculated age of a sample with all modern carbon ( $0 \%$ dead carbon)

\subsubsection{Additional Implications for paleoclimate proxies}

This study has yielded unique observations that shed new light on the effects of climate on the "residence time" of OC in a drainage basin, and on the interpretation of organic geochemical proxies for paleoclimate. For example, Ponton et al. (2012) used the $\delta^{13} C_{w a x}$ record from the core that forms the basis of this study with a chronology based on planktonic foraminifera to infer past vegetation and hydroclimate changes in the Indian core monsoon zone. This record has been used to deduce a gradual aridification of the Godavari drainage basin beginning 4,000 yrs BP until 1,700 yrs PB, followed by the persistence of aridity after that. At about 4,000 yrs BP the age offset between long-chain fatty acids and planktonic foraminifera is $\sim 750 \mathrm{yrs}$, implying a lag in signal transmission from biological source to sedimentary sink. Age offsets increase as aridification intensifies, and by 2,000 yrs BP the long-chain fatty acids are $\sim 1,400$ yrs older than the planktonic foraminifera. This lag could imply that the interpreted persistence of aridityadapted plants in central India after 1,700 yrs BP started earlier in the drainage basin. The oxygen isotopic composition of planktonic foraminifera indicate that emergence of 
drought-prone conditions started as early as $\sim 3000$ years BP, but their frequency may not be captured at the current resolution of that proxy.

The observed protracted storage of terrestrial carbon in the drainage basin described above also suggests that the $\delta^{13} C_{\text {wax }}$ may be a relatively blunt or sluggish proxy for reconstructing short-lived and or less intense changes in hydroclimate under certain climatic conditions. Although frequently employed as an integrative proxy to reconstruct drainage basin-wide paleoclimate, changes in the source area (provenance) and transport times within the basin can affect the results to show responses biased by changes only occurring in sub-sectors of the drainage basin.

\subsection{Conclusions}

Radiocarbon measurements of plant wax biomarkers (long-chain fatty acids) compared to planktonic foraminifera show an increase in age offset from mid to late Holocene. When coupled with $\delta^{13} \mathrm{C}_{\mathrm{wax}}$ and bulk sediment $\varepsilon \mathrm{Nd}_{\text {detrital }}$ measurements, this suggests that increased aridity may have either slowed carbon cycling and/or transport rates, or altered the proportions and/or fluxes of fresh versus pre-aged biospheric carbon, resulting in an apparent increase of terrestrial storage times of vascular plant carbon. Either scenario implies a direct link between climate dynamics and carbon cycling within this river drainage basin.

During the early Holocene $(5,000-11,000$ yrs BP), the residence time of terrestrial carbon within the system is short, implying near-instantaneous transfer (within dating uncertainties) of terrestrial biospheric carbon from source to sink. During the mid Holocene $(5,000-2,000$ yrs BP), increased latency of terrestrial carbon within the system appears to accompany the onset of aridification in central India. During the late Holocene $(2,000-0$ yrs BP), the climate turned arid, resulting in a shift in vegetation type towards a preponderance of $\mathrm{C}_{4}$ biomass. The increasing age offsets during this period may stem from slower carbon turnover within soils coupled with enhanced 
exhumation of old soil $\mathrm{OM}$ as a consequence of greater erosion under more arid conditions and anthropogenic pertubation.

Irrespective of the underlying mechanisms and processes, the marked variations in storage time and/or proportions of fresh versus aged biospheric carbon under progressively more arid conditions imply there is direct a climatic effect on the flow of OC through the drainage basin. This poses problems for paleoclimate reconstructions using long-chain fatty acids and possibly other terrestrial proxies - both organic and inorganic - as well. Climate-driven modulation of terrestrial biomarker transfer times through the river drainage basin and to the ocean may cause variable offsets of the associated proxy signal when interpreted using a chronology based on marine sedimentary components. Furthermore, when there is enhanced exhumation of old soil $\mathrm{OM}$, only a small fraction of the long-chain fatty acid $\delta^{13} \mathrm{C}$ signal will actually reflect instantaneous vegetation responses within the drainage basin. Clearly, many aspects of the carbon cycle remain poorly understood, and important questions concerning the transfer of organic matter from continents to oceans remain unresolved.

\section{References}

Asouti, E. and D.Q. Fuller. 2008. Trees and Woodlands in South India, Archaeological Perspectives. Walnut Creek (California): Left Coast Press.

Blair, N. E., K. Fournillier, E. L. Leithold, and L. B. Childress. 2010. Resolving organic carbon of differing diagenetic/catagenetic states in riverine and marine sediments. Geochimica Et Cosmochimica Acta 74 (12):A95-A95.

Blair, N. E., E. L. Leithold, and R. C. Aller. 2004. From bedrock to burial: the evolution of particulate organic carbon across coupled watershed-continental margin systems. Marine Chemistry 92 (1-4):141-156.

Bookhagen, B., D. Fleitmann, K. Nishiizurrli, M. R. Strecker, and R. C. Thiede. 2006. Holocene monsoonal dynamics and fluvial terrace formation in the northwest Himalaya, India. Geology 34 (7):601-604. 
Butzer, K. W., J. T. Abbott, C. D. Frederick, P. H. Lehman, C. E. Cordova, and J. F. Oswald. 2008. Soil-geomorphology and "wet" cycles in the Holocene record of NorthCentral Mexico. Geomorphology 101 (1-2):237-277.

Clift, P. D., and J. Blusztajn. 2005. Reorganization of the western Himalayan river system after five million years ago. Nature 438 (7070):1001-1003.

Colin, C., L. Turpin, J. Bertaux, A. Desprairies, and C. Kissel. 1999. Erosional history of the Himalayan and Burman ranges during the last two glacial-interglacial cycles. Earth and Planetary Science Letters 171 (4):647-660.

DePaolo, D.J., 1988. Neodymium Isotope Geochemistry, An Introduction. SpringerVerlag, Berlin, 187 p.

Drenzek N. J. 2007. The temporal dynamics of terrestrial organic matter transfer to the oceans: initial assessment and application. Ph. D. thesis, MIT/WHOI Joint Program in Oceanography/Applied Ocean Science and Engineering.

Drenzek, N. J., K. A. Hughen, D. B. Montlucon, J. R. Southon, G. M. dos Santos, E. R. M. Druffel, L. Giosan, and T. I. Eglinton. 2009. A new look at old carbon in active margin sediments. Geology 37 (3):239-242.

Dutta, K., R. Bhushan, and B. L. K. Somayajulu. 2001. Delta R correction values for the northern Indian Ocean. Radiocarbon 43 (2A):483-488.

Fisher, E., F. Oldfield, R. Wake, J. Boyle, P. Appleby, and G. A. Wolff. 2003. Molecular marker records of land use change. Organic Geochemistry 34 (1):105-119.

Galy, V., Eglinton, T.I. 2011. Protracted storage of biospheric carbon in the GangesBrahmaputra basin. Nature Geoscience 4:843-847.

Galy, V., C. France-Lanord, O. Beyssac, B. Lartiges, and M. Rhaman. 2011. Organic Carbon Cycling During Himalayan Erosion: Processes, Fluxes and Consequences for the Global Carbon Cycle. In Climate Change and Food Security in South Asia, edited by R. Lal, M. V. K. Sivakumar, S. M. A. M. A. Faiz, A. H. M. H. M. M. Mustafizur Rahman and K. R. R. Islam: Springer Netherlands.

Galy, V., C. France-Lanord, and B. Lartiges. 2008. Loading and fate of particulate organic carbon from the Himalaya to the Ganga-Brahmaputra delta. Geochimica Et Cosmochimica Acta 72 (7):1767-1787. 
Gustafsson, O., B. E. van Dongen, J. E. Vonk, O. V. Dudarev, and I. P. Semiletov. 2011. Widespread release of old carbon across the Siberian Arctic echoed by its large rivers. Biogeosciences 8 (6):1737-1743.

Hedges, J. I., and J. M. Oades. 1997. Comparative organic geochemistries of soils and marine sediments. Organic Geochemistry 27 (7-8):319-361.

Hill, C.V. 2008. South Asia - An environmental history. Santa Barbara (California): ABC-Clio Inc.

Kusch, S., J. Rethemeyer, E. Schefuss, and G. Mollenhauer. 2010a. Controls on the age of vascular plant biomarkers in Black Sea sediments. Geochimica et Cosmochimica Acta 74 (24):7031-7047.

Kusch, S., T. I. Eglinton, A. C. Mix, and G. Mollenhauer. 2010b. Timescales of lateral sediment transport in the Panama Basin as revealed by radiocarbon ages of alkenones, total organic carbon and foraminifera. Earth and Planetary Science Letters 290 (3-4):340350 .

Mollenhauer, G., and T. I. Eglinton. 2007. Diagenetic and sedimentological controls on the composition of organic matter preserved in California Borderland Basin sediments. Limnology and Oceanography 52 (2):558-576.

Molnar, P., R. S. Anderson, G. Kier, and J. Rose. 2006. Relationships among probability distributions of stream discharges in floods, climate, bed load transport, and river incision. Journal of Geophysical Research-Earth Surface 111 (F2).

Murthy, M. V. K., P. K. Padhy, and D. N. Prasad. 2011. Mesozoic hydrogeologic systems and hydrocarbon habitat, Mandapeta-Endamuru area, Krishna Godavari Basin, India. AAPG Bulletin 95 (1):147-167.

Ohkouchi, N., T. I. Eglinton, L. D. Keigwin, and J. M. Hayes. 2002. Spatial and temporal offsets between proxy records in a sediment drift. Science 298 (5596):1224-1227.

Ponton, C., L. Giosan, T. I. Eglinton, D. Q. Fuller, J. E. Johnson, P. Kumar, and T. S. Collett. 2012. Holocene aridification of India. Geophysical Research Letters (39) L03704, doi:10.1029/2011GL050722.

Quideau, S. A., O. A. Chadwick, A. Benesi, R. C. Graham, and M. A. Anderson. 2001. A direct link between forest vegetation type and soil organic matter composition. Geoderma 104 (1-2):41-60.

Ruff, M., L. Wacker, H. W. Gaggeler, M. Suter, H. A. Synal, and S. Szidat. 2007. A gas ion source for radiocarbon measurements at $200 \mathrm{kV}$. Radiocarbon 49 (2):307-314. 
Santos, G. M., J. R. Southon, N. J. Drenzek, L. A. Ziolkowski, E. Druffel, X. M. Xu, D. C. Zhang, S. Trumbore, T. I. Eglinton, and K. A. Hughen. 2010. Blank assessment for ultra-small radiocarbon samples: chemical extraction and separation versus AMS. Radiocarbon 52 (3):1322-1335.

Schimel, J. P., J. A. M. Wetterstedt, P. A. Holden, and S. E. Trumbore. 2011. Drying/rewetting cycles mobilize old $\mathrm{C}$ from deep soils from a California annual grassland. Soil Biology \& Biochemistry 43 (5):1101-1103.

Southon, J., M. Kashgarian, M. Fontugne, B. Metivier, and W. W. S. Yim. 2002. Marine reservoir corrections for the Indian Ocean and southeast Asia. Radiocarbon 44 (1):167180.

Stuiver, M., and H. A. Polach. 1977. Reporting of C-14 data - Discussion. Radiocarbon 19 (3):355-363.

Stuiver, M., and H. G. Ostlund. 1983. GEOSECS Indian-ocean and Mediterranean radiocarbon. Radiocarbon 25 (1):1-29.

Stuiver, M., G. W. Pearson, and T. Braziunas. 1986. Radiocarbon age calibration of marine samples back to 9000 cal yr bp. Radiocarbon 28 (2B):980-1021.

Syvitski, J. P. M., C. J. Vorosmarty, A. J. Kettner, and P. Green. 2005. Impact of humans on the flux of terrestrial sediment to the global coastal ocean. Science 308 (5720):376380 .

Trumbore, S. E. 1997. Potential responses of soil organic carbon to global environmental change. Proceedings of the National Academy of Sciences of the United States of America 94 (16):8284-8291.

Tucker, G. E. 2004. Drainage basin sensitivity to tectonic and climatic forcing: Implications of a stochastic model for the role of entrainment and erosion thresholds. Earth Surface Processes and Landforms 29 (2):185-205.

Wang, Y., R. Amundson, and S. Trumbore. 1999. The impact of land use change on C turnover in soils. Global Biogeochemical Cycles 13 (1):47-57.

Yang, H., Y. Yuan, Q. Zhang, J. Tang, Y. Liu, and X. Chen. 2011. Changes in soil organic carbon, total nitrogen, and abundance of arbuscular mycorrhizal fungi along a large-scale aridity gradient. Catena 87 (1):70-77. 


\section{Supplementary Information}

Table S1. TOC and fatty acid estimated fluxes.

\begin{tabular}{ccccccc}
$\begin{array}{c}\text { Depth interval } \\
(\mathrm{m})\end{array}$ & $\begin{array}{c}\text { MAR } \\
\left(\mathrm{g} \mathrm{sed} / \mathrm{cm}^{2} \cdot \mathrm{ky}^{*}\right.\end{array}$ & $\begin{array}{c}\text { TOC } \\
\text { concentration } \\
(\mathrm{g} \mathrm{C} / \mathrm{g} \mathrm{sed})\end{array}$ & $\begin{array}{c}\text { TOC flux } \\
\left(\mathrm{gC} / \mathrm{cm}^{2} \cdot \mathrm{ky}\right)\end{array}$ & $\begin{array}{c}\text { Fatty acid } \\
\text { concentration } \\
(\mathrm{ug} / \mathrm{g})^{\star *}\end{array}$ & $\begin{array}{c}\text { Fatty acid } \\
\text { flux } \\
\left(\mathrm{ugC} / \mathrm{cm}^{2} \cdot \mathrm{ky}\right)\end{array}$ & $\begin{array}{c}\text { Foram age } \\
(\mathrm{y})\end{array}$ \\
\hline \hline $0.06-0.09$ & 87.0 & 0.0133 & 1.157 & 1.35 & 117.7 & 0 \\
$1.46-1.49$ & 151.2 & 0.0137 & 2.071 & 2.70 & 407.8 & 1104 \\
$2.96-2.99$ & 70.7 & 0.0169 & 1.198 & 1.26 & 88.9 & 1852 \\
$4.03-4.06$ & 47.8 & 0.0191 & 0.912 & 2.23 & 106.4 & 2895 \\
$4.76-4.79$ & 41.8 & 0.0194 & 0.810 & 3.86 & 161.2 & 4046 \\
$5.34-5.37$ & 49.2 & 0.0205 & 1.007 & 3.69 & 181.4 & 5331 \\
$6-6.03$ & 31.0 & 0.0196 & 0.608 & 3.19 & 98.9 & 5996 \\
$6.42-6.45$ & 31.0 & 0.0191 & 0.592 & 2.76 & 85.6 & 6198 \\
$7.2-7.23$ & 23.7 & 0.0171 & 0.405 & 2.75 & 65.3 & 9056 \\
$7.64-7.67$ & 23.7 & 0.0175 & 0.414 & -- & -- & 10314 \\
$7.87-7.9$ & 25.8 & 0.0184 & 0.475 & 2.96 & 76.5 & 10619 \\
\hline
\end{tabular}

${ }^{*}$ Mass accumulation rate

${ }^{* *} \mathrm{C}_{26}$ to $\mathrm{C}_{32}$ 
Table S2. Fatty acid $\delta^{13} \mathrm{C}$ data

\begin{tabular}{ccc|ccc}
$\begin{array}{c}\text { Depth interval } \\
(\mathrm{m})\end{array}$ & $\begin{array}{c}\text { Fatty acid } \\
\delta^{13} \mathrm{C}(\% \circ)^{*}\end{array}$ & $\begin{array}{c}\text { Foram } \\
\text { age }(\mathrm{y})\end{array}$ & $\begin{array}{c}\text { Depth interval } \\
(\mathrm{m})\end{array}$ & $\begin{array}{c}\text { Fatty acid } \\
\delta^{13} \mathrm{C}(\% \circ)^{*}\end{array}$ & $\begin{array}{c}\text { Foram } \\
\text { age }(\mathrm{y})\end{array}$ \\
\hline \hline $0.00-0.02$ & -24.43 & 0 & $4.40-4.42$ & -26.83 & 4115 \\
$0.20-0.22$ & -24.03 & 147 & $4.60-4.62$ & -26.80 & 4462 \\
$0.40-0.42$ & -24.72 & 294 & $4.80-4.82$ & -27.72 & 4636 \\
$0.60-0.62$ & -23.39 & 442 & $5.00-5.02$ & -29.37 & 4809 \\
$0.80-0.82$ & -24.77 & 600 & $5.10-5.12$ & -28.13 & 5106 \\
$1.00-1.02$ & -24.57 & 761 & $5.20-5.22$ & -27.55 & 5403 \\
$1.20-1.22$ & -24.17 & 921 & $5.40-5.42$ & -27.85 & 5699 \\
$1.40-1.42$ & -24.02 & 1082 & $5.60-5.62$ & -28.80 & 5996 \\
$1.60-1.62$ & -23.48 & 1171 & $5.80-5.82$ & -28.49 & 6468 \\
$1.70-1.72$ & -24.70 & 1215 & $6.00-6.02$ & -27.79 & 6940 \\
$1.90-1.92$ & -24.30 & 1304 & $6.20-6.22$ & -28.89 & 7412 \\
$2.10-2.12$ & -23.60 & 1393 & $6.40-6.42$ & -28.23 & 7648 \\
$2.20-2.22$ & -24.38 & 1437 & $6.60-6.62$ & -26.82 & 7884 \\
$2.40-2.42$ & -24.81 & 1526 & $6.70-6.72$ & -29.27 & 8120 \\
$2.50-2.52$ & -24.46 & 1571 & $6.80-6.82$ & -29.10 & 8356 \\
$2.60-2.62$ & -26.05 & 1615 & $6.90-6.92$ & -28.50 & 8652 \\
$2.70-2.72$ & -25.32 & 1660 & $7.00-7.02$ & -28.83 & 8949 \\
$2.80-2.82$ & -26.09 & 1903 & $7.10-7.12$ & -28.63 & 9245 \\
$2.90-2.92$ & -25.47 & 2101 & $7.20-7.22$ & -28.98 & 9541 \\
$3.00-3.02$ & -26.06 & 2300 & $7.30-7.32$ & -30.19 & 9838 \\
$3.20-3.22$ & -25.38 & 2498 & $7.40-7.42$ & -28.64 & 10134 \\
$3.40-3.42$ & -26.13 & 2697 & $7.50-7.52$ & -27.94 & 10430 \\
$3.60-3.62$ & -24.74 & 2895 & $7.60-7.62$ & -28.02 & 10726 \\
$3.80-3.82$ & -26.78 & 3186 & $7.70-7.72$ & -27.22 & 11023 \\
$4.00-4.02$ & -25.34 & 3477 & $7.80-7.82$ & -26.83 & 11319 \\
$4.20-4.22$ & -27.04 & 3769 & & & \\
\hline & & & &
\end{tabular}

weighted average from $\mathrm{C}_{26}$ to $\mathrm{C}_{32}$ 
Table S3. Nd isotopic data

\begin{tabular}{lccc} 
Depth $(\mathrm{m})$ & ${ }^{143} \mathrm{Nd} /{ }^{144} \mathrm{Nd}$ & $\varepsilon \mathrm{Nd}$ & foram age $(\mathrm{y})$ \\
\hline \hline 0.00 & 0.51200 & -12.4649 & 0 \\
0.16 & 0.51197 & -12.9721 & 118 \\
0.32 & 0.51204 & -11.7627 & 239 \\
0.80 & 0.51195 & -13.4988 & 601 \\
1.70 & 0.51202 & -12.0943 & 1215 \\
2.50 & 0.51195 & -13.5183 & 1570 \\
3.00 & 0.51189 & -14.6302 & 1902 \\
3.60 & 0.51189 & -14.6302 & 2498 \\
4.00 & 0.51183 & -15.7616 & 2895 \\
4.80 & 0.51178 & -16.7370 & 4115 \\
5.40 & 0.51181 & -16.1713 & 5106 \\
6.00 & 0.51185 & -15.4300 & 5996 \\
6.50 & 0.51186 & -15.2544 & 7176 \\
6.90 & 0.51183 & -15.7226 & 8120 \\
7.20 & 0.51180 & -16.3273 & 8949 \\
7.60 & 0.51182 & -15.9177 & 10134 \\
\hline
\end{tabular}


Table S4. $\delta^{18}$ O G. ruber data

Sealevel

Depth interval $\quad \delta^{13} \mathrm{C} \quad \delta^{18} \mathrm{O} \quad$ corrected $\delta^{18} \mathrm{O} \quad$ Foram age

\begin{tabular}{|c|c|c|c|c|}
\hline (m) & $(\%))^{*}$ & $(\%)^{*}$ & $(\%)$ & (y) \\
\hline $0.000-0.020$ & 0.02 & -2.82 & -2.82 & 0 \\
\hline $0.025-0.045$ & -0.43 & -2.48 & -2.48 & 18 \\
\hline $0.050-0.070$ & 0.60 & -1.93 & -1.93 & 37 \\
\hline $0.075-0.095$ & 0.13 & -2.70 & -2.70 & 55 \\
\hline $0.100-0.120$ & 0.02 & -2.50 & -2.50 & 74 \\
\hline $0.125-0.145$ & 0.28 & -2.74 & -2.73 & 92 \\
\hline $0.150-0.170$ & -0.13 & -2.76 & -2.76 & 110 \\
\hline $0.175-0.195$ & 1.02 & -2.76 & -2.76 & 129 \\
\hline $0.200-0.220$ & 0.20 & -1.88 & -1.87 & 147 \\
\hline $0.225-0.245$ & 0.18 & -2.98 & -2.98 & 166 \\
\hline $0.250-0.270$ & 1.05 & -2.80 & -2.79 & 184 \\
\hline $0.275-0.295$ & 0.46 & -2.66 & -2.65 & 202 \\
\hline $0.300-0.320$ & 1.13 & -2.69 & -2.69 & 221 \\
\hline $0.325-0.345$ & 0.69 & -2.70 & -2.69 & 239 \\
\hline $0.350-0.370$ & 0.26 & -2.71 & -2.71 & 258 \\
\hline $0.380-0.400$ & 0.70 & -2.52 & -2.52 & 280 \\
\hline $0.400-0.420$ & 0.52 & -2.81 & -2.80 & 294 \\
\hline $0.425-0.445$ & -0.14 & -2.75 & -2.74 & 313 \\
\hline $0.450-0.470$ & 0.98 & -2.46 & -2.46 & 331 \\
\hline $0.475-0.495$ & 0.34 & -2.74 & -2.73 & 350 \\
\hline $0.500-0.520$ & 0.61 & -2.18 & -2.17 & 368 \\
\hline $0.525-0.545$ & 0.79 & -2.67 & -2.66 & 386 \\
\hline $0.550-0.570$ & 1.32 & -2.66 & -2.66 & 405 \\
\hline $0.575-0.595$ & 0.52 & -3.14 & -3.13 & 423 \\
\hline $0.600-0.620$ & 0.54 & -2.42 & -2.41 & 442 \\
\hline $0.625-0.645$ & 0.01 & -2.83 & -2.82 & 460 \\
\hline $0.650-0.670$ & 1.55 & -2.71 & -2.70 & 480 \\
\hline $0.675-0.695$ & -0.44 & -2.78 & -2.76 & 500 \\
\hline
\end{tabular}


Table S4 cont.

\begin{tabular}{|c|c|c|c|c|}
\hline $\begin{array}{l}\text { Depth interval } \\
(\mathrm{m})\end{array}$ & $\begin{array}{l}\delta^{13} \mathrm{C} \\
(\% \circ)^{*}\end{array}$ & $\begin{array}{l}\delta^{18} \mathrm{O} \\
(\% \circ)^{*}\end{array}$ & $\begin{array}{c}\text { Sealevel } \\
\text { corrected } \delta^{18} \mathrm{O} \\
(\%) \\
\end{array}$ & $\begin{array}{c}\text { Foram age } \\
(\mathrm{y})\end{array}$ \\
\hline $0.700-0.720$ & 1.43 & -2.71 & -2.68 & 520 \\
\hline $0.725-0.745$ & 0.11 & -2.97 & -2.94 & 540 \\
\hline $0.750-0.770$ & 0.73 & -2.87 & -2.84 & 560 \\
\hline $0.775-0.795$ & 0.79 & -2.95 & -2.92 & 580 \\
\hline $0.800-0.820$ & 0.45 & -2.40 & -2.37 & 600 \\
\hline $0.825-0.845$ & 0.40 & -2.55 & -2.52 & 621 \\
\hline $0.850-0.870$ & 0.41 & -2.87 & -2.83 & 641 \\
\hline $0.875-0.895$ & 0.21 & -2.95 & -2.92 & 661 \\
\hline $0.925-0.945$ & 0.34 & -2.56 & -2.53 & 701 \\
\hline $0.950-0.970$ & 0.52 & -2.86 & -2.83 & 721 \\
\hline $0.975-0.995$ & 0.91 & -2.27 & -2.24 & 741 \\
\hline $1.000-1.020$ & 0.51 & -2.63 & -2.60 & 761 \\
\hline $1.025-1.045$ & 0.79 & -2.65 & -2.62 & 781 \\
\hline $1.050-1.070$ & 1.10 & -2.56 & -2.52 & 801 \\
\hline $1.075-1.095$ & -0.04 & -2.70 & -2.67 & 821 \\
\hline $1.100-1.120$ & 1.17 & -2.79 & -2.76 & 841 \\
\hline $1.125-1.145$ & 0.03 & -3.06 & -3.03 & 861 \\
\hline $1.150-1.170$ & 0.68 & -1.59 & -1.56 & 881 \\
\hline $1.175-1.195$ & -0.61 & -3.27 & -3.24 & 901 \\
\hline $1.200-1.220$ & 0.21 & -2.52 & -2.49 & 921 \\
\hline $1.225-1.245$ & -0.17 & -3.27 & -3.24 & 942 \\
\hline $1.250-1.270$ & 1.58 & -2.62 & -2.59 & 962 \\
\hline $1.275-1.295$ & 0.47 & -2.97 & -2.93 & 982 \\
\hline $1.325-1.345$ & 0.32 & -3.00 & -2.97 & 1022 \\
\hline $1.375-1.395$ & 0.38 & -2.89 & -2.86 & 1062 \\
\hline $1.400-1.420$ & 0.68 & -2.69 & -2.66 & 1082 \\
\hline $1.425-1.445$ & 0.86 & -2.68 & -2.65 & 1093 \\
\hline $1.450-1.470$ & 0.99 & -2.57 & -2.54 & 1104 \\
\hline $1.475-1.495$ & -0.10 & -2.77 & -2.74 & 1115 \\
\hline $1.500-1.520$ & 0.42 & -2.88 & -2.84 & 1126 \\
\hline
\end{tabular}


Table S4 cont.

Sealevel

\begin{tabular}{|c|c|c|c|c|}
\hline $\begin{array}{l}\text { Depth interval } \\
(\mathrm{m})\end{array}$ & $\begin{array}{l}\delta^{13} \mathrm{C} \\
(\% \circ)^{*}\end{array}$ & $\begin{array}{l}\delta^{18} \mathrm{O} \\
(\% \circ)^{*}\end{array}$ & $\begin{array}{c}\text { corrected } \delta^{18} \mathrm{O} \\
(\% \circ)\end{array}$ & $\begin{array}{c}\text { Foram age } \\
(\mathrm{y})\end{array}$ \\
\hline $1.550-1.570$ & 0.44 & -2.49 & -2.46 & 1149 \\
\hline $1.600-1.620$ & 0.62 & -2.61 & -2.58 & 1171 \\
\hline $1.680-1.700$ & 0.42 & -2.97 & -2.94 & 1206 \\
\hline $1.700-1.720$ & 0.38 & -2.80 & -2.77 & 1215 \\
\hline $1.750-1.770$ & 0.91 & -2.79 & -2.76 & 1238 \\
\hline $1.800-1.820$ & 0.38 & -2.40 & -2.37 & 1260 \\
\hline $1.850-1.870$ & 0.58 & -2.28 & -2.25 & 1282 \\
\hline $1.900-1.920$ & 0.04 & -1.94 & -1.91 & 1304 \\
\hline $1.950-1.970$ & 0.65 & -2.24 & -2.21 & 1326 \\
\hline $2.000-2.020$ & 0.04 & -2.65 & -2.63 & 1349 \\
\hline $2.050-2.070$ & 0.67 & -2.46 & -2.44 & 1371 \\
\hline $2.100-2.120$ & 0.41 & -1.86 & -1.84 & 1393 \\
\hline $2.150-2.170$ & 1.07 & -2.25 & -2.23 & 1415 \\
\hline $2.200-2.220$ & 1.02 & -2.65 & -2.62 & 1437 \\
\hline $2.250-2.270$ & 0.93 & -1.94 & -1.91 & 1460 \\
\hline $2.300-2.320$ & -0.36 & -2.07 & -2.04 & 1482 \\
\hline $2.350-2.370$ & 1.13 & -2.34 & -2.30 & 1504 \\
\hline $2.400-2.420$ & 1.25 & -2.43 & -2.38 & 1526 \\
\hline $2.450-2.470$ & 1.12 & -2.54 & -2.50 & 1549 \\
\hline $2.480-2.500$ & 0.66 & -2.78 & -2.74 & 1562 \\
\hline $2.500-2.520$ & -0.90 & -2.83 & -2.80 & 1571 \\
\hline $2.550-2.570$ & 1.62 & -2.27 & -2.23 & 1593 \\
\hline $2.600-2.620$ & 1.04 & -2.00 & -1.97 & 1615 \\
\hline $2.650-2.670$ & 1.42 & -2.38 & -2.36 & 1637 \\
\hline $2.680-2.700$ & 0.99 & -2.58 & -2.56 & 1651 \\
\hline $2.700-2.720$ & 0.10 & -1.89 & -1.87 & 1660 \\
\hline $2.750-2.770$ & 0.93 & -2.49 & -2.48 & 1682 \\
\hline $2.800-2.820$ & 0.19 & -2.48 & -2.46 & 1704 \\
\hline $2.850-2.870$ & 1.09 & -2.47 & -2.45 & 1754 \\
\hline $2.875-2.895$ & 0.56 & -2.65 & -2.62 & 1778 \\
\hline
\end{tabular}


Table S4 cont.

Sealevel

\begin{tabular}{|c|c|c|c|c|}
\hline $\begin{array}{l}\text { Depth interval } \\
(\mathrm{m})\end{array}$ & $\begin{array}{l}\delta^{13} \mathrm{C} \\
(\% \circ)^{*}\end{array}$ & $\begin{array}{l}\delta^{18} \mathrm{O} \\
(\% \circ)^{*}\end{array}$ & $\begin{array}{c}\text { corrected } \delta^{18} \mathrm{O} \\
(\%)\end{array}$ & $\begin{array}{c}\text { Foram age } \\
(\mathrm{y})\end{array}$ \\
\hline $2.900-2.920$ & 0.68 & -2.70 & -2.68 & 1803 \\
\hline $2.925-2.945$ & 0.10 & -2.84 & -2.82 & 1828 \\
\hline $2.950-2.970$ & 0.29 & -2.78 & -2.76 & 1853 \\
\hline $2.980-3.000$ & 0.03 & -2.85 & -2.82 & 1883 \\
\hline $3.000-3.020$ & -0.28 & -2.88 & -2.85 & 1903 \\
\hline $3.025-3.045$ & 0.97 & -2.58 & -2.55 & 1927 \\
\hline $3.050-3.070$ & 0.90 & -2.77 & -2.74 & 1952 \\
\hline $3.075-3.095$ & 0.83 & -2.57 & -2.54 & 1977 \\
\hline $3.100-3.120$ & 0.91 & -2.63 & -2.60 & 2002 \\
\hline $3.125-3.145$ & 0.31 & -2.79 & -2.76 & 2027 \\
\hline $3.150-3.170$ & 0.80 & -2.61 & -2.59 & 2051 \\
\hline $3.180-3.200$ & -0.02 & -2.64 & -2.61 & 2081 \\
\hline $3.200-3.220$ & 1.22 & -2.82 & -2.79 & 2101 \\
\hline $3.225-3.245$ & 1.06 & -2.59 & -2.56 & 2126 \\
\hline $3.250-3.270$ & 1.25 & -2.52 & -2.49 & 2151 \\
\hline $3.275-3.295$ & 1.16 & -2.81 & -2.77 & 2175 \\
\hline $3.300-3.320$ & 0.67 & -2.72 & -2.69 & 2200 \\
\hline $3.325-3.345$ & 1.22 & -2.55 & -2.52 & 2225 \\
\hline $3.350-3.370$ & 0.62 & -2.91 & -2.88 & 2250 \\
\hline $3.375-3.395$ & 1.20 & -2.76 & -2.72 & 2275 \\
\hline $3.400-3.420$ & 0.55 & -2.70 & -2.66 & 2300 \\
\hline $3.425-3.445$ & 1.01 & -2.75 & -2.72 & 2324 \\
\hline $3.450-3.470$ & 0.94 & -2.33 & -2.30 & 2349 \\
\hline $3.475-3.495$ & 1.69 & -2.47 & -2.44 & 2374 \\
\hline $3.500-3.520$ & 1.18 & -2.95 & -2.92 & 2399 \\
\hline $3.525-3.545$ & 1.18 & -2.66 & -2.63 & 2424 \\
\hline $3.550-3.570$ & 0.81 & -2.66 & -2.62 & 2448 \\
\hline $3.575-3.595$ & 0.71 & -2.86 & -2.82 & 2473 \\
\hline $3.600-3.620$ & 1.51 & -2.64 & -2.61 & 2498 \\
\hline $3.625-3.645$ & 0.32 & -2.73 & -2.69 & 2523 \\
\hline
\end{tabular}


Table S4 cont.

Sealevel

\begin{tabular}{|c|c|c|c|c|}
\hline $\begin{array}{l}\text { Depth interval } \\
(\mathrm{m})\end{array}$ & $\begin{array}{l}\delta^{13} \mathrm{C} \\
(\% \circ)^{*}\end{array}$ & $\begin{array}{l}\delta^{18} \mathrm{O} \\
(\%)^{*}\end{array}$ & $\begin{array}{c}\text { corrected } \delta^{18} \mathrm{O} \\
(\% \circ)\end{array}$ & $\begin{array}{c}\text { Foram age } \\
(\mathrm{y})\end{array}$ \\
\hline $3.650-3.670$ & 1.34 & -2.57 & -2.53 & 2548 \\
\hline $3.675-3.695$ & 1.24 & -2.59 & -2.55 & 2572 \\
\hline $3.700-3.720$ & 1.01 & -2.51 & -2.46 & 2597 \\
\hline $3.725-3.745$ & 0.02 & -2.88 & -2.84 & 2622 \\
\hline $3.750-3.770$ & 0.27 & -2.55 & -2.50 & 2647 \\
\hline $3.775-3.795$ & 1.01 & -2.64 & -2.60 & 2672 \\
\hline $3.800-3.820$ & 1.34 & -1.55 & -1.51 & 2697 \\
\hline $3.825-3.845$ & 1.00 & -2.75 & -2.71 & 2721 \\
\hline $3.850-3.870$ & 0.56 & -2.13 & -2.08 & 2746 \\
\hline $3.875-3.895$ & 1.03 & -2.64 & -2.59 & 2771 \\
\hline $3.900-3.920$ & 0.70 & -2.63 & -2.59 & 2796 \\
\hline $3.925-3.945$ & 0.83 & -2.62 & -2.58 & 2821 \\
\hline $3.950-3.970$ & 0.81 & -2.64 & -2.59 & 2845 \\
\hline $3.975-3.995$ & 0.71 & -2.65 & -2.60 & 2870 \\
\hline $4.000-4.020$ & 0.66 & -2.61 & -2.56 & 2895 \\
\hline $4.020-4.040$ & 0.92 & -2.68 & -2.63 & 2924 \\
\hline $4.050-4.070$ & 0.62 & -2.72 & -2.67 & 2968 \\
\hline $4.075-4.095$ & 1.29 & -2.94 & -2.89 & 3004 \\
\hline $4.100-4.120$ & 0.86 & -2.60 & -2.54 & 3041 \\
\hline $4.125-4.145$ & 1.00 & -2.92 & -2.87 & 3077 \\
\hline $4.150-4.170$ & 1.56 & -2.72 & -2.66 & 3113 \\
\hline $4.175-4.195$ & 1.41 & -2.63 & -2.57 & 3150 \\
\hline $4.200-4.220$ & 0.03 & -2.77 & -2.71 & 3186 \\
\hline $4.225-4.245$ & 1.29 & -2.66 & -2.60 & 3223 \\
\hline $4.250-4.270$ & 0.97 & -2.69 & -2.63 & 3259 \\
\hline $4.275-4.295$ & 1.42 & -2.87 & -2.81 & 3295 \\
\hline $4.300-4.320$ & 0.51 & -2.73 & -2.67 & 3332 \\
\hline $4.325-4.345$ & 1.40 & -2.80 & -2.74 & 3368 \\
\hline $4.350-4.370$ & 0.38 & -2.64 & -2.59 & 3405 \\
\hline $4.380-4.400$ & 0.27 & -2.58 & -2.52 & 3448 \\
\hline
\end{tabular}


Table S4 cont.

Sealevel

\begin{tabular}{|c|c|c|c|c|}
\hline $\begin{array}{l}\text { Depth interval } \\
(\mathrm{m})\end{array}$ & $\begin{array}{l}\delta^{13} \mathrm{C} \\
(\% \circ)^{*}\end{array}$ & $\begin{array}{l}\delta^{18} \mathrm{O} \\
(\% \circ)^{*}\end{array}$ & $\begin{array}{c}\text { corrected } \delta^{18} \mathrm{O} \\
(\% \circ)\end{array}$ & $\begin{array}{c}\text { Foram age } \\
(\mathrm{y})\end{array}$ \\
\hline $4.400-4.420$ & 0.50 & -2.88 & -2.82 & 3477 \\
\hline $4.425-4.445$ & 1.22 & -2.84 & -2.78 & 3514 \\
\hline $4.450-4.470$ & 0.70 & -3.00 & -2.94 & 3550 \\
\hline $4.475-4.495$ & 1.55 & -3.12 & -3.07 & 3587 \\
\hline $4.500-4.520$ & 1.34 & -2.42 & -2.37 & 3623 \\
\hline $4.525-4.545$ & 0.78 & -2.85 & -2.80 & 3659 \\
\hline $4.550-4.570$ & 0.69 & -3.15 & -3.10 & 3696 \\
\hline $4.580-4.600$ & 0.71 & -3.16 & -3.12 & 3739 \\
\hline $4.600-4.620$ & 1.15 & -2.83 & -2.78 & 3769 \\
\hline $4.625-4.645$ & 1.60 & -2.59 & -2.54 & 3812 \\
\hline $4.650-4.670$ & 0.28 & -2.99 & -2.93 & 3855 \\
\hline $4.675-4.695$ & 1.63 & -2.65 & -2.58 & 3899 \\
\hline $4.700-4.720$ & 1.02 & -2.68 & -2.61 & 3942 \\
\hline $4.725-4.745$ & 1.25 & -2.89 & -2.82 & 3985 \\
\hline $4.750-4.770$ & 0.76 & -2.86 & -2.80 & 4029 \\
\hline $4.800-4.820$ & 0.52 & -2.49 & -2.43 & 4115 \\
\hline $4.825-4.845$ & 1.48 & -2.53 & -2.46 & 4159 \\
\hline $4.850-4.870$ & 1.43 & -2.78 & -2.72 & 4202 \\
\hline $4.875-4.895$ & 1.10 & -2.97 & -2.91 & 4245 \\
\hline $4.900-4.920$ & 0.62 & -2.88 & -2.82 & 4289 \\
\hline $4.925-4.945$ & 1.54 & -2.50 & -2.44 & 4332 \\
\hline $4.950-4.970$ & 1.24 & -3.01 & -2.95 & 4375 \\
\hline $4.975-4.995$ & 1.39 & -2.67 & -2.61 & 4419 \\
\hline $5.000-5.020$ & 1.15 & -2.81 & -2.75 & 4462 \\
\hline $5.025-5.045$ & 1.40 & -2.73 & -2.67 & 4506 \\
\hline $5.050-5.070$ & 0.81 & -2.92 & -2.86 & 4549 \\
\hline $5.075-5.095$ & 0.90 & -2.84 & -2.78 & 4592 \\
\hline $5.100-5.120$ & 0.91 & -2.91 & -2.85 & 4636 \\
\hline $5.150-5.170$ & 1.16 & -3.04 & -2.99 & 4722 \\
\hline $5.180-5.200$ & 0.73 & -2.87 & -2.81 & 4774 \\
\hline
\end{tabular}


Table S4 cont.

Sealevel

\begin{tabular}{|c|c|c|c|c|}
\hline $\begin{array}{l}\text { Depth interval } \\
(\mathrm{m})\end{array}$ & $\begin{array}{l}\delta^{13} \mathrm{C} \\
(\% 0)^{*} \\
\end{array}$ & $\begin{array}{l}\delta^{18} \mathrm{O} \\
(\% 0)^{*} \\
\end{array}$ & $\begin{array}{c}\text { corrected } \delta^{18} \mathrm{O} \\
(\% \circ)\end{array}$ & $\begin{array}{c}\text { Foram age } \\
(\mathrm{y})\end{array}$ \\
\hline $5.200-5.220$ & 0.29 & -2.74 & -2.68 & 4809 \\
\hline $5.225-5.245$ & 1.32 & -2.78 & -2.73 & 4846 \\
\hline $5.250-5.270$ & 1.61 & -2.82 & -2.76 & 4883 \\
\hline $5.275-5.295$ & 1.02 & -2.70 & -2.65 & 4920 \\
\hline $5.300-5.320$ & 0.53 & -2.69 & -2.63 & 4957 \\
\hline $5.350-5.370$ & 1.20 & -2.49 & -2.43 & 5032 \\
\hline $5.375-5.395$ & 1.45 & -2.65 & -2.60 & 5069 \\
\hline $5.400-5.420$ & 1.15 & -2.81 & -2.76 & 5106 \\
\hline $5.425-5.445$ & 1.11 & -2.93 & -2.88 & 5143 \\
\hline $5.450-5.470$ & 1.33 & -2.69 & -2.63 & 5180 \\
\hline $5.475-5.495$ & 0.76 & -2.95 & -2.89 & 5217 \\
\hline $5.500-5.520$ & 0.59 & -3.29 & -3.24 & 5254 \\
\hline $5.525-5.545$ & 0.75 & -2.97 & -2.91 & 5291 \\
\hline $5.550-5.570$ & 0.81 & -2.99 & -2.94 & 5328 \\
\hline $5.575-5.595$ & 1.45 & -2.99 & -2.93 & 5365 \\
\hline $5.600-5.620$ & 0.74 & -2.97 & -2.91 & 5403 \\
\hline $5.625-5.645$ & 0.97 & -2.87 & -2.81 & 5440 \\
\hline $5.650-5.670$ & 0.51 & -2.92 & -2.86 & 5477 \\
\hline $5.675-5.695$ & 0.94 & -2.66 & -2.61 & 5514 \\
\hline $5.700-5.720$ & 1.36 & -3.02 & -2.96 & 5551 \\
\hline $5.725-5.745$ & 0.72 & -2.79 & -2.73 & 5588 \\
\hline $5.750-5.770$ & 0.70 & -2.83 & -2.77 & 5625 \\
\hline $5.775-5.795$ & 0.63 & -2.56 & -2.50 & 5662 \\
\hline $5.800-5.820$ & 0.52 & -2.94 & -2.88 & 5699 \\
\hline $5.825-5.845$ & 1.23 & -2.83 & -2.77 & 5736 \\
\hline $5.850-5.870$ & 0.28 & -2.92 & -2.86 & 5773 \\
\hline $5.880-5.900$ & 1.01 & -2.61 & -2.56 & 5818 \\
\hline $5.900-5.920$ & 0.79 & -2.85 & -2.78 & 5848 \\
\hline $5.950-5.970$ & 1.46 & -2.78 & -2.71 & 5922 \\
\hline $5.980-6.000$ & 1.10 & -2.83 & -2.77 & 5966 \\
\hline
\end{tabular}


Table S4 cont.

Sealevel

\begin{tabular}{|c|c|c|c|c|}
\hline $\begin{array}{l}\text { Depth interval } \\
(\mathrm{m})\end{array}$ & $\begin{array}{l}\delta^{13} \mathrm{C} \\
(\% \circ)^{*}\end{array}$ & $\begin{array}{l}\delta^{18} \mathrm{O} \\
(\% \circ)^{*}\end{array}$ & $\begin{array}{c}\text { corrected } \delta^{18} \mathrm{O} \\
(\% \circ)\end{array}$ & $\begin{array}{c}\text { Foram age } \\
(\mathrm{y})\end{array}$ \\
\hline $6.000-6.020$ & 0.13 & -2.67 & -2.60 & 5996 \\
\hline $6.025-6.045$ & 0.84 & -2.63 & -2.56 & 6055 \\
\hline $6.050-6.070$ & 1.16 & -2.51 & -2.44 & 6114 \\
\hline $6.075-6.095$ & 1.04 & -2.96 & -2.89 & 6173 \\
\hline $6.100-6.120$ & 1.02 & -2.90 & -2.83 & 6232 \\
\hline $6.125-6.145$ & 0.40 & -2.84 & -2.77 & 6291 \\
\hline $6.150-6.170$ & 1.07 & -2.62 & -2.54 & 6350 \\
\hline $6.175-6.195$ & 1.19 & -2.99 & -2.91 & 6409 \\
\hline $6.200-6.220$ & 0.82 & -2.71 & -2.62 & 6468 \\
\hline $6.225-6.245$ & 1.15 & -2.81 & -2.73 & 6527 \\
\hline $6.250-6.270$ & 1.10 & -2.51 & -2.43 & 6586 \\
\hline $6.275-6.295$ & 1.03 & -2.79 & -2.70 & 6645 \\
\hline $6.300-6.320$ & 0.60 & -2.53 & -2.44 & 6704 \\
\hline $6.325-6.345$ & 0.99 & -2.86 & -2.77 & 6763 \\
\hline $6.350-6.370$ & 1.02 & -2.85 & -2.76 & 6822 \\
\hline $6.375-6.395$ & 0.96 & -2.60 & -2.50 & 6881 \\
\hline $6.400-6.420$ & 0.79 & -2.76 & -2.66 & 6940 \\
\hline $6.425-6.445$ & 0.63 & -2.41 & -2.31 & 6999 \\
\hline $6.450-6.470$ & 0.85 & -2.42 & -2.32 & 7058 \\
\hline $6.475-6.495$ & 1.02 & -2.94 & -2.84 & 7117 \\
\hline $6.500-6.520$ & 0.21 & -3.07 & -2.97 & 7176 \\
\hline $6.525-6.545$ & 0.68 & -2.65 & -2.54 & 7235 \\
\hline $6.550-6.570$ & 0.80 & -2.84 & -2.74 & 7294 \\
\hline $6.575-6.595$ & 1.19 & -2.98 & -2.86 & 7353 \\
\hline $6.600-6.620$ & 1.07 & -2.77 & -2.66 & 7412 \\
\hline $6.625-6.645$ & 0.83 & -2.87 & -2.75 & 7471 \\
\hline $6.650-6.670$ & 0.63 & -2.70 & -2.59 & 7530 \\
\hline $6.675-6.695$ & 1.29 & -2.72 & -2.60 & 7589 \\
\hline $6.700-6.720$ & 1.17 & -2.86 & -2.74 & 7648 \\
\hline $6.725-6.745$ & 1.49 & -3.04 & -2.92 & 7707 \\
\hline
\end{tabular}


Table S4 cont.

Sealevel

\begin{tabular}{|c|c|c|c|c|}
\hline $\begin{array}{l}\text { Depth interval } \\
(\mathrm{m})\end{array}$ & $\begin{array}{l}\delta^{13} \mathrm{C} \\
(\% 0)^{*}\end{array}$ & $\begin{array}{l}\delta^{18} \mathrm{O} \\
(\% \circ)^{*}\end{array}$ & $\begin{array}{c}\text { corrected } \delta^{18} \mathrm{O} \\
(\% \circ)\end{array}$ & $\begin{array}{c}\text { Foram age } \\
(\mathrm{y})\end{array}$ \\
\hline $6.750-6.770$ & 1.00 & -2.53 & -2.41 & 7766 \\
\hline $6.775-6.795$ & 1.74 & -2.49 & -2.37 & 7825 \\
\hline $6.800-6.820$ & 1.16 & -2.57 & -2.44 & 7884 \\
\hline $6.825-6.845$ & 1.44 & -3.00 & -2.86 & 7943 \\
\hline $6.850-6.870$ & 0.34 & -2.72 & -2.58 & 8002 \\
\hline $6.875-6.895$ & 1.15 & -3.24 & -3.09 & 8061 \\
\hline $6.900-6.920$ & -0.30 & -2.94 & -2.79 & 8120 \\
\hline $6.925-6.945$ & 0.93 & -3.06 & -2.90 & 8179 \\
\hline $6.950-6.970$ & 0.29 & -2.96 & -2.80 & 8238 \\
\hline $6.975-6.995$ & 1.28 & -2.86 & -2.70 & 8297 \\
\hline $7.000-7.020$ & 1.10 & -2.13 & -1.96 & 8356 \\
\hline $7.025-7.045$ & 1.07 & -2.24 & -2.07 & 8430 \\
\hline $7.050-7.070$ & 0.50 & -2.79 & -2.61 & 8504 \\
\hline $7.075-7.095$ & 0.79 & -2.97 & -2.78 & 8578 \\
\hline $7.100-7.120$ & 0.37 & -2.68 & -2.50 & 8652 \\
\hline $7.125-7.145$ & 0.58 & -2.72 & -2.53 & 8726 \\
\hline $7.150-7.170$ & 0.30 & -2.48 & -2.29 & 8800 \\
\hline $7.175-7.195$ & 0.83 & -3.05 & -2.86 & 8875 \\
\hline $7.200-7.220$ & 0.67 & -3.00 & -2.80 & 8949 \\
\hline $7.225-7.245$ & 0.80 & -2.69 & -2.49 & 9023 \\
\hline $7.250-7.270$ & 0.69 & -2.64 & -2.43 & 9097 \\
\hline $7.275-7.295$ & 0.46 & -3.14 & -2.93 & 9171 \\
\hline $7.300-7.320$ & 0.88 & -2.83 & -2.60 & 9245 \\
\hline $7.325-7.345$ & 1.04 & -2.72 & -2.50 & 9319 \\
\hline $7.350-7.370$ & -0.12 & -2.67 & -2.42 & 9393 \\
\hline $7.375-7.395$ & 0.88 & -2.79 & -2.55 & 9467 \\
\hline $7.400-7.420$ & 0.60 & -2.17 & -1.97 & 9541 \\
\hline $7.425-7.445$ & 0.65 & -2.94 & -2.73 & 9615 \\
\hline $7.450-7.470$ & -0.11 & -2.70 & -2.43 & 9689 \\
\hline $7.475-7.495$ & -0.25 & -2.63 & -2.35 & 9763 \\
\hline
\end{tabular}


Table S4 cont.

\begin{tabular}{ccccc}
$\begin{array}{c}\text { Depth interval } \\
(\mathrm{m})\end{array}$ & $\begin{array}{c}\delta^{13} \mathrm{C} \\
(\% \text { o) }\end{array}$ & $\begin{array}{c}\delta^{18} \mathrm{O} \\
(\% \circ)^{*}\end{array}$ & $\begin{array}{c}\text { Sealevel } \\
\text { corrected } \delta^{18} \mathrm{O} \\
(\%)\end{array}$ & $\begin{array}{c}\text { Foram age } \\
(\mathrm{y})\end{array}$ \\
\hline \hline $7.500-7.520$ & 0.69 & -2.30 & -2.01 & 9838 \\
$7.525-7.545$ & 0.65 & -2.69 & -2.40 & 9912 \\
$7.550-7.570$ & -0.49 & -2.90 & -2.59 & 9986 \\
$7.575-7.595$ & 0.41 & -3.02 & -2.71 & 10060 \\
$7.600-7.620$ & 0.16 & -1.31 & -0.99 & 10134 \\
$7.625-7.645$ & 0.09 & -2.89 & -2.57 & 10208 \\
$7.650-7.670$ & 0.27 & -2.69 & -2.35 & 10282 \\
$7.675-7.695$ & 0.26 & -3.00 & -2.66 & 10356 \\
$7.700-7.720$ & -0.34 & -2.57 & -2.23 & 10430 \\
$7.725-7.745$ & 0.05 & -3.14 & -2.79 & 10504 \\
$7.750-7.770$ & -0.22 & -2.69 & -2.34 & 10578 \\
$7.775-7.795$ & 0.91 & -2.68 & -2.32 & 10652 \\
$7.800-7.820$ & -0.49 & -2.44 & -2.08 & 10726 \\
$7.825-7.845$ & 0.38 & -2.77 & -2.41 & 10800 \\
$7.850-7.870$ & 0.28 & -2.89 & -2.53 & 10875 \\
$7.875-7.895$ & -0.37 & -2.54 & -2.18 & 10949 \\
$7.900-7.920$ & 0.61 & -1.94 & -1.58 & 11023 \\
$7.925-7.945$ & 0.23 & -1.26 & -0.90 & 11097 \\
$7.950-7.970$ & -0.02 & -2.55 & -2.17 & 11171 \\
$7.975-7.995$ & 0.93 & -2.43 & -2.04 & 11245 \\
$8.000-8.020$ & 0.27 & -2.06 & -1.64 & 11319 \\
\hline
\end{tabular}

"reported relative to VPDB 


\title{
CHAPTER 4
}

\section{The Indus Shelf: Holocene Sedimentation and Paleoclimate Reconstruction}

\begin{abstract}
This study presents results from the first high-resolution seismic survey of the Indus River subaqueous delta, and documents the existence of a well-developed Holocene clinoform deposited over relict clinoforms that survived previous sea level cycles. We use seismic and core records to explore the suitability of using subaqueous deltaic sedimentary deposits from the Pakistani shelf to reconstruct the paleoclimate in the Indus drainage basin. We find that fine-grained sediments trapped primarily from suspension in morphological depressions located laterally from the shelf clinothems are well suited for climate reconstructions. $\delta^{13} \mathrm{C}$ analyses on terrestrial plant leaf waxes preserved in such sediments show a remarkably stable record indicating a predominance of $\mathrm{C}_{4}$ plants $(\sim 75 \%)$ in the Indus River drainage basin during the last 6,000 yrs. These results are in disagreement with the consistent accounts of Indian monsoon weakening over the Holocene in other regions of South Asia. However, given that modern $\mathrm{C}_{3}$ vegetation cover is restricted to small areas of the upper river basin, monsoon variability was probably too small to decisively affect the dominant $\mathrm{C}_{4}$ vegetation of the arid lower Indus basin.
\end{abstract}

\subsection{Introduction}

Continental shelves are the terrace-like submerged edges of continents that gently slope offshore and extend to a point of steep descent (the shelf break) toward the ocean bottom. They are usually covered with sediments that originated from inland erosion and were transported by rivers to the shore (Mitchum et al., 1977; Nittrouer et al., 1986; Kuehl et al., 1989; Walsh et al., 2004). Sediments on the continental shelf are redistributed and deposited along and across the shelf by waves, currents and underwater sediment flows (Nittrouer and Wright, 1994; Friedrichs and Wright, 2004; Macquaker et al., 2010). Sea level changes exert a first-order control on sedimentary processes because they represent changes of the base level above which sediments cannot be deposited in the ocean and 
also the base level below which rivers cannot erode their beds (Mitchum et al., 1977; Posamentier et al., 1988: Chistie-Blick and Driscoll, 1995). However, the presence of persistent sediment source, such as in front of large, delta-building rivers, adds another primary control on the sedimentation patterns and sedimentary architecture (McKee et al., 1983; Nittrouer et al., 1986; Kuehl et al., 2004).

River-dominated continental margins offer an opportunity for paleoclimate reconstruction because they integrate both marine and continental signals in their sedimentary record (e.g., Galy et al., 2008; Colin et al. 2010; Ponton et al., 2012). Furthermore, sedimentation rates are generally higher than anywhere in the ocean and thus, allow high temporal resolution studies. Because delta-building processes directly respond to fluvial sediment discharge, deltaic shelves where river loads are climatically controlled are good candidates for paleoclimatic studies using both stratigraphy and sediment composition to track climatic variability. In contrast, sedimentary records from continental slope settings are additionally modified and delayed by shelf processes before reaching their depositional locus (Nittrouer and Wright, 1994; Macquaker et al, 2010), which adds a layer of complexity in their interpretation. Exceptions to this rule are systems with narrow continental shelves (e.g., Ponton et al., 2012) or submarine canyons that extend near to the river mouth where fluvial sediments are directly deposited on the slope (e.g., Weijers et al., 2009).

Here we use seismic imaging and downcore records to explore the suitability of using deltaic sedimentary deposits from the Pakistani shelf to reconstruct paleoclimate in the Indus drainage basin. This study presents results from the first high-resolution seismic survey of the Indus River subaqueous delta, which documents the existence of a welldeveloped modern clinoform on the Indus subaqueous delta deposited over relict clinoforms that survived previous sea level cycles. Based on the interpretation of sedimentary environments and plant wax compositional variability in sedimentary deposits, I present results suggesting large-scale stability of the flora within the Indus watershed since middle Holocene. 


\subsection{Background}

\subsubsection{Shelf morphology}

Shelf sedimentary architecture and sediment composition can be used for paleoclimatic reconstructions as long as their dynamics are understood for the time interval of interest. Rich (1951) first described the depositional environments on sedimentary terraces of different ocean basins and defined them as shelf, slope and bottom. The surfaces corresponding to these environments were termed undaform, clinoform and fondoform respectively, and their sedimentary deposits undathem, clinothem and fondothem. Clinoforms occur at different scales varying from centimeters to tens of kilometers and are characterized by lateral stacking of sedimentary packages of sigmoidal shape (clinothems). Although the entire continental margin itself can be thought as a clinoform/clinothem (Figure 1), similar landscapes and deposits of smaller scale occur across the shelf and especially in front of deltas (Walsh et al., 2004), constituting the building blocks of the continental margin (Sømme et al., 2009; Carvajal et al. 2009).

The term clinoform has been used to describe either the morphology of a feature (i.e., sigmoidal in cross-section) or its sedimentary dynamics (i.e., aggradationalprogradational feature of a sigmoidal shape; e.g., Walsh et al., 2004). In the latter, process-based, use of the term, the clinoform is composed of topset, foreset, and bottomset beds (Figure 1). In this work, I use "clinoform" to describe the form (morphology) and "clinothem" to distinguish deposits associated with that form. Variability in clinoform/clinothem in cross section has been discussed e.g., in Slingerland et al. (2008; Figure 1) and Driscoll and Karner (1999) respectively.

Classic sequence stratigraphic models suggest that under a low-stand the coast emerges and large quantities of terrigenous sediments are spread outwards and downward onto the outer shelf, slope and basin floor (Mitchum et al. 1977, Posamentier et al. 1988). On the contrary, a high-standing sea submerges the coast and as a result the environments lying farther seaward experience sediment starvation. The progression of sea level cycles 
transforms the sedimentary structures and sediment distribution on the continental shelf. At the start of a low-stand, the shoreline shifts outwards (basinward or offshore) and the previously underwater shelf sediments become exposed and eroded by streams that incise valleys and deliver sediments to the outermost sector of the topset and foreset as well as to the heads of submarine canyons. The topset/foreset boundary will shift outwards and the canyons will deliver sediments to deep sea fans. Under these conditions the clinoform builds laterally or progrades offshore (Figure 1).
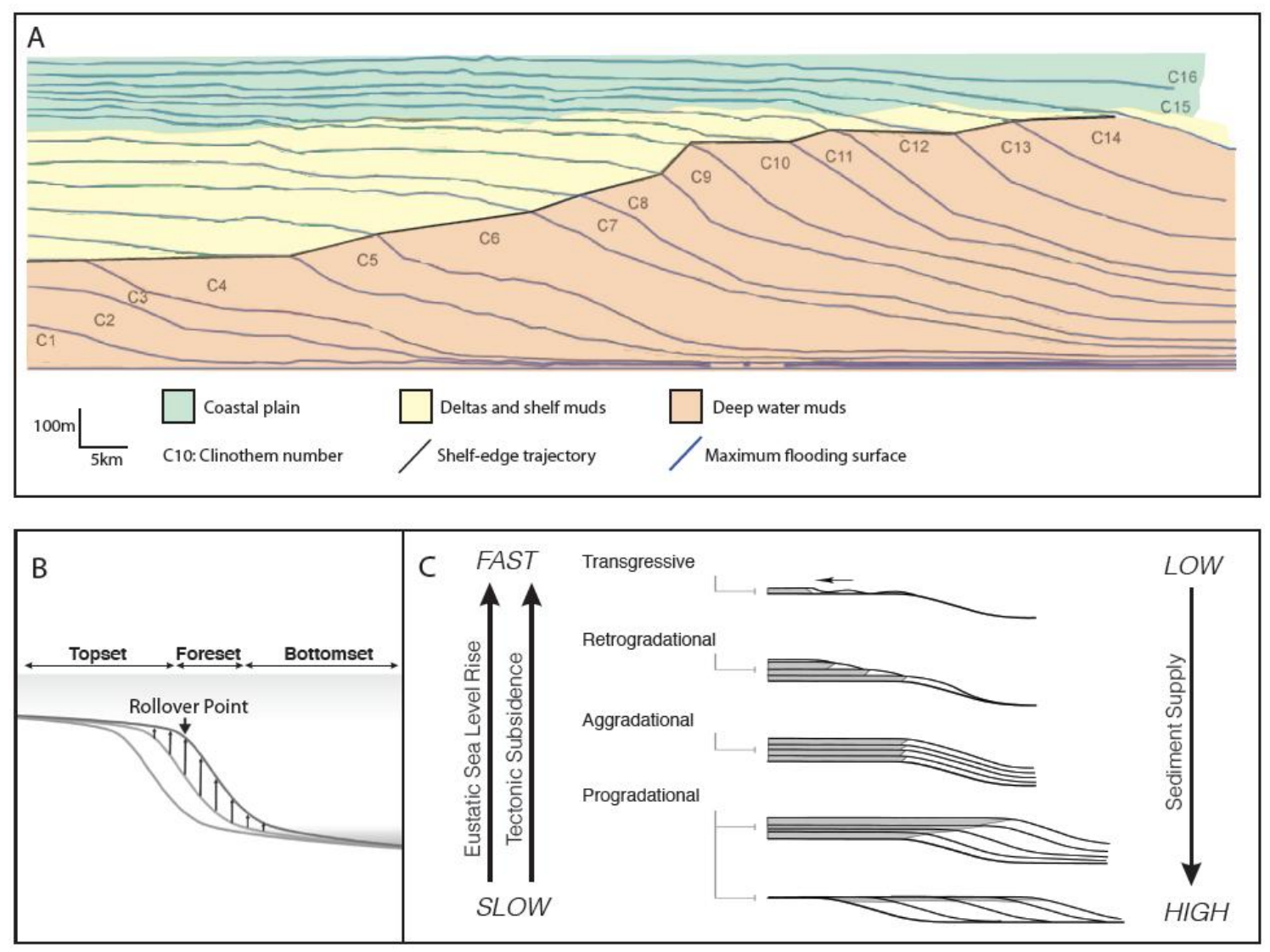

Figure 1. (A) Cross section along direction of propagation of the Lewis-Fox Hill shelfmargin from the Late Cretaceous in southern Wyoming. Notice the clinothem stacking along the margin (modified from Carvajal et al., 2009); (B) Anatomy of a clinoform (Walsh et al., 2004); (C) Schematic illustrating controls in clinoform geometry: when sediment supply is greater than new accommodation, progradation occurs. Aggradation occurs when supply is equal to accommodation, and retrogradation occurs when sediment supply is less than accommodation (Slingerland et al., 2008). 
When the sea level begins to rise, conditions may not change much, and the lowstand configuration will continue to accumulate. However, as the rate of submergence increases, and the shoreline transgresses landward, the sediment supply to the offshore region may be cut off abruptly resulting in deposition of strata much thinner than during lowstand. On the topset, a thin and discontinuous sand layer is deposited until the maximum submergence has been reached. However, where terrigenous sediment is abundant, the coastline may continue to prograde or restart progradation offshore even under rising sea levels (Posamentier et al. 1988) by constructing deltaic clinothems.

Observations on modern mid-shelf clinoforms reveal information about the processes by which they were formed. Studies on large modern subaqueous deltas like the Amazon (Kuehl et al, 1986; Nittrouer et al., 1986; Nittrouer et al., 1996; Kineke et al., 1996) and the Ganges-Brahmaputra (Kuehl et al. 1997; 2005; Michels et al., 1998) show that hyperpycnal sediment plumes play a crucial role in transporting and delivering sediment from the river mouth to the clinoform, and that alongshore currents redistribute sediments allowing clinoform development along-shelf as well as across-shelf (Driscoll and Karner, 1999; Giosan et al., 2006). Modeling studies for gravity-driven, wave-supported sediment transport predict the equilibrium profile of a mid-shelf clinoform as a function of wave climate and fluvial sediment supply (Friedrichs and Wright, 2004; Wright and Friedrichs, 2006). Deeper and broader profiles correspond to higher wave energy relative to river supply. In the Amazon delta the clinoform rollover occurs at $\sim 40 \mathrm{~m}$ water depth over $150 \mathrm{~km}$ from the coast (Nittrouer et al., 1986). On the Ganges-Brahmaputra rollover occurs at $\sim 30$ m water depth (Kuehl et al., 1997). When applying the Friedrichs and Wright (2004) model to the Indus shelf, the results suggest the Indus delta should have developed a clinoform anywhere from $\sim 40$ to $100 \mathrm{~m}$ depth (Giosan et al., 2006). 


\subsubsection{Indian monsoon variability}

The Indian monsoon is a principal water contributor, together with glacier meltwater, to the Indus River (Karim and Veizer, 2002) and it has been proposed to modulate its sediment discharge (Clift et al., 2008). Although water discharge reconstructions for the Indus have been attempted (Staubwasser et al., 2003), it is unclear how they reflect the variability of the Indus monsoon considering that the main contribution of the water originates from western Asia via the Westerlies (Karim and Veizer, 2002). Other regional high-resolution proxy records of precipitation (Fleitmann et al., 2003) and wind intensity (Gupta et al., 2003) during the Holocene are available from the coastal and offshore regions of Oman respectively. These reconstructions, supported by other records (Sirocko et al., 1993; Overpeck et al., 1996; Schulz et al., 1998; Ivanochko et al., 2005), show a gradual decrease in precipitation during the Holocene associated with coeval weakening of summer monsoon winds, and have been interpreted (Fleitmann et al., 2007) as the result of the ITCZ southward migration (Haug et al., 2001). Foraminiferal oxygen isotopic records from the southeastern Arabian Sea (Sarkar et al., 2000) and reconstructed precipitation on the island of Socotra, offshore Yemen (Fleitmann et al., 2007), both suggest that the monsoon intensified in the late Holocene, possibly responding to the ITCZ southward retreat. Terrestrial and marine records from the core monsoon zone in central India present a consistent picture of progressive monsoon weakening since the mid-Holocene, and document that after a humid early Holocene there was a gradual increase in aridity-adapted vegetation (Ponton et al., 2012). The same records also suggest that in the late Holocene aridification intensified in central India through a series of sub-millennial dry episodes. Holocene monsoon reconstructions from the NW Indian peninsula are limited to lower resolution lacustrine records and have not yielded clear evidence for increased precipitation in early Holocene corresponding to the interval of intensified summer monsoon winds (Prasad and Enzel, 2006). Instead the lake records show active periods and intervals of desiccation that are not coherent across the region, suggesting localized causes for hydrologic variability. 


\subsection{Study area}

The Indus River drains the western Himalaya and Karakoram Mountains, crosses the arid plains of Pakistan and flows into the Arabian Sea via a complex network of mouths. The Indus is now heavily dammed but it used to be one of the most important sedimentproducing rivers in the world and built an extensive delta and the second largest submarine fan in the present-day ocean. It is estimated that before the 1960's the annual sediment discharge for the Indus River was between 300 and 675 million tons (Milliman et al., 1982; Milliman and Syvitski, 1992), making it the river with the $5^{\text {th }}$ largest sediment load in the world (Wells and Coleman, 1984). The sediment reaching the delta and continental shelf is dominantly silt (65\%) with variable quantities of sand and clay (Kazmi, 1984). The Indus receives the highest deep-water wave energy of major world's deltas due to intense monsoonal winds arriving from the southwest during May to September (Wells and Coleman, 1984), but after attenuation by the wide shallow shelf the wave energy at the coast is lower than for typical wave-dominated deltas (Wells and Coleman, 1984). Sediment dispersal by tidal and wind-driven currents also occurs. The mean current along the coast switches from southeasterly during the summer monsoon to northwesterly during the winter monsoon (Rizvi et al., 1988; Fig 2).

The most prominent feature of the Indus shelf is the Indus Canyon that dissects the shelf. Using successive bathymetric surveys, Giosan et al. (2006) showed that the Indus built an extensive lobate subaqueous delta during the Holocene. This delta exhibits a compound clinoform morphology with a shallow delta front or coastal clinoform extending along the entire delta cost from the shore to 10-25 m water depth and a shelf clinoform between 30-90 m water depth (Giosan et al., 2006). Herein we focus on the latter feature. The Indus shelf clinoform developed asymmetrically around the canyon (Giosan et al., 2006). On the eastern shelf the clinoform is much more advanced towards the edge of the shelf and the rollover point occurs between 80 and $100 \mathrm{~km}$ offshore, while on the western shelf the rollover point occurs at less than $50 \mathrm{~km}$ offshore (Figure 2). One explanation proposed by Giosan et al. (2006) for the advanced position of the shelf clinoform east of 
the Indus Canyon, is the existence of a relict pre-Holocene clinoform on the eastern shelf. Alternatively, Holocene sedimentation may have preferentially occurred on the eastern shelf due to subaerial delta morphodynamics and/or shelf circulation (Giosan et al., 2006).

\subsection{Methods}

During December 2008 - January 2009 the R/V Pelagia cruise 64PE300 surveyed the Indus shelf to image and core the shallow sub-seafloor and document the nature of sediment transport in the Holocene subaqueous delta. We employed an Edgetech SB-512i Chirp seismic reflection system optimized for imaging in the 20-200 m sub-seafloor range. The frequency range was set to $0.7-12.0 \mathrm{kHz}$ for the duration of our operations, and the fish was towed behind the ship at a depth of $\sim 5 \mathrm{~m}$ and a speed of $\sim 4$ knots. The data was recorded using EdgeTech Sub-Bottom 3.42 software and then imported into analysis software package Triton SB-I. Automatic gain control filters and swell corrections were applied when necessary to optimize seismic imaging. Sediment thicknesses were estimated using a sound velocity of $1500 \mathrm{~ms}^{-1}$. Prominent reflectors were digitized across the acquired lines and high-resolution image files with predetermined scaling factor were exported to construct composite seismic profiles for interpretation.

The cruise recovered 11 piston cores, 16 gravity cores, 16 multi-cores, and 5 box cores along the Indus shelf. These cores were described and information recorded on core logs during the cruise. Samples for radiocarbon dating were collected upon description where in situ mollusk shells, preferably articulated, were available. Additional samples for radiocarbon dating were obtained after washing the sediment on $63 \mu \mathrm{m}$ sieves and picking fresh-looking mollusk shells. When whole pteropod shells were available they were preferentially used, given that their fragile tests insure that they are preserved in situ. Otherwise, small articulated bivalves and gastropod shells $(<1 \mathrm{~cm}$ diameter) were used. 
Radiocarbon measurements were performed at the National Ocean Sciences Accelerator Mass Spectrometry Facility (NOSAMS) in Woods Hole, MA, USA. ${ }^{14} \mathrm{C}$ ages were converted to calendar ages using the CALIB 6.0 program (Stuiver and Reimer, 1993) and the Marine09 calibration curve (Reimer et al., 2009). Available reservoir estimates for the Arabian Sea surface waters are not substantially different from the standard marine reservoir correction (Dutta et al., 2001; Southon et al., 2002), which we used to calibrate our data. However, Staubwasser et al. (2003) counting seasonal layers from a laminated core in the Pakistani margin documented elevated ages for the natural ${ }^{14} \mathrm{C}$ marine reservoir during the Holocene and proposed an age calibration model with variable reservoir ages between $530-670$ yrs. We also converted our ${ }^{14} \mathrm{C}$ ages to calendar ages using their age model and present results for both calibrations for comparison.

Compound-specific carbon isotope analyses on sedimentary plant waxes (long-chain [>C $\left.\mathrm{C}_{24}\right] n$-alkanoic acids) were performed on 17 samples of core Indus-10A-P spanning the last 6,000 yrs BP. Complete methodology for this procedure can be found in Chapter 2 of this dissertation. In brief, solvent-soluble organic matter was extracted from freezedried sediments using a microwave-accelerated reaction system. The resulting total lipid extract was saponified and the acid fraction purified and then methylated using methanol of known isotopic composition. A gas chromatograph with isotope ratio monitoring mass spectrometer (GC-irMS; Thermo Trace GC Ultra connected to a Thermo Delta V Plus MS via a Thermo GC Isolink and Thermo Conflow IV) was used to obtain the $\delta^{13} \mathrm{C}$ measurements on the isolated $n$-alkanoic acids (measured as fatty acid methyl esters). All samples were analyzed in triplicate; $\delta^{13} \mathrm{C}$ values were determined relative to a reference gas $\left(\mathrm{CO}_{2}\right)$ of known isotopic composition, introduced in pulses during each run. GC-irMS accuracy and precision are both better than $0.3 \%$. Results were corrected for $\delta^{13} \mathrm{C}$ of the methyl derivative based on isotopic mass balance to derive $\delta^{13} \mathrm{C}$ values for the original $n$ alkanoic acids. 


\subsection{Results and Discussions}

\subsubsection{The western shelf}

The extent of the entire seismic survey of the Indus shelf on both sides of the canyon can be seen in Figure 2 . Bathymetry shows the difference in the shapes of the two lobes of the delta divided by the canyon. The spacing of the contours indicates where the rollover of the clinoform occurs. The western shelf clinoform does not develop out far onto the shelf (ca. $50 \mathrm{~km}$ from shore), and extends laterally along the shoreline for more than 120 $\mathrm{km}$. A composite of chirp lines tracking the western clinoform along-shore (strikewise) is shown in Figure 3. It presents the modern clinothem deposited along-shore. The composite line provides a general cross section of the western delta lobe thinning westward, with the bulge of sediment developed close to the canyon.

The stratigraphy and architecture of the clinoform has been imaged close to the canyon down to ca. 20 meters below sea floor (mbsf). The presence of gas (blue mask in Figure 3) precluded deeper penetration of the seismic signal. At shallower depths homogenous transparent units reminiscent of mudflows occur (traced in black with a white mask in Figures 3-4). Similar transparent units consisting of homogenized sediments have been observed in the Ganges-Brahmaputra subaqueous delta and interpreted as liquefaction flows triggered by earthquakes (Palamenghi et al., 2011) and the passage of tropical cyclones (Rogers and Goodbred, 2010). 


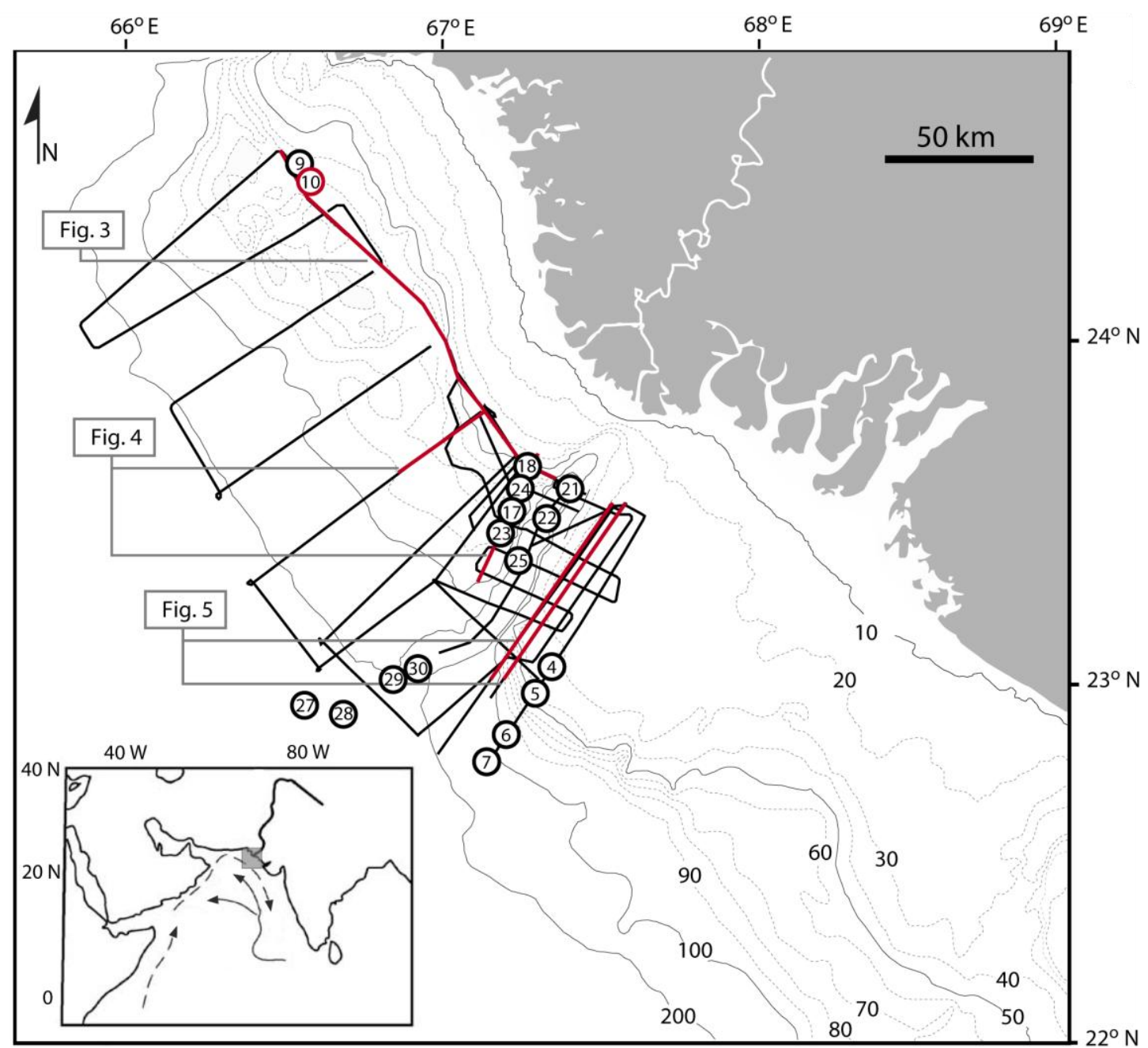

Figure 2. Map of the Indus shelf with bathymetry of the subaqueous delta and ship track of the seismic survey. The numbered circles indicate the location of sediment cores. Core 10 (in red circle) was used for down-core reconstruction. Inset in the lower left corner shows the location of the Indus River and the surface currents in the Arabian Sea during the summer monsoon (dashed arrows) and winter monsoon (solid arrows).

Figure 3 (on next page). Composite of chirp lines along the western shelf clinoform extending westward from the canyon (from right to left). Panel A shows the processed seismic data. Panel B shows interpreted erosional horizons and shows two generations of clinoforms developing over a well-defined erosional surface traced in red color. Liquefaction deposits are delimited in black and a transparent white mask and gas-rich deposits are highlighted with a blue mask. Panel $\mathrm{C}$ shows a close-up of lowstand incised valleys that have been subsequently infilled. 
Kilometers from the Canyon
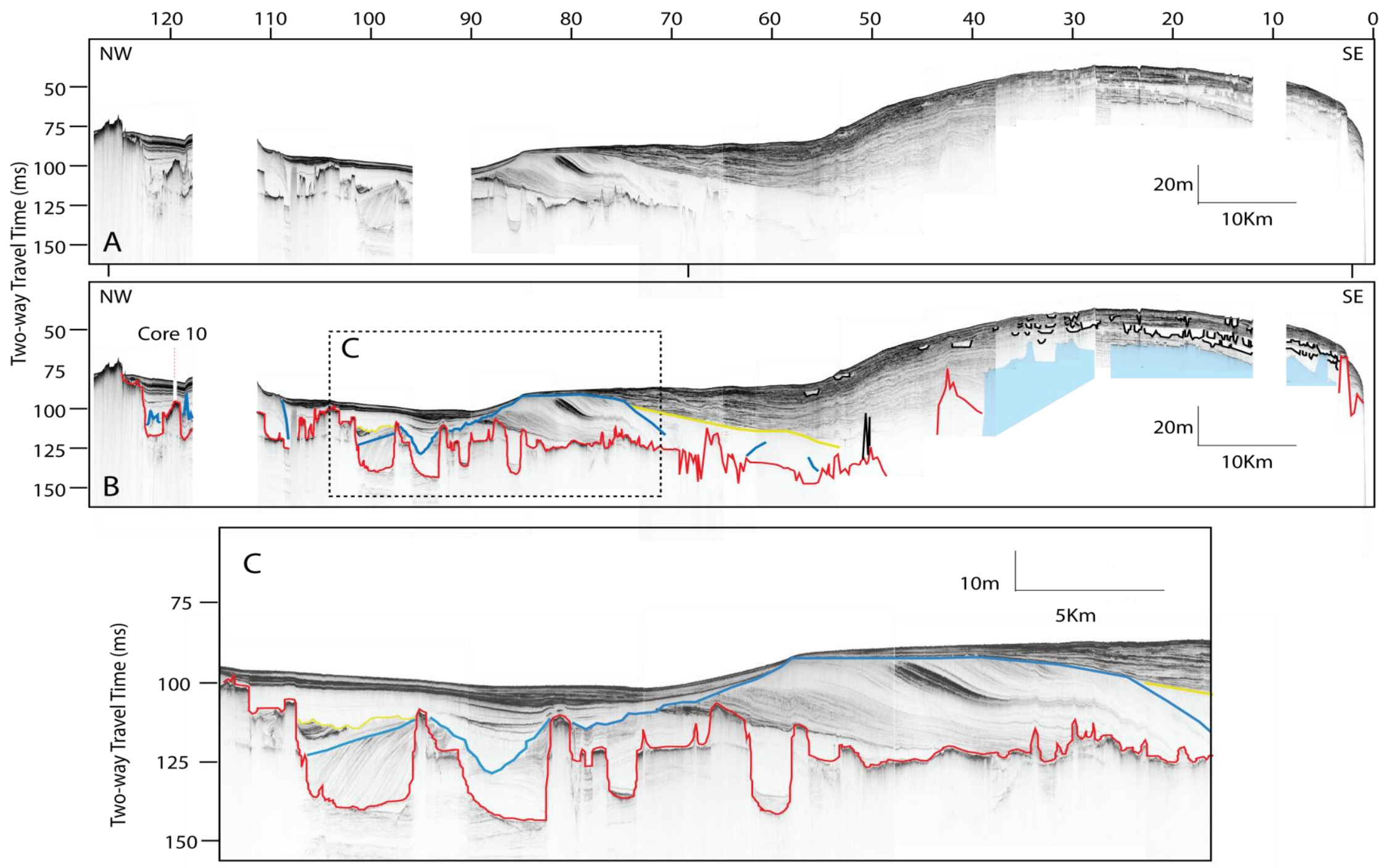
At about $40 \mathrm{~km}$ west of the canyon an erosional unconformity becomes evident under the modern clinothem (red color in Figure 3B) that can be tracked almost continuously to the end of the line (130 km west of the canyon). This horizon shows the outline of wide incised valley (over $80 \mathrm{~km}$ wide) with several smaller localized incisions (2-6 km wide) that have been subsequently infilled (Figure 3C) with complex bedding configuration. In between the modern clinoform and the strong erosional horizon (red), there is a series of horizons marking angular unconformities, representing the remains of previous clinothems (e.g., blue horizon). There is almost no penetration below the strong erosional reflector (in red) due to local induration, a possible consequence of subareal exposure and fresh water percolation during lowstand.

Figure 4 shows two across shelf (dip-oriented) profiles over the clinoform, with the first one from $\sim 40 \mathrm{~km}$ west of the canyon and the second at $\sim 10 \mathrm{~km}$ west of the canyon. Both profiles image the modern clinoform draping over the previously eroded surface identified before (red horizon in Figures 3-4) or earlier clinothem deposits. In the first profile the clinoform bottomset extends for $\sim 55 \mathrm{~km}$ offshore until it is blocked by submarine outcrops. On the second profile the clinoform extension is truncated at $\sim 42$ $\mathrm{km}$ offshore due to the presence of an extensional graben-like structure. The presence of acoustically transparent layers continuously across the foreset indicates repeated liquefaction events. Under the foreset region closer to the shore limited penetration due to gas-rich sediments (highlighted with blue mask in Figure 4) prevents imaging the base of the clinothem and the surface over which it was deposited.

Figure 4 (on next page). Two dip-oriented chirp lines across the western shelf clinoform. Top panel shows the processed seismic data. Bottom panel shows vertical scale-enhanced interpreted profiles of the modern clinoform developing over a well-defined erosional surface traced in red color. Liquefaction deposits are delimited in black and gas blowouts highlighted with a blue mask. 


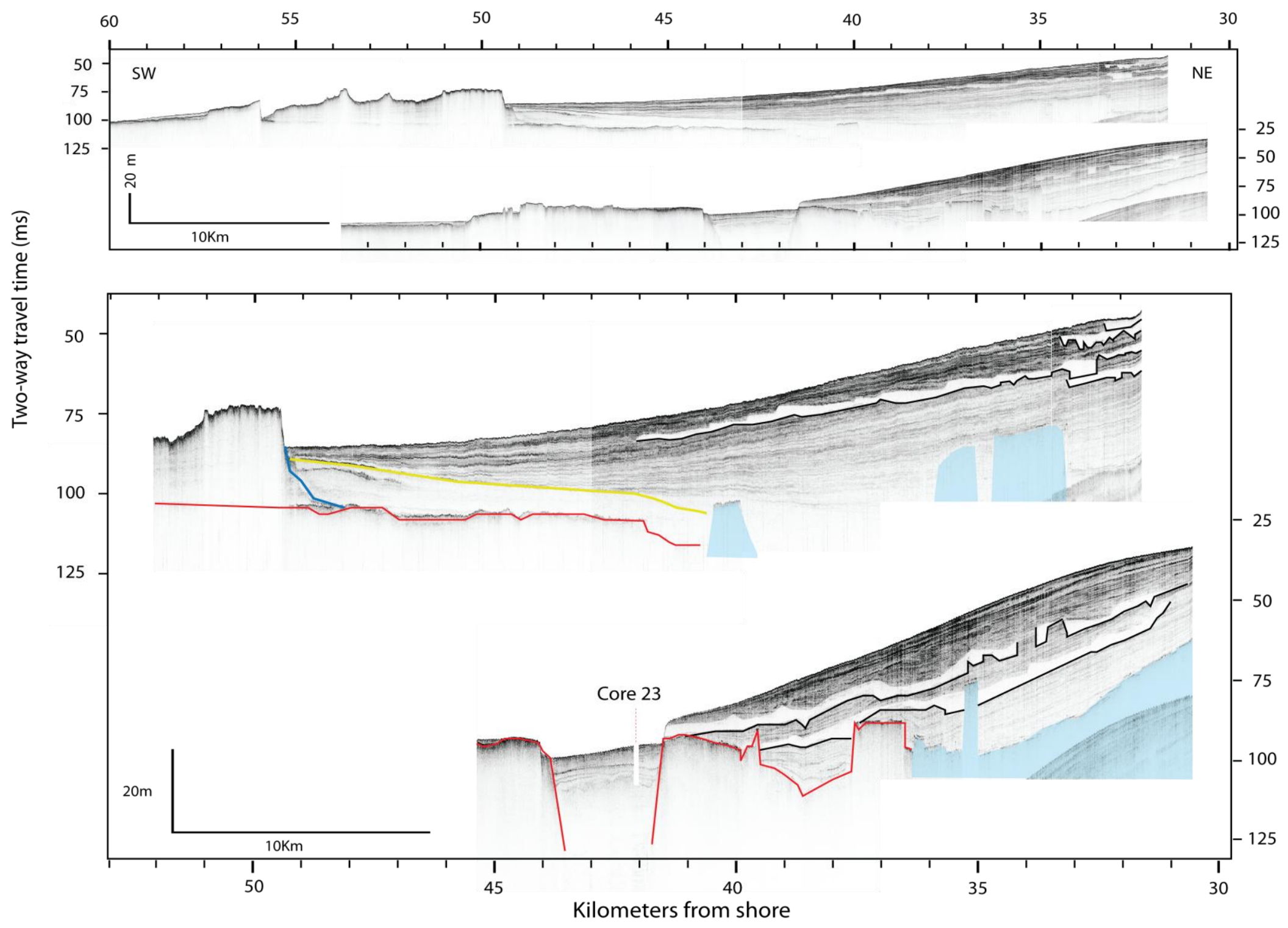




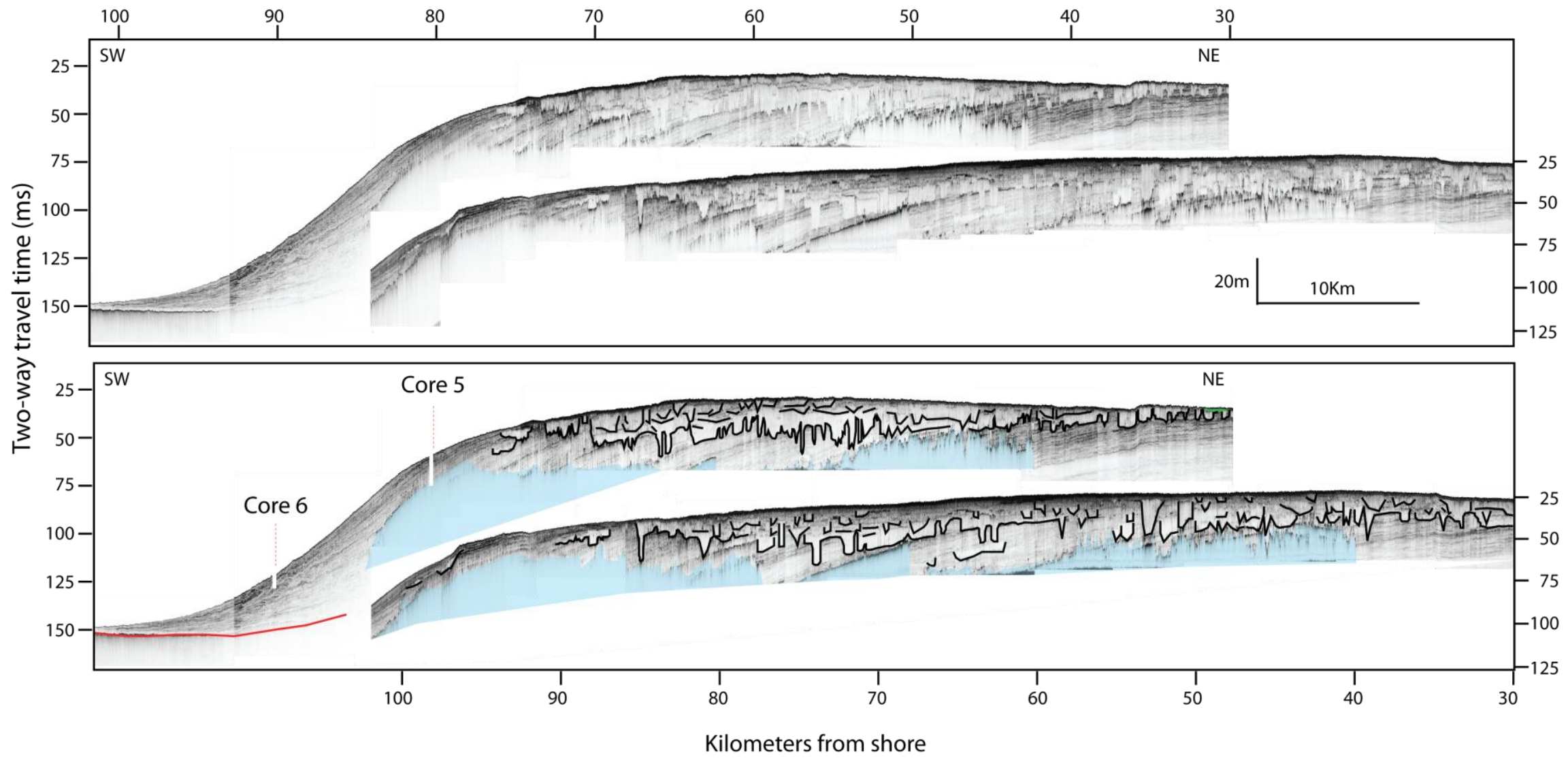

Figure 5. Two dip-oriented chirp lines across the eastern shelf clinoform. Top panel shows the processed seismic data. Bottom panel traces the complex pseudo-erosional surfaces that affect the continuity of foreset horizons. 


\subsubsection{The eastern shelf}

The eastern lobe of the subaqueous delta extends much farther towards the shelf edge, with the clinoform rollover occurring between 80 and $100 \mathrm{~km}$ offshore (Figure 2). The eastern clinothem is not only more extensive but also much thicker than its western shelf equivalent. Profiles in Figure 5 show two chirp lines extending offshore across the shelf. The well-defined erosional horizon in these profiles, likely equivalent to the one traced on the western side, is only observed under the bottomset, where the clinothem is thinnest (traced in red in Figure 5). At the topset, the clinothem exhibits a complex structure with clear but discontinuous (pseudo-)erosional surfaces (traced in black and with white masks in Figure 5) infilled by homogenous sediments for the most part. These could represent the topset expression of liquefaction events (Rogers and Goodbred, 2010; Palamenghi et al., 2011) similar to those observed on the western shelf.

\subsubsection{Sediment cores}

Analysis of seismic data across the Indus shelf indicates that sediments of the topset and foreset are not appropriate for paleoclimate reconstructions where effects of liquefaction and mass sediment transport are dominant. Therefore, sediment cores from locations on the western shelf, away from clinothems and within morphological depressions stemming from lowstand incision (Core 10; Figure 3) or tectonic subsidence (Core 23; Figure 4), were selected for investigation. These locations receive most of the sediment through suspension and resuspension of topset sediments and are less influenced by turbidites and liquefaction. On the eastern shelf, cores were selected from the foreset where the clinothem is less affected by erosional channels and liquefaction events (Cores 5-6; Figure 5).

Figure 6 presents the sedimentary logs for the cores considered in this study with corresponding radiocarbon ages. Ages indicate that the last Indus delta clinothem is Holocene in age. Cores from the eastern shelf contain frequent turbidite-like coarse beds 
whereas cores from the western shelf collected away from the clinothem contain mostly fine-grained sediments. Sedimentation rates on the eastern shelf clinothem foreset are very high (>100 cm/kyr). On the western shelf, the sedimentation rates in cores are still high but less than in cores collected directly on the foreset ( $>50 \mathrm{~cm} / \mathrm{kyr})$.

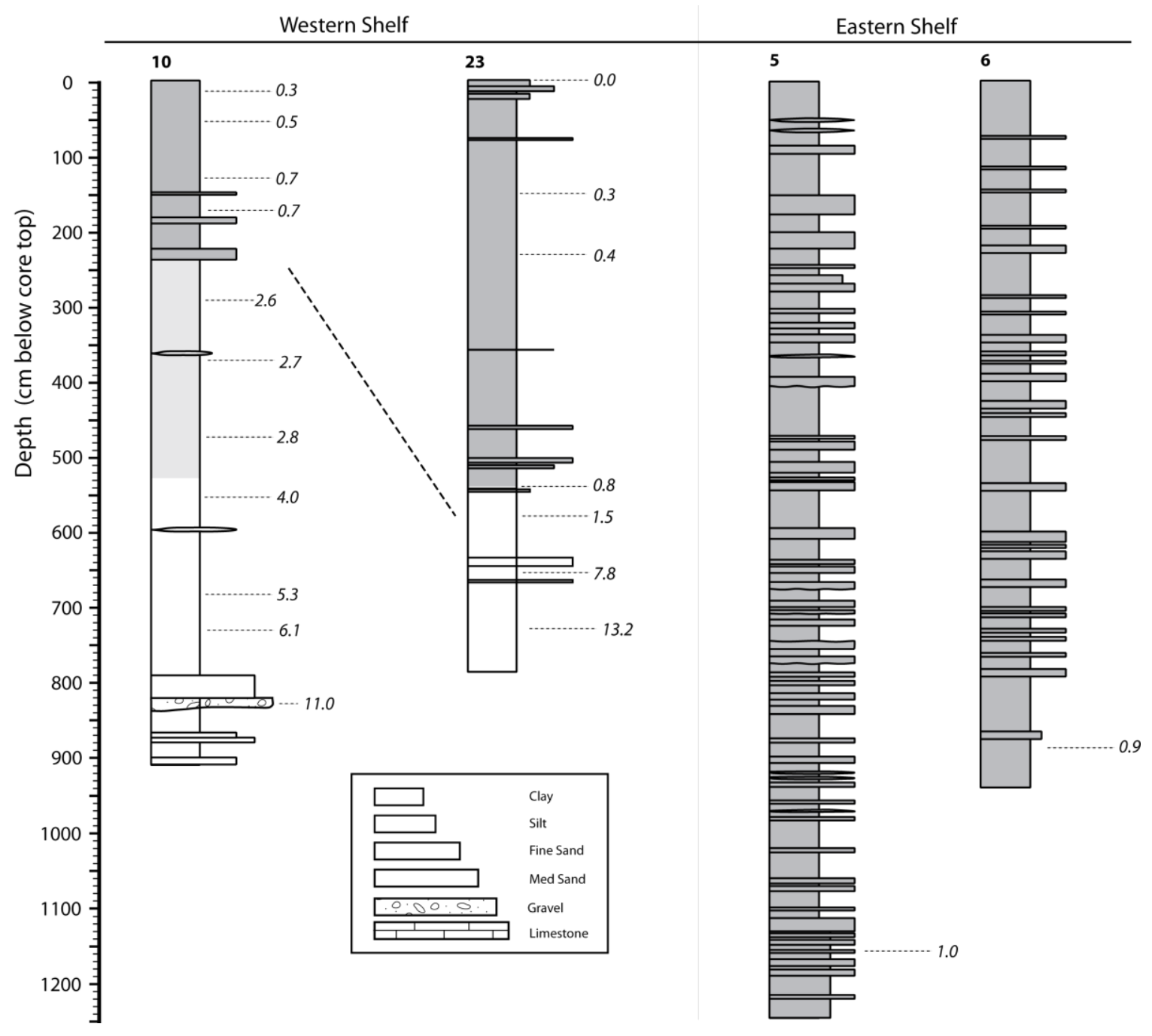

Figure 6. Sediment cores from the Indus shelf. Radiocarbon ages in ka BP. 


\subsubsection{Paleoclimate record}

Core 10 was selected for assessing the $\delta^{13} \mathrm{C}$ signature of higher plant waxes $\left(\delta^{13} \mathrm{C}_{\mathrm{wax}}\right)$ preserved in the sedimentary sequence. The age model for this $\sim 9 \mathrm{~m}$-long core shows continuous sedimentation throughout the last 6,000 yrs (Figure 7). Nd isotopes measured on detrital fractions from this core show a signature typical of Indus suspended sediment over the Holocene with rare episodic inputs from submarine outcrops (Limmer et al. 2012; Figure 8g). Thus, core 10 should integrate sediment delivered by the Indus River from its watershed and dispersed by shelf re-circulation.

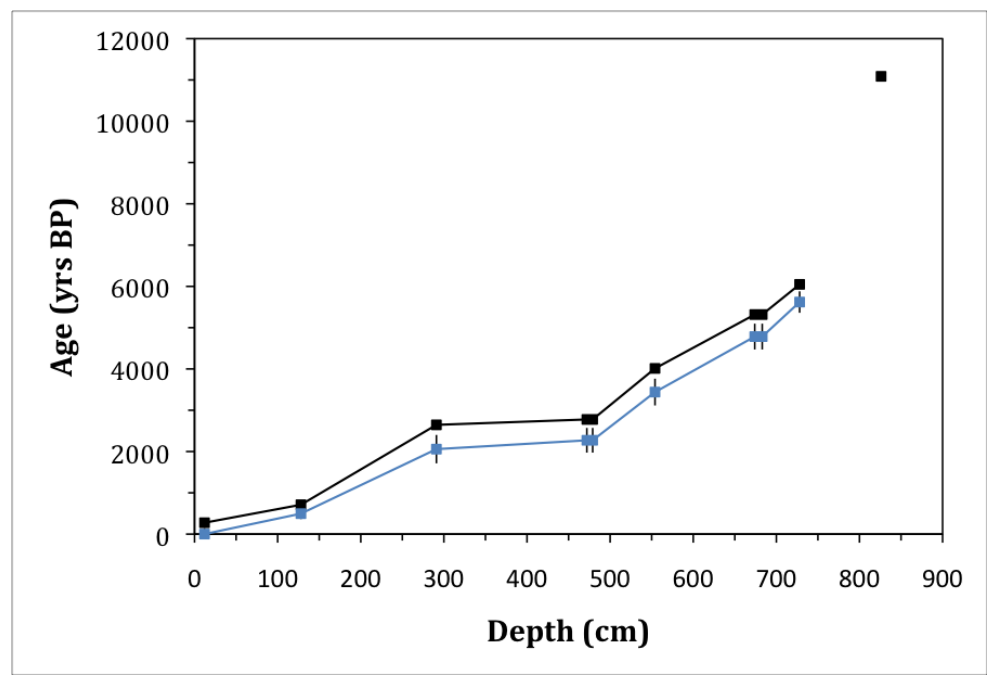

Figure 7. Age-depth relationships for core 10. In black, a constant $400 \mathrm{yr}$ reservoir age was used for ${ }^{14} \mathrm{C}$ age calibrations with the Marine09 curve (Reimer et al., 2009). In blue, calibration results (Marine09) but with variable reservoir ages based on Staubwasser et al., 2003. Error bars where not apparent, are smaller than symbols denoting data points.

$\delta^{13} \mathrm{C}_{\text {wax }}$ measurements representing the weighted average of long-chain $n$-alkanoic acids $\left(\mathrm{C}_{24-32}\right)$ are plotted in Figure 8 together with other paleoclimate proxy records from the Indian monsoon region. The $\delta^{13} \mathrm{C}_{\mathrm{wax}}$ data is plotted on two different age models, differing only in the reservoir age used for the age calibration. The light blue curve represents an age model with constant 400 year reservoir age, while the dark blue curve represents an age model with variable reservoir ages calculated for the northeastern 
Arabian Sea by Staubwasser et al. (2003). On average, the calibrated ages using the standard reservoir age model are $260 \mathrm{yr}$ older than those calibrated using the variable age model (Figure 7). The $\delta^{13} \mathrm{C}_{\mathrm{wax}}$ data shows a remarkably stable record with values that suggest a dominant $\mathrm{C}_{4}$ plant population $(\sim 75 \%)$ in the Indus River drainage basin throughout the record. Vegetation cover was estimated using the same two-end member model described in Chapter 2 of this dissertation.

Precipitation and upwelling records from the Arabian Sea (Fleitmann et al., 2003; Gupta et al., 2003; Figure 8a-b) show a decreasing rainfall trend and relatively low wind intensities for the past 6,000 yrs indicting a weakening of the monsoon, culminating with a brief monsoon strengthening after 1,000 yrs BP. Records from the Bay of Bengal monsoon branch provide a consistent account of monsoon weakening over the Holocene. Plant wax isotope records reveal the aridification of central India in a stepwise fashion starting at around 4,000 years ago and again after 1,700 years, manifested as a change in flora toward aridity-adapted $\left(\mathrm{C}_{4}\right)$ vegetation (Ponton et al., 2012; Figure 8e). Oxygen isotopic compositions of $G$. ruber from the same core shows high variability over the last 1,700 years, indicating the monsoon entered into a drought-prone regime (Sinha et al., 2011; Ponton et al., 2012; Figure 8d). The Indian monsoon weakening from the mid to late Holocene is not captured by records from the Indus River. Besides our new $\delta^{13} \mathrm{C}_{\mathrm{wax}}$ data (Figure 8f), oxygen isotopic composition of G. ruber from sediments off the mouth of the Indus River have been interpreted as a proxy for river discharge (Staubwasser et al., 2003; Figure 8c) and also show a relatively flat record. This is not surprising, given the Indus River discharge is not exclusively depending on monsoonal rains. Karim and Veizer (2002) estimate that currently $\sim 30 \%$ of the Indus River discharge is the result of runoff from the Karakoram and the Himalayas.

We interpret our new plant wax data as an integrated record of the entire Indus River drainage basin. The lack of variability in floral composition suggests that the Indus watershed has been arid overall during the last 6,000 years and the wetter monsoon that is evident in other regions of South Asia never developed in the Indus basin to the extent to 
favor $\mathrm{C}_{3}$ vegetation over $\mathrm{C}_{4}$ plants. In other words, the $\mathrm{C}_{4}$ carbon reservoir in the drainage basin has been too large to be affected by minor changes in flora related to a slightly wetter monsoon. At present $\sim 90 \%$ of the Indus River drainage basin is covered by vegetation representing arid to semi-arid climate, mostly tropical and subtropical dry scrub vegetation (Ansari et al., 2007) and only less than 5\% of the drainage basin supports temperate and coniferous forests (Ansari et al., 2007) that are restricted to the foothills of the Himalayas in the upper basin. Modeling, geochemical, and palynological studies (Galy et al., 2008; Schulz et al., 1998; Ansari et al., 2007; respectively) indicate that during the last glacial maximum conditions in this region were even drier than today. The almost invariable $\delta^{13} \mathrm{C}_{\text {wax }}$ values could occur if the $\mathrm{C}_{3}$ vegetation signature in the headwaters is stripped from the sediments during transit through the lower reaches of the basin to be replaced by a $\mathrm{C}_{4}$ vegetation signature. Analogous conditions have been documented to occur in the Ganges-Brahmaputra River basin (Galy et al., 2011). Stripping of carbon originating in the headwaters emphasizes even more the interpretation that the lower basin was not decisively influenced by a stronger monsoon earlier in the Holocene.

An alternative interpretation for the constancy of the carbon isotopic record would be that the Holocene erosion of the upper Pleistocene floodplain of the Indus and its tributaries (Giosan et al., 2012) provides plant waxes with a "dry" signature. This alternative can be dismissed when a sediment budget is calculated for the Indus system (Clift and Giosan, in prep.) Indeed, the largest quantity of sediment freed by floodplain incision comes from the Himalayan and Sub-Himalayan reaches of these rivers (Bookhagen et al., 2006) where the $\mathrm{C}_{3}$ signature is strongest. Yet another alternative explanation for the plant wax record would be that erosion and resuspension on the modern clinoform topset has a dominantly $\mathrm{C}_{4}$ signature. However, the topset is just a transfer region with minimal erosion as documented by its constant depth and high sedimentation rates on the eastern clinoform foreset far from the coast. Taken together, our data provides evidence in support of a disproportionately large $\mathrm{C}_{4}$ plant-derived carbon reservoir in the Indus lower drainage basin that has remained largely arid since middle Holocene. 


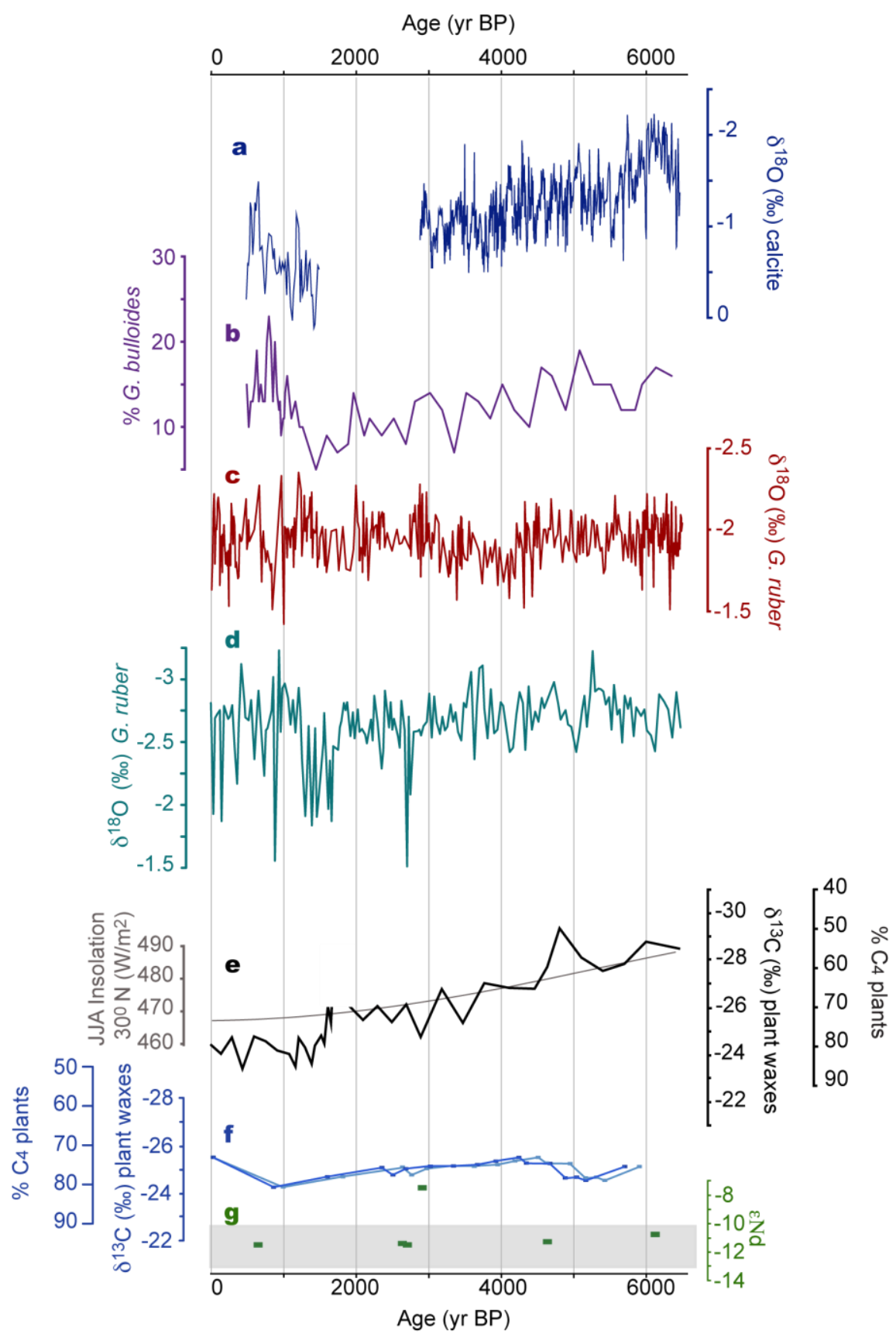

Figure 8. (a) Indian monsoon precipitation record (Fleitmann et al., 2003) (b) Indian monsoon upwelling record (Gupta et al., 2003); (c) Indus river discharge reconstruction (Staubwasser et al., 2003); (d) $\delta^{18} \mathrm{O}_{\text {ruber }}$ as a salinity proxy reconstruction from Bay of Bengal (Ponton et al., 2012); (e) Vegetation reconstruction from central India (Ponton et al., 2012) in black. Gray line is the June-July-August insolation at $30^{\circ} \mathrm{N}$; (f) $\delta^{13} \mathrm{C}_{\mathrm{wax}}$ from the Indus River drainage basin (this study) plotted on two age models; (g) Sediment provenance reconstruction from the Indus delta (Limmer et al., 2012). 


\subsection{Conclusions}

Our study confirms that the clinoforms of the Indus shelf have been built during the Holocene (Giosan et al. 2006). The western clinoform is developed in part over partially eroded, relict clinothems, but limited penetration due to gas and/or local induration of sedimentary layers precludes an assessment on the occurrence of similar relict features at the base of the western clinothem. Acoustically transparent sediment layers suggest that repeated liquefaction events affected both the western and eastern clinothems. Textural and structure variations in cores collected on foreset clinoforms show sandy microturbidite layers. Both liquefaction and turbiditic activity affect the quality of the sedimentary records collected on clinoforms and limit their suitability for paleoclimate reconstructions.

Sediment accumulation has been heterogeneous across the Indus shelf and controlled by subaerial delta dynamics as well as the morphology of the shelf and a strong alongshore redistribution (Giosan et al., 2006). The utility of Indus shelf sedimentary records for climate reconstruction appears strongly dependent on the stratigraphy of the cores. Whereas cores collected on the foreset of the shelf clinothems offer the highest sedimentation rates $(>100 \mathrm{~cm} / \mathrm{ka}$ ), they also contain frequent turbidite-like coarse beds that imply reworking. Instead, fine-grained sediments trapped in morphological depressions located laterally from the shelf clinothems and trapping sediments delivered in suspension are better suited for climate reconstructions. These latter sequences are still characterized by high sedimentation rates at $>50 \mathrm{~cm} / \mathrm{ka}$ and are largely compositionally uniform (Limmer et al., 2012).

Core 10, located in a morphological depression, preserves an integrative paleoclimate record of the entire Indus River drainage basin. The $\delta^{13} \mathrm{C}_{\mathrm{wax}}$ data suggests a remarkably stable climate over the arid regions of the Indus plain with a biome dominated by $\mathrm{C}_{4}$ vegetation for the last 6,000 yrs. While reconstructions from the Arabian Sea and Bay of Bengal provide a consistent account of monsoon weakening over the Holocene, our reconstruction from the Indus River does not track these changes, and instead indicates 
that conditions in the lower drainage basin remained predominantly dry. Because $\mathrm{C}_{3}$ vegetation cover is restricted to small areas of the upper river basin, any signal coming from these areas appears to be overprinted by a large invariable $\mathrm{C}_{4}$ plant-derived carbon reservoir in the lower drainage basin.

\section{References}

Ansari, M. H., and A. Vink. 2007. Vegetation history and palaeoclimate of the past $30 \mathrm{kyr}$ in Pakistan as inferred from the palynology of continental margin sediments off the Indus Delta. Review of Palaeobotany and Palynology 145 (3-4):201-216.

Carvajal, C., R. Steel, and A. Petter. 2009. Sediment supply: The main driver of shelf-margin growth. Earth-Science Reviews 96 (4):221-248.

Christie-Blick, N., and N. W. Driscoll. 1995. Sequence stratigraphy. Annual Review of Earth and Planetary Sciences 23:451-478.

Clift, P. D., L. Giosan, J. Blusztajn, I. H. Campbell, C. Allen, M. Pringle, A. R. Tabrez, M. Danish, M. M. Rabbani, A. Alizai, A. Carter, and A. Lueckge. 2008. Holocene erosion of the Lesser Himalaya triggered by intensified summer monsoon. Geology 36 (1):79-82.

Clift, P. D. and L. Giosan, in prep., Control on sediment buffering and flux rates in the postglacial Indus River basin, Quaternary Science Reviews.

Colin, C., G. Siani, M. A. Sicre, and Z. Liu. 2010. Impact of the East Asian monsoon rainfall changes on the erosion of the Mekong River basin over the past 25,000 yr. Marine Geology 271 (1-2):84-92.

Driscoll, N. W., and G. D. Karner. 1999. Three-dimensional quantitative modeling of clinoform development, Marine Geology 154 (1-4):383-398.

Dutta, K., R. Bhushan, and B. L. K. Somayajulu. 2001. Delta R correction values for the northern Indian Ocean. Radiocarbon 43 (2A):483-488.

Fleitmann, D., S. J. Burns, A. Mangini, M. Mudelsee, J. Kramers, I. Villa, U. Neff, A. A. AlSubbary, A. Buettner, D. Hippler, and A. Matter. 2007. Holocene ITCZ and Indian monsoon dynamics recorded in stalagmites from Oman and Yemen (Socotra). Quaternary Science Reviews 26 (1-2):170-188.

Fleitmann, D., S. J. Burns, M. Mudelsee, U. Neff, J. Kramers, A. Mangini, and A. Matter. 2003. 
Holocene forcing of the Indian monsoon recorded in a stalagmite from Southern Oman. Science 300 (5626): 1737-1739.

Friedrichs, C. T., and L. D. Wright. 2004. Gravity-driven sediment transport on the continental shelfimplications for equilibrium profiles near river mouths. Coastal Engineering 51 (8-9):795811.

Galy, V., L. Francois, C. France-Lanord, P. Faure, H. Kudrass, F. Palhol, and S. K. Singh. 2008. C4 plants decline in the Himalayan basin since the Last Glacial Maximum. Quaternary Science Reviews 27 (13-14):1396-1409.

Galy, V., T. Eglinton, C. France-Lanord, and S. Sylya. 2011. The provenance of vegetation and environmental signatures encoded in vascular plant biomarkers carried by the GangesBrahmaputra rivers. Earth and Planetary Science Letters 304 (1-2):1-12.

Giosan, L., S. Constantinescu, P. D. Clift, A. R. Tabrez, M. Danish, and A. Inam. 2006. Recent morphodynamics of the Indus delta shore and shelf. Continental Shelf Research 26 (14):16681684.

Giosan L. et al., 2012, Fluvial Landscapes of the Harappan Civilization, PNAS, in press.

Gupta, A. K., D. M. Anderson, and J. T. Overpeck. 2003. Abrupt changes in the Asian southwest monsoon during the Holocene and their links to the North Atlantic Ocean. Nature 421 (6921):354-357.

Haug, G. H., K. A. Hughen, D. M. Sigman, L. C. Peterson, and U. Rohl. 2001. Southward migration of the intertropical convergence zone through the Holocene. Science 293 (5533):13041308.

Ivanochko, T. S., R. S. Ganeshram, G. J. A. Brummer, G. Ganssen, S. J. A. Jung, S. G. Moreton, and D. Kroon. 2005. Variations in tropical convection as an amplifier of global climate change at the millennial scale. Earth and Planetary Science Letters 235 (1-2):302-314.

Karim, A., and J. Veizer. 2002. Water balance of the Indus River Basin and moisture source in the Karakoram and western Himalayas: Implications from hydrogen and oxygen isotopes in river water. Journal of Geophysical Research-Atmospheres 107 (D18).

Kazmi, A.H.1984. Geology of the Indus Delta. In: Haq, B.U., Milliman, J.D. (Eds.), Marine Geology and Oceanography of Arabian Sea and Coastal Pakistan. Van Nostrand Reinhold, New York, pp. 65-70.

Kineke, G. C., R. W. Sternberg, J. H. Trowbridge, and W. R. Geyer. 1996. Fluid-mud processes on the Amazon continental shelf. Continental Shelf Research 16 (5-6):667-696. 
Kuehl, S. A., G. J. Brunskill, K. Burns, D. Fugate, T. Kniskern, and L. Meneghini. 2004. Nature of sediment dispersal off the Sepik River, Papua New Guinea: preliminary sediment budget and implications for margin processes. Continental Shelf Research 24 (19):2417-2429.

Kuehl, S. A., D. J. Demaster, and C. A. Nittrouer. 1986. Nature of sediment accumulation on the Amazon continental-shelf. Continental Shelf Research 6 (1-2):209-225.

Kuehl, S. A., T. M. Hariu, and W. S. Moore. 1989. Shelf sedimentation off the GangesBrahmaputra river system - evidence for sediment bypassing to the bengal fan. Geology 17 (12):1132-1135.

Kuehl, S. A., B. M. Levy, W. S. Moore, and M. A. Allison. 1997. Subaqueous delta of the Ganges-Brahmaputra river system. Marine Geology 144 (1-3):81-96.

Limmer, D. R., P. Boning, L. Giosan, C. Ponton, C. M. Kohler, M. J. Cooper, A. R. Tabrez, and P. D. Clift. 2012. Geochemical record of Holocene to Recent sedimentation on the Western Indus continental shelf, Arabian Sea. Geochemistry Geophysics Geosystems 13.

Macquaker, J. H. S., S. J. Bentley, and K. M. Bohacs. 2010. Wave-enhanced sediment-gravity flows and mud dispersal across continental shelves: Reappraising sediment transport processes operating in ancient mudstone successions. Geology 38 (10):947-950.

McKee, B. A., C. A. Nittrouer, and D. J. DeMaster. 1983. Concepts of sediment deposition and accumulation applied to the continental-shelf near the mouth of the Yangtze-River. Geology 11 (11):631-633.

Michels, K. H., H. R. Kudrass, C. Hubscher, A. Suckow, and M. Wiedicke. 1998. The submarine delta of the Ganges-Brahmaputra: cyclone-dominated sedimentation patterns. Marine Geology 149 (1-4):133-154.

Milliman, J.D., Meade, R.H. 1982. World-wide delivery of sediment to the oceans. Journal of Geology 91 (1), 1-21.

Milliman, J.D., Syvistski, J.P.M.. 1992. Geomorphic/tectonic control of sediment discharge to the ocean: the importance of small mountainous rivers. Journal of Geology, 100, 525-544, doi.10.1086/629606.

Mitchum, R. M., Jr., P. R. Vail, and J. B. Sangree. 1977). Seismic stratigraphy and global changes of sea level. Part 6: Stratigraphic interpretation of seismic reflection patterns in depositional sequences, in Seismic Stratigraphy: Applications to Hydrocarbon Exploration, C. E. Payton (ed), pp. 135- 143, Am. Assoc. of Petrol. Geol., Tulsa, Okla.

Nittrouer, C. A., S. A. Kuehl, A. G. Figueiredo, M. A. Allison, C. K. Sommerfield, J. M. Rine, L. E. C. Faria, and O. M. Silveira. 1996. The geological record preserved by Amazon shelf sedimentation. Continental Shelf Research 16 (5-6):817. 
Nittrouer, C. A., and L. D. Wright. 1994. Transport of particles across continental shelves. Reviews of Geophysics 32 (1):85-113.

Overpeck, J., D. Anderson, S. Trumbore, and W. Prell. 1996. The southwest Indian Monsoon over the last 18000 years. Climate Dynamics 12 (3):213-225.

Palamenghi, L., T. Schwenk, V. Spiess, and H. R. Kudrass. 2011. Seismostratigraphic analysis with centennial to decadal time resolution of the sediment sink in the Ganges-Brahmaputra subaqueous delta. Continental Shelf Research 31 (6):712-730.

Ponton, C., L. Giosan, T. I. Eglinton, D. Q. Fuller, J. E. Johnson, P. Kumar, and T. S. Collett. 2012. Holocene aridification of India. Geophysical Research Letters 39:6.

Posamentier, H. W., and P. R. Vail. 1988. Sequences, systems tracts, and eustatic cycles. Aapg Bulletin-American Association of Petroleum Geologists 72 (2):237-237.

Prasad, S., and Y. Enzel. 2006. Holocene paleoclimates of India. Quaternary Research 66 (3):442-453.

Reimer, P. J., M. G. L. Baillie, E. Bard, A. Bayliss, J. W. Beck, P. G. Blackwell, C. B. Ramsey, C. E. Buck, G. S. Burr, R. L. Edwards, M. Friedrich, P. M. Grootes, T. P. Guilderson, I. Hajdas, T. J. Heaton, A. G. Hogg, K. A. Hughen, K. F. Kaiser, B. Kromer, F. G. McCormac, S. W. Manning, R. W. Reimer, D. A. Richards, J. R. Southon, S. Talamo, C. S. M. Turney, J. van der Plicht, and C. E. Weyhenmeye. 2009. Intcal09 and marine09 radiocarbon age calibration curves, 0-50,000 years cal BP. Radiocarbon 51 (4):1111-1150.

Rich, J. L. 1951. Three critical environments of deposition, and criteria for recognition of rocks deposited in each of them. Geological Society of America Bulletin 62 (1):1.

Rizvi, S.H.N., Ali, A., Naeem, S.A., Tahir, M., Baquer, J., Saleem, M., Tabrez, S.M. 1988. Comparison of the physical properties of seawater offshore the Karachi coast between the northeast and southwest monsoons. In: Thompson, M., Tirmizi, N.M. (Eds.), Marine Science of the Arabian Sea. Proceedings of an International Conference, American Institute of Biological Sciences, Washington, DC.

Rogers, K. G., and S. L. Goodbred. 2010. Mass failures associated with the passage of a large tropical cyclone over the Swatch of No Ground submarine canyon (Bay of Bengal). Geology 38 (11):1051-U123.

Sarkar, A., R. Ramesh, B. L. K. Somayajulu, R. Agnihotri, A. J. T. Jull, and G. S. Burr. 2000. High resolution Holocene monsoon record from the eastern Arabian Sea. Earth and Planetary Science Letters 177 (3-4):209-218. 
Schulz, H., U. von Rad, and H. Erlenkeuser. 1998. Correlation between Arabian Sea and Greenland climate oscillations of the past 110,000 years. Nature 393 (6680):54-57.

Sinha, A., L. Stott, M. Berkelhammer, H. Cheng, R. L. Edwards, B. Buckley, M. Aldenderfer, and M. Mudelsee. 2011. A global context for megadroughts in monsoon Asia during the past millennium. Quaternary Science Reviews 30 (1-2):47-62.

Sirocko, F., M. Sarnthein, H. Erlenkeuser, H. Lange, M. Arnold, and J. C. Duplessy. 1993. Century-scale events in monsoonal climate over the past 24,000 years. Nature 364 (6435):322324.

Slingerland, R., N. W. Driscoll, J. D. Milliman, S. R. Miller, and E. A. Johnstone. 2008. Anatomy and growth of a Holocene clinothem in the Gulf of Papua. Journal of Geophysical Research-Earth Surface 113 (F1).

Somme, T. O., W. Helland-Hansen, and D. Granjeon. 2009. Impact of eustatic amplitude variations on shelf morphology, sediment dispersal, and sequence stratigraphic interpretation: Icehouse versus greenhouse systems. Geology 37 (7):587-590.

Staubwasser, M., F. Sirocko, P. M. Grootes, and M. Segl. 2003. Climate change at the 4.2 ka BP termination of the Indus valley civilization and Holocene south Asian monsoon variability. Geophysical Research Letters 30 (8).

Stuiver, M., and P. J. Reimer. 1993. Extended C-14 data-base and revised Calib 3.0 c-14 age calibration program. Radiocarbon 35 (1):215-230.

Walsh, J. P., C. A. Nittrouer, C. M. Palinkas, A. S. Ogston, R. W. Sternberg, and G. J. Brunskill. 2004. Clinoform mechanics in the Gulf of Papua, New Guinea. Continental Shelf Research 24 (19):2487-2510.

Weijers, J. W. H., S. Schouten, E. Schefuss, R. R. Schneider, and J. S. Sinninghe Damste. 2009. Disentangling marine, soil and plant organic carbon contributions to continental margin sediments: A multi-proxy approach in a 20,000 year sediment record from the Congo deep-sea fan. Geochimica Et Cosmochimica Acta 73 (1):119-132.

Wells, J.T., Coleman, J.M. 1984. Deltaic morphology and sedimentology, with special reference to the Indus River delta. In: Haq, B.U., Milliman, J.D. (Eds.), Marine Geology and Oceanography of Arabian Sea and Coastal Pakistan. Van Nostrand Reinhold, New York, pp. 85-100.

Wright, L. D., and C. T. Friedrichs. 2006. Gravity-driven sediment transport on continental shelves: A status report. Continental Shelf Research 26 (17-18):2092-2107. 


\section{CHAPTER 5}

\section{Conclusions and Directions for Future Research}

Complete Holocene Indian monsoon reconstructions that are available from the Arabian Sea region show a gradual decrease in precipitation coeval with a weakening of the summer monsoon winds. These trends in monsoon characteristics have been interpreted to reflect a southward migration of the intertropical convergence zone (ITCZ). Although implied, it is not certain these records can also explain the hydroclimate of the Indian peninsula because of the heterogeneity of the monsoon expression at regional scales. Furthermore, monsoon precipitation linked to the Bay of Bengal branch, the component that affects most of the population in India and neighboring Southeast Asian countries, has been reconstructed only for portions of the late Holocene or at low resolution.

This thesis provides new Holocene records of Indian monsoon variability using sediment cores characterized by high accumulation rates from river-dominated margins in the Bay of Bengal and the Arabian Sea, allowing millennial scale variability in hydrology and integrate marine and continental signals to be resolved over extensive regions on the Indian subcontinent. Results from this work have implications for the Indian monsoon system as whole, as well as for changes in vegetation cover, sedimentation, terrestrial carbon cycle and human civilizations in this region during the Holocene.

This thesis first reconstructs the Holocene paleoclimate in the core monsoon zone (CMZ) of the Indian peninsula using a sediment core recovered offshore from the mouth of Godavari River (Chapter 2). Carbon isotopes of sedimentary leaf waxes can provide an integrated and regionally extensive record of the flora in the CMZ, and here we interpret carbon isotopic compositions as evidence for a gradual increase in aridity-adapted vegetation from $\sim 4,000$ until 1,700 years ago followed by the persistence of aridity-

adapted plants after that as the drainage basin became increasingly perturbed by 
anthropogenic activity. The oxygen isotopic composition of planktonic foraminifer Globigerinoides ruber detects unprecedented high salinity events in the Bay of Bengal over the last 3,000 years, and especially after 1,700 years ago, which suggest that the CMZ aridification intensified in the late Holocene through a series of sub-millennial dry episodes. The Holocene aridification of central India supports the view that changes in the seasonality of Northern Hemisphere insolation associated with the orbital precession, led to progressively weaker monsoons. However, in order to better constrain ITCZ fluctuations, a latitudinal transect of complete Holocene hydroclimate reconstructions would be necessary. Replicating this summer monsoon rainfall record, both to the north and south of the Godavari basin, will hopefully allow observing a correlation between the time of onset of aridification and latitudinal location, reconstructing the regional monsoon regime and its relationship to ITCZ variability.

The newly generated paleoclimate record for central India was also compared to cultural changes in prehistoric human civilizations of the Indian subcontinent (Chapter 2). Considering archeological evidence as a proxy for activities of past human population and their reliability on early agricultural practices, correlations between major cultural and climatic changes in this region become apparent. As the Indian subcontinent became more arid after $\sim 4,000$ yrs sedentary agriculture took hold in central and south India. In the already arid northwestern region of the subcontinent along the Indus River (Chapter 4), from $\sim 3,900$ to 3,200 years BP, the urban Harappan civilization entered a phase of protracted collapse. Late Harappan rural settlements became instead more numerous in the rainier regions of the foothills of the Himalaya and in the Ganges watershed. Correlations between hydroclimate and cultural changes in the Indian subcontinent suggest distinct societal responses to climate stress, and underline the importance of studying the monsoon in a dynamic context at synoptic scales.

The aridity record from the Godavari river drainage basin also provided an opportunity to examine relationships between hydroclimate and the dynamics of terrestrial carbon 
discharge to the sea (Chapter 3), which in turn, provides important constraints on the temporal phasing of terrestrial proxy records embedded in continental margins sediments influenced by Godavari River discharge. Radiocarbon measurements of long-chain fatty acids derived from higher plants are compared to planktonic foraminifera and show increasing age offsets between the two from mid to late Holocene. This trend implies that increased aridity slowed carbon cycling and/or transport rates resulting in an apprarent increase of terrestrial storage times of vascular plant carbon. Since $\sim 4,000 \mathrm{yrs}$ $\mathrm{BP}$, higher plant fatty acids are on average $\sim 1,200$ yrs older than the foraminifera, indicating either increasing residence times of terrestrial carbon or increasing erosion and mobilization of pre-aged vascular plant-derived carbon as a consequence of a less humid climate.

The observed progressive increase in age offset suggests that storage times of plant waxes, and, by inference, terrestrial biospheric carbon, on the continents is very sensitive to environmental changes. While an ecosystem requires a significant change in hydrological cycle to restructure its vegetation cover from $\mathrm{C}_{3}$ to $\mathrm{C}_{4}$ flora or vice versa, it seems that the residence time of terrestrial carbon might rapidly respond to more subtle changes in hydroclimate. In this respect, it may be useful to compare the changes in age offsets between plant waxes and foraminifera with more direct and sensitive hydrological proxies such as plant wax deuterium isotopes $(\delta \mathrm{D})$. An enrichment in deuterium will indicate a more precise timing for the onset of aridification in the drainage basin, and record short-lived variability in the precipitation regime to which carbon cycling can be sensitive.

The observed correlation between climate change and terrestrial carbon dynamics justifies a more quantitative approach to reconstruct carbon fluxes between different reservoirs within the drainage basin. Besides TOC and long-chain fatty acids, quantification of other biomarker proxies, like soil-derived branched glycerol dialkyl glycerol tetraether lipids (GDGT's) will be helpful in discerning those fractions of the 
complex mixture of total organic matter that are preferentially being stored or mobilized in the drainage basin. It is important to bear in mind that organic matter concentrations in sediments reflect both input fluxes and preservation characteristics, so examining carbonnormalized fluxes may be of value in distinguishing the effects of supply versus preservation. Another key addition to this research will be to obtain estimates of soil accumulation rates within different regions of the drainage basin, or access soil age-depth profiles, to understand how deep soils incise to expose and erode significantly pre-aged organic carbon. This type of information will also place some bounds on the relative size and age of the different soil reservoirs (upland, lowland) in the basin. Detailed characterization of the parameters described above will make the Godavari basin an ideal setting for running quantitative modeling simulations to match the age offsets between planktonic foraminifera and long-chain fatty acids observed in the sediments and generate different scenarios or modes of climate dynamics and carbon cycling within the basin.

While further work is clearly needed to resolve underlying processes, the present study clearly demonstrates that changing climate in monsoonal regions markedly affects the nature and dynamics of terrestrial carbon transfer to the marine environment. Variations in either storage time or the proportions of fresh versus aged carbon both indicate climate-driven controls on the overall flow of terrestrial carbon through drainage systems.

In an effort to provide a more comprehensive view of river-dominated margins affected by the Indian monsoon, this thesis also includes a morphological description of the Indus River subaqueous delta on the Arabian Sea continental margin and a paleoclimate reconstruction from a sediment core at this location (Chapter 4). Results from the first high-resolution seismic survey of the Indus River subaqueous delta confirm the most prominent feature of the Indus shelf is the Indus Canyon that dissects the shelf and the subaqueous delta in two asymmetric lobes. The Indus shelf clinoform developed asymmetrically around the canyon. On the eastern shelf it is much more advanced 
towards the edge of the shelf and the rollover occurs between 80 and $100 \mathrm{~km}$ offshore, while on the western shelf the rollover occurs at less than $50 \mathrm{~km}$ offshore. This work presents the surface morphology and internal stratigraphy of a modern subaqueous clinoform as imaged by a 2-D chirp survey and reveals the occurrence of well-developed Holocene shelf clinothems deposited over relict clinoforms. Radiocarbon dates on mollusk shells from sediment cores show that sediment accumulation has been heterogeneous across the Indus shelf and the utility sedimentary records for climate reconstruction appears strongly dependent on the stratigraphy of the cores. Whereas cores collected on the foreset of the shelf clinothems offer the highest sedimentation rates (> $100 \mathrm{~cm} / \mathrm{ka}$ ), they also contain frequent turbidite-like coarse beds that imply reworking. Instead, fine-grained sediments trapped in morphological depressions located laterally from the shelf clinothems and trapping sediments delivered in suspension are deduced to be better suited for climate reconstructions. These latter sequences are still characterized by high sedimentation rates at $>50 \mathrm{~cm} / \mathrm{ka}$ and are largely compositionally uniform.

A core recovered from a morphological depression, preserves an integrative paleoclimate record of the entire Indus River drainage basin. The carbon isotopic composition of sedimentary plant waxes suggests a remarkably stable climate over the arid regions of the Indus plain with a terrestrial biome dominated by $\mathrm{C}_{4}$ vegetation for the last 6,000 yrs. While reconstructions from the Arabian Sea and Bay of Bengal provide a consistent account of monsoon weakening over the Holocene, this reconstruction from the Indus River does not reflect these changes, and instead indicates that conditions in the lower drainage basin remained predominantly dry. Because $\mathrm{C}_{3}$ vegetation cover is restricted to small areas of the upper river basin, any signal coming from these areas appears to be overprinted by a large invariable $\mathrm{C}_{4}$ plant-derived carbon reservoir in the lower drainage basin. On the other hand, the collapse of the Indus Harappan civilization $(3,900-3,200$ yrs BP; Chapter 2) implies that human populations were more susceptible to the monsoon weakening that imposed water limitations on an already arid environment. 
Overall this thesis provides new paleoclimate reconstructions of the Indian monsoon from river-dominated margins, and shows the monsoon displayed a largely cohesive response during the Holocene. It combines continental and marine climate proxies from high accumulation rate sites in river-dominated margins that integrate signals over extensive areas to present regional reconstructions. Results from this work have importance for our understanding of the Indian monsoon system as whole, as well as its impact on vegetation cover, sedimentation, terrestrial carbon cycle and human civilizations in the Indian subcontinent. Results also have implications for the use of terrestrial proxies preserved in continental margin sediments in paleoclimate reconstructions; in particular the temporal phasing of terrestrial and marine proxy signals in the context of a variable hydroclimate deserves further investigation. 